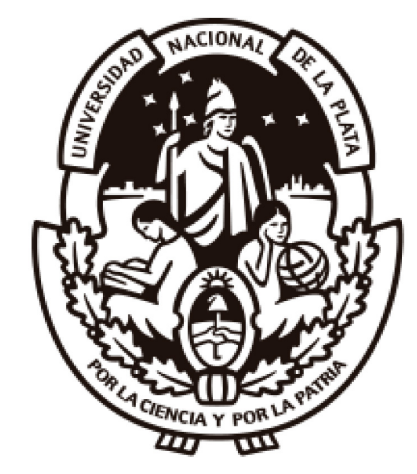

\title{
Género y política exterior: los casos de Cristina Fernández, Michelle Bachelet y Dilma Rousseff
}

Tesis de Maestría en Relaciones Internacionales

Instituto de Relaciones Internacionales Facultad de Ciencias Jurídicas y Sociales Universidad Nacional de La Plata

Maestranda: Lic. Prof. Dulce Daniela Chaves Director: Dr. Roberto Miranda 
Maestranda: Lic. Prof. Dulce Daniela Chaves 


\section{Agradecimientos}

Aún no soy madre, pero esta tesis fue lo más cercano que hice y que se asemeja al acto de parir. Di vida a esta investigación. Su concepción fue con mucho amor, pero la etapa de gestación -que se extendió a mucho más de nueve meses- tuvo momentos de angustia, replanteos y preocupaciones. El nacimiento de esta "criatura" (sin dudas, ¡es una nena!), fue gracias a muchxs y por eso me enorgullece tanto.

Como feminista de izquierda, creo fervientemente en las construcciones colectivas, en el edificar en conjunto; por eso, quiero comenzar por confesar que esta tesis ha sido fruto del apoyo de muchas personas queridas:

Mis amigxs, que durante tantos años me escucharon hablar de la tesis, a Gi, Mari, Cin, Orne, Kari, Fede, Marce, Jime, Lore, Meli, San y Gime, por su incondicionalidad y apoyo cuando lo necesité. Por el "vos podés" o "confiamos en vos", cuando sentía que la cuesta se me hacía demasiado empinada. En especial, quiero agradecer a mi amiga Ornela Matteucci, por acompañarme en la vida, y en mis tesis, con su diseño y color.

A la lectura atenta de algunos de los capítulos aquí presentados y sugerencias de textos de mis amigas, la Prof. Sonia Voscoboinik y la Lic. Gimena Palermo. Por transmitirme siempre confianza y cariño.

A mis compañerxs de la cátedra de Antropología Social y Cultural de la Facultad de Periodismo y Comunicación Social, por la bibliografía específica que me facilitaron y el aliento brindado.

A mi mamá, a Migue, a mis hermanos Javi y Santi, a mi tío Rubén, a mi Tata, a mis padrinxs Sergio, Stella y Rosita, a mi ahijada Belén y a Panchito, por contenerme y amarme. Por respetarme cada vez que me ausentaba de eventos familiares porque estaba "con la tesis". Por transmitirme seguridad y por acompañarme siempre en mis metas y sueños.

A mis docentes y compañeras de la Universidad de Huelva (España), por el aporte académico y humano. Especialmente agradezco a quien fuera mi tutora durante mi estancia en el 2016, la Dra. María del Mar Gallego Durán, de quien aprendí mucho.

A mi director, Dr. Roberto Miranda, por creer en mí aún en el disenso y respetarme. Por su guía y acompañamiento desde mi época de alumna, por animarme siempre a más. 
Por avalarme en mis estancias en el extranjero y en mis ganas de crecer como investigadora en formación.

A la gente hermosa que conocí en mi estancia en México, por su amistad y apoyo emocional con esta investigación: Citla, Erik, Migue, Vic, Coni, Juli, Irma y Angélica. En especial, a Miguel Ángel Rivera, amigo y colega, quien leyó con detenimiento esta tesis y me realizó valiosas observaciones. Asimismo, quiero mencionar a la Dra. Ileana Cid Capetillo, quien se desempeñó como mi tutora durante un semestre en el marco del Posgrado en Ciencias Políticas y Sociales de la UNAM. Su calidez humana y su nivel académico incidieron notablemente en el resultado de este trabajo.

A los y las Profesores y compañerxs del Instituto de Relaciones Internacionales de la Facultad de Ciencias Jurídicas y Sociales; espacio al que pertenezco desde lo institucional y afectivo. Al Mg. Javier Surasky, la Mg. Luz Marina Mateo y el Dr. Alejandro Simonoff, por las palabras justas y la bibliografía de género que me fueron acercando de forma desinteresada y genuina. A Georgina, por creer en mí. A Juani e Inés, por las risas y complicidades. Al Dr. Leandro Sánchez y al Mg. Gabriel Tudda, por las conversaciones "anti-stress", por su amistad constructiva. A mi amiga, la Mg. Mariel Lucero, por las extensas llamadas donde hablábamos de teoría de las Relaciones Internacionales y género. Por ayudarme a reflexionar y valorarme.

Quiero expresar un especial agradecimiento a la Mag. Laura Lucía Bogado Bordázar. Como Secretaria Académica de la Maestría, fue la primera persona que conocí al llegar al Instituto en Relaciones Internacionales. Corría el año 2011 y yo era una joven con muchas ilusiones y poca experiencia. Desde la entrevista de admisión al Posgrado, sentí su apoyo; y con el tiempo, éste se fue reafirmando y extendiendo. Sería imposible imaginar esta tesis sin sus palabras de aliento y cariño incondicional.

Al Director del IRI, el Dr. Consani, por haber creído en mí y por la alegría que le genera verme concretar este sueño.

Al Dr. Gilberto Aranda y a la Lic. Magdalena Del Carmen Mella, por hacer de mi estancia en Chile una experiencia entrañable. Por la invaluable ayuda que me brindaron para concretar mis entrevistas en Santiago. En este sentido, agradezco también el tiempo y predisposición de mis entrevistadas. 
Finalmente, dedico amorosamente mi tesis a todxs lxs que, desde su lugar y disciplina, trabajan por visibilizar y cuestionar las injusticias en general y las desigualdades de género en particular. Con la convicción de que nuestro aporte contribuye a la creación de un mundo más habitable, empático y equitativo para todxs.

Dulce Daniela Chaves 
Maestranda: Lic. Prof. Dulce Daniela Chaves 


\section{ÍNDICE}

\section{CAPÍTULO 1}

Antecedentes: Antecedentes: Conformación histórica del rol social de las mujeres

1.1. Espacio público y espacio privado: la dicotomía que invisibiliza a las mujeres en las 14 Relaciones Internacionales

1.2. Normativa internacional sobre los derechos de las mujeres

1.3. La igualdad de género: una prioridad del siglo XXI

\section{CAPÍTULO 2}

Marco teórico

2.1. Problematización y perspectivas analíticas

\section{CAPÍTULO 3}

La concreción del problema en los casos de Argentina, Brasil y Chile

3.2. Historia personal de las presidentas como dirigentes políticas.

3.2.3. La elegida de Lula

\section{CAPÍTULO 4}

4.1. Modelo metodológico para el análisis discursivo

4.2. "Yo como mujer"/ "Es un gobierno de mujeres"

4.2.1. Las mandatarias como amenaza de un statu quo patriarcal

4.2.2. Características socialmente valoradas atribuidas al género femenino 69

4.2.3. ¿Estado maternalista?

4.2.4. Mujeres y algo más $\quad 74$

4.2.5. Irrupción en el Ejecutivo $\quad 76$

\section{CAPÍTULO 5}

5.1. "Es tiempo de pensar en las mujeres"/ "Queremos una sociedad más igualitaria"

5.1.1. Representación femenina y visibilidad

5.1.2. Lenguaje inclusivo 


\section{CAPÍTULO 6}

6.2. Reflexiones sobre el ejercicio del poder y la toma de decisiones

6.2.1. Construcciones colectivas y disposición para el diálogo

6.2.2. El Estado cerca de los pueblos

95

6.2.3. Democracia y derechos humanos

99

CONCLUSIÓN

BIBLIOGRAFÍA 


\title{
CAPÍTULO 1
}

Antecedentes: Conformación histórica del rol social de las mujeres

\begin{abstract}
"En el estado actual de la sociedad parece que, para buscar las verdades más elementales, se hace necesario remontarse a los principios esenciales y disputar cada pulgada de terreno a los prejuicios existentes"

Mary Wollstonecraft, 1792:27.
\end{abstract}

Para comenzar a describir la conformación del rol social ${ }^{1}$ de las mujeres debemos remontarnos a la tradición androcéntrica de nuestras sociedades occidentales. "La producción de formas culturalmente apropiadas de conducta masculina y femenina es una función central de la autoridad social y está mediada por un amplio espectro de instituciones económicas, sociales, políticas y religiosas.” (Conway y otros, 1987:2) La política $^{2}$ ha sido desde los tiempos de Platón, arena de los varones. Maquiavelo, Hobbes, Rousseau, Hegel, son algunos de los nombres que se nos presentan cuando pensamos en los orígenes de la filosofía política. Ellos pensaban en un poder, gobierno, sistema de producción y Estado masculino. Como afirma Federici (2010:24): "Marx nunca podría haber supuesto que el capitalismo allanaba el camino hacia la liberación humana si hubiera mirado su historia desde el punto de vista de las mujeres.",3

La religión judeocristiana de Occidente, por su parte, fomentó el sistema machista. Los semitas identificaron el problema del pecado con el sexo, por lo cual la mujer se convertía en un peligro para la virtud religiosa del hombre; esto la rodeó de una connotación negativa, bajo la percepción de ser una amenaza para la abstinencia sexual que se defendía en esos tiempos. Dichas circunstancias -sumadas a la "caza de brujas"posteriormente serían blanco de fuertes críticas feministas; dado que era evidente que el discurso (y accionar) eclesiástico proponía una mirada despectiva hacia el género femenino.

\footnotetext{
${ }^{1}$ Vale aclarar que cuando nos referimos a "rol social", lo entendemos en términos de Conway y otros (1987), en el sentido de cuánto varían las categorías de género con el tiempo y con ellas los territorios sociales y culturales asignados a mujeres y hombres. Así, los sistemas de género representan medios de conceptualización cultural y de organización social.

${ }^{2}$ Utilizamos el concepto de "política" tal como la define Smith $(1956 ; 1960 ; 1966)$, cuando dice que ésta hace referencia a un "conjunto de acciones por medio de las cuales se dirigen y administran los asuntos públicos".

${ }^{3}$ En una línea de análisis similar a la de Federici, Rubin (1986: 135) afirma: "Quizás al movimiento de las mujeres corresponda la tarea de efectuar el mismo tipo de cambio social para un sistema que Marx sólo imperfectamente percibió."
} 
“(E)1 advenimiento del cristianismo fue una mala noticia para la situación de la mujer (...) Lutero, Calvino y sus seguidores volvieron a las fuentes de la más dura misoginia. La mujer no solamente debía ser madre y nada más, sino que era mala y el centro de todos los males del universo" (Maristany, 2000:48-50). Lo que subyace en este tipo de etnocentrismo religioso, de acuerdo a Moreno (1991), es la negación del derecho a la diferencia y la utilización de ésta como justificadora de la desigualdad y dominación.

Por otro lado, el Código civil francés - publicado en 1804-, cuyo fin fue afianzar las conquistas logradas durante la Revolución Francesa de $1789^{4}$, incorporaba el concepto de "igualdad jurídica". Pero, ante tantos cambios, nos preguntamos cómo eran consideradas las mujeres en esta normativa; la respuesta es: relegadas ante la ley. En primer lugar, con la autoridad paternal que fue restaurada e implicó que el matrimonio quedaba sometido al consentimiento del padre; y, una vez casada, la mujer permanecía bajo la tutela del marido, con la imposibilidad de ejercer actos jurídicos, civiles y comerciales sin su autorización ${ }^{5}$. Es decir, la voluntad de ésta se hallaba subsumida a la de un varón (primero, a la de su progenitor y luego a la del esposo).

Las mujeres, de acuerdo al Código Napoleónico, tampoco podían ejercer ninguna profesión sin el aval de sus maridos y la obligación de fidelidad conyugal fue fijada en forma desigual para ambos géneros ${ }^{6}$. En consideración de esto, resulta paradójico que el origen del término "feminismo" sea francés ${ }^{7}$; aunque también es cierto que fue un francés, el filósofo Jean Antoine Condorcet, uno de los primeros en comparar la condición social de las mujeres de su época con la de los esclavos, en "Bosquejo de una tabla histórica de los progresos del Espíritu Humano" (1743). Y fue una francesa, la literata Olimpia de Gouges,

\footnotetext{
${ }^{4}$ Es decir, igualdad jurídica para todos los ciudadanos, libertad de trabajo, individualidad de la propiedad, principio de laicidad, libertad de conciencia y la separación en tres poderes.

${ }^{5}$ Los artículos que determinaban dicha restricción de derechos para las mujeres serán modificados en los años 1965 y 1975.

${ }^{6} \mathrm{Si}$ la mujer era infiel, sería penalizada con la cárcel por un plazo de hasta 2 años; mientras que si el infiel era el hombre, éste sólo era advertido con una simple enmienda escrita. Así lo expresa Maristany (2000. 39): "Como parece ser una permanente en la Historia, el adulterio masculino no es grave, mientras el femenino es letal". Esta doble moral sexual, también la encontramos, por ejemplo, en el Código español de 1870, donde se establecía que si el marido asesinaba o agredía a una esposa infiel sólo sería castigado con el destierro, mientras que si el crimen era perpetrado por una mujer, se la condenaba a cadena perpetua. En la época del franquismo, el aborto, el adulterio y el concubinato, eran condenados con años de cárcel en el caso de las mujeres. (León Rodríguez, 2006:35-43).

${ }^{7}$ Sin embargo, vale aclarar que Dora Barrancos (2008:7-8) afirma que "Francia fue una de las plazas donde más actividad de reuniones masivas de mujeres hubo en los tramos finales del XIX y no debe sorprender entonces que finalmente fuera la cuna del vocablo con que hasta nuestros días se identifica la expresión política que proclama los derechos de las mujeres".
} 
quien en 1791 escribió “Declaración de los Derechos de la Mujer y de la Ciudadana”, que representaba la versión feminista de la "Declaración de Derechos del Hombre y del Ciudadano" 8 proclamada por la Revolución Francesa; poniendo en evidencia que la revolución había omitido a las mujeres en su proyecto igualitario y liberador. Tal como sostiene Facio (2001), los aportes de casi todas nuestras antepasadas fueron censurados, olvidados y condenados a la desaparición de la historia oficial. ${ }^{9}$

Retomando la explicación del origen del concepto de "feminismo", fue en la década de 1880 cuando Hubertine Auclert lo introdujo por primera vez "en las páginas de "La Citoyenne", con el significado de denuncia de la sujeción femenina y abogacía por los derechos de las mujeres" (Barrancos, 2008:7). Luego comenzó a mencionarse desde un tono despectivo, asociado a ciertos estereotipos malintencionados; pero ya desde fines del siglo XIX el término se popularizó - gracias al discurso de las sufragistas-, como sinónimo de emancipación de la mujer, primordialmente vinculado al derecho al voto y la participación política femenina.

En 1792, Mary Wollstonecraft realiza desde su libro Vindicación de los derechos de la mujer un extenso ensayo respecto a la situación denigrante en que se encontraban las mujeres en el siglo XVIII. Allí la autora critica la concepción de la época que pretendía identificarlas como seres infantiles, poco racionales, afines a la dulzura y sensibilidad; características asociadas a la debilidad. Asimismo, a través de su obra, Wollstonecraft reclama el acceso femenino a la educación, en igualdad de derechos con los varones; al mismo tiempo que afirma que la docilidad y fragilidad de su género no son particularidades naturales, sino adquiridas y asignadas socialmente. Es decir, se las convencían de sus limitaciones al ser tratadas desde niñas como seres inferiores, cuya única meta a conquistar en su vida debería reducirse a la de ser (buena) madre y (buena) esposa.

Basándose en lo anterior, la escritora inglesa denunció -hace ya tres siglos- que las mujeres debían emanciparse de aquella opresión masculina, que las dominaba a través de

\footnotetext{
${ }^{8}$ Su magnífica obra, su activismo y las contundentes denuncias ante las estructurales desigualdades de género, le costaron la vida. "Fue guillotinada (el) 3 de noviembre de 1793. Según la declaración de un inspector de la policía y de la información del periódico contrarrevolucionario Le Journal, Olympe de Gouges subió al cadalso con valor y dignidad. Su hijo, Pierre Aubry, renegó de ella públicamente poco después de su ejecución, por temor a ser detenido". (Infobae, 8/3/2017)

${ }^{9}$ En un sentido similar, Conway, Bourque y Scott (1987:2), afirmaban: “Así como la especificidad de género de la lengua ejerce influencia sobre cómo se piensan o dicen las cosas, las formas narrativas arquetípicas de Occidente que asumen un protagonista masculino influyen sobre cómo se cuentan historias sobre mujeres."
} 
mecanismos coercitivos, que -invisibilizados- creaban la ilusión de voluntad individual, a partir de engaños. Del siguiente modo lo expresa Wollstonecraft:

Rechazando, pues, todas esas bonitas expresiones femeninas que los hombres utilizan con condescendencia para así dulcificar nuestro estado de servil dependencia, despreciando esta mezquina elegancia, esta exquisita sensibilidad y esta blanda docilidad que se suponen son características del sexo más débil, deseo mostrar que la elegancia es inferior a la virtud, que el primer objeto de una loable ambición consiste en adquirir una personalidad en tanto que ser humano, sin distinción de sexos (ibid.,1792: 22-23. Cursiva nuestra).

En una línea de pensamiento similar, casi 80 años después, John Stuart Mill publicaba un libro, titulado "La esclavitud femenina" (1869), donde afirmaba que la conformación del régimen de la desigualdad proviene de la ley del más fuerte. Así argumentaba su postura:

...desde los primeros días de la sociedad humana, la mujer fue entregada como esclava al hombre que tenía interés o capricho en poseerla, y a quien no podía resistir ni oponerse, dada la inferioridad de su fuerza muscular. Las leyes y los sistemas sociales empiezan siempre por reconocer el estado material de relaciones existente ya entre los individuos. Lo que en los comienzos no era más que un hecho brutal, un acto de violencia, un abuso inicuo, llega a ser derecho legal, garantizado por la sociedad, apoyado y protegido por las fuerzas sociales, que sustituyeron a las luchas sin orden ni freno de la fuerza física. (...) La esclavitud (...) llegó a ser institución legal, sancionada y protegida por el derecho escrito. (ibid.: 20. Cursiva nuestra).

De lo que nos advertía el autor -al igual que su predecesora, Wollstonecraft- es que las mujeres estaban sometidas a una dependencia blanda, a un "estado primitivo de esclavitud, que se perpetúa a través de una serie de endulzamientos y modificaciones"10 y que disimularían de algún modo la condición subalterna en la que se encontraban. Dicha manipulación pretendería - a nuestro juicio- eternizar el régimen que hoy caracterizamos como patriarcal y androcéntrico. Este tipo de esclavitud moderna, según Stuart Mill, no tiene razón de ser ya que se basa en argumentos refutables.

En forma análoga a la de los pensadores citados previamente, durante la primera década de 1900, Georg Simmel escribió una serie de ensayos ${ }^{11}$ en los que reflexiona acerca

\footnotetext{
${ }^{10}$ Ibídem., 21.

${ }^{11}$ Estos ensayos fueron recogidos en un volumen titulado "Philosophische Kultur" (1911). En España se conocieron entre 1923 y 1925, gracias a Ortega y Gasset y la Revista de Occidente. En dicho medio, aparecían los siguientes ensayos: "Filosofía de la moda", "Los masculino y lo femenino: Para una psicología de los sexos" y "Cultura femenina". Estos tres artículos, sumados a un cuarto denominado "Filosofía de la coquetería", fueron recogidos en el volumen Cultura femenina y otros ensayos por Espasa Calpe Mexicana, Colección Austral, México, 1938. De esta edición, en versión online, fueron extraídos los párrafos de Simmel
} 
de la representación social de lo femenino en una sociedad que se rige por patrones masculinos. El sociólogo alemán afirmó que la costumbre es asociar la objetividad con la masculinidad, así como la subjetividad con la mujer; situación que surgiría del carácter masculino de la cultura, resultado de una compleja fusión de motivos históricos y psicológicos:

Quede ante todo establecido el hecho de que la cultura humana, aún en sus más depurados contenidos, no es asexuada. No por objetiva hemos de figurárnosla situada allende la diferencia entre varón y hembra. Nuestra cultura, en realidad, es enteramente masculina -con excepción de muy escasas esferas-. Son los hombres los que han creado el arte y la industria, la ciencia y el comercio, el Estado y la religión. Y si todo el mundo cree en una cultura puramente "humana", indiferente a la dualidad sexual, es porque todo el mundo ingenuamente identifica "hombre" con "varón" (Simmel, 1938:15. Cursiva nuestra).

Relacionado con lo anterior, Ortner (2006:17), explica la dominación masculina universal (o casi universal) "como el resultado de una compleja interacción de disposiciones funcionales, dinámicas de poder, y factores corporales"; y desde el posicionamiento que la mujer es respecto al varón lo que la naturaleza es a la cultura ${ }^{12}$. De este modo, dirá la autora, "el género se convierte en un lenguaje muy poderoso para hablar de las grandes preguntas existenciales sobre la naturaleza y la cultura". ${ }^{13}$

Con lo hasta aquí recopilado, es factible confirmar que las sociedades occidentales traen acumulados siglos de "doble estándar" respecto a lo que varones y mujeres pueden y deben hacer en el marco de los derechos y, en definitiva, como ciudadanos y ciudadanas de Estados Nación. En este contexto, no debería extrañarnos la insurgencia de organizaciones feministas que en todo el mundo, durante el siglo XIX, comenzaron a cuestionar la condición desigual en la que se encontraban. Entre las demandas principales de estos colectivos de mujeres, podemos mencionar: la obtención de derechos políticos y civiles; la defensa del estatuto de la maternidad (que implicaba un pedido de reconocimiento del Estado sobre la reproducción) y el derecho a la educación superior.

Respecto al significado de la negación a la instrucción femenina, Maristany (2000) afirma que la resistencia masculina a que las mujeres estudiaran estaba relacionada a la

que en esta tesis se presentan: http://es.scribd.com/doc/66086909/Simmel-Cultura-Femenina\#scribd. El libro, en inglés titulado "On Women, Sexuality and Love", apareció recién en 1984.

${ }^{12}$ Verena Stolcke (2000: 26) sostiene que "el sentido común occidental moderno distingue la naturaleza de la cultura como si se tratara de dos aspectos de la experiencia humana obviamente distintos".

${ }^{13}$ Ibídem., 18. 
libertad que el estudio y la capacitación suponía. "Resultaba más conveniente tenerlas para la procreación y el placer, sin arriesgar la situación transfiriéndoles poder para que pudieran actuar por sí mismas" ${ }^{\prime 14}$. Por esta percepción machista, el inicio del proceso de acceso de las mujeres a las universidades y profesiones puede situarse recién en el siglo XIX: "era un bastión defendido calurosamente por la resistencia masculina y el debate estaba organizado alrededor de ideas sobre la 'naturaleza' de la inteligencia de las mujeres" (Evans, 1995: 94).

A pesar de la renuencia de los varones, el ingreso femenino en las Casas de Altos Estudios comenzó en Estados Unidos en 1830, continuó en las décadas siguientes en Europa, comenzando por Francia, Suiza y Reino Unido; siguió en Italia, España, Bélgica, Dinamarca, Alemania y Rusia, y llegó a América Latina y a Argentina hacia fines del siglo XIX. Otro dato paradigmático es que la mayoría de las primeras universitarias fueron médicas (Palermo, 2016); particularidad cuya explicación reside en que se instó a las mujeres con aspiraciones académicas a seguir carreras que respondieran al estereotipo de la mujer como un ser con vocación asistencial y apta para los cuidados ${ }^{15}$. Así, y refiriéndose al caso de Estados Unidos, Conway y otros (1987:3) afirman que se habían establecido "límites para separar las profesiones femeninas en los servicios, enseñanza, enfermería y trabajo social, de las profesiones masculinas de más prestigio, como el derecho, la ingeniería y la investigación científica.”

Por su parte, Alexandra Mikhailovna Domontovich Kollontay -quien se convertiría en la primera mujer del mundo en integrar un gobierno (el ruso) y en desempeñar un cargo de embajadora ${ }^{16}$, afirmaba, en una de las catorce Conferencias brindadas en la Universidad Sverdlov de Leningrado (1921), que "el problema de la mujer” nació de esa “contradicción entre la importancia del trabajo femenino en la producción, por un lado, y la

\footnotetext{
${ }^{14}$ Ibidem., 78.

${ }^{15}$ Sobre la incorporación de las mujeres en las universidades, Evans (1995:52) sostiene: "las barreras institucionales cayeron ante las nuevas actitudes: por ejemplo, las mujeres fueron admitidas a la profesión médica mucho antes de que la visión médica del cuerpo femenino fuera reinterpretada desde un punto de vista femenino. El caso de las relaciones de las mujeres con el derecho es análoga: se permitió a las mujeres ser abogadas mucho antes de que los principios jurídicos sobre las mujeres fueran objeto de crítica desde el feminismo".

${ }^{16}$ En 1917 fue nombrada Comisaria del Pueblo para la Asistencia Pública, cargo de rango ministerial. Desde ese puesto consiguió que gran parte de las reivindicaciones exigidas por las mujeres se transformaran en legislación aprobada por el nuevo gobierno revolucionario. En 1922 fue enviada a su primer puesto en el extranjero, como consejera de la misión comercial en Oslo. Un año más tarde, fue designada embajadora soviética en Noruega; función que asumió el 1 de febrero de 1924, cuando el gobierno noruego reconoció a la Unión Soviética (Tejero Coni, 2014:17. En: Kollontay, A, 2014).
} 
falta de derechos de la mujer en el aspecto político y social, pero asimismo la tutela adicional de su marido -quien hace ya tiempo ha dejado de ser su "sustentador" (Kollontay, 2014: 124). Kollontay, al igual que Moreau de Justo y tantas otras intelectuales de la época, pasarían a la historia por sus aportes invaluables a la lucha que desde el socialismo se llevaba a cabo por la igualdad de la mujer.

1.1. Espacio público y espacio privado: la dicotomía que invisibiliza a las mujeres en las Relaciones Internacionales

Al igual que otros autores, Coelho y Baptista (2009), afirman que el mundo moderno atribuyó a las mujeres funciones propias del dominio privado, como los cuidados de la casa y de los hijos, en el mantenimiento de una estructura que permitió la preponderancia del hombre sobre la mujer, disimulada bajo la forma de protección. Al mismo tiempo, los varones fueron asociados a los asuntos políticos y económicos, consolidándose como propietarios del ámbito público. Desde la perspectiva de la distribución, el sexo genera la división fundamental entre trabajo "productivo" remunerado y trabajo "reproductivo" y trabajo doméstico no remunerado; el resultado es una estructura económica que genera modos de explotación, marginación y privación específicos del sexo (Fraser, 1997). Incluso cuando se trata de un mismo tipo de trabajo, se produce una diferenciación sexual en el salario, situación que plantea preguntas desde los estudios de género: "cómo y por qué gastos similares de energía humana han recibido históricamente distintos niveles de recompensa según el sexo del trabajador o de la trabajadora" (Conway, 1987:5).

De modo similar lo señala Ruiz Giménez Arrieta (2000), quien afirma que desde el triunfo de la sociedad liberal-burguesa en el siglo XIX, el sistema de género occidental se articula sobre dos esferas: la pública y la privada. Este tipo de sociedad -de acuerdo a la autora- provocó una ruptura entre el mundo laboral, económico y político, y el mundo doméstico:

Por un lado las mujeres fueron relegadas a su función natural dentro de la esfera privada. Al identificarse lo privado con lo doméstico y por lo tanto, con los valores femeninos de afectividad, sentimiento, debilidad, sumisión, irracionalidad, inestabilidad y apatía, se produjo un fuerte desprestigio de esta esfera. Por otro lado el mundo público se vio revalorizado al ser asociado con los valores masculinos de 
racionalidad, autonomía, estabilidad, fortaleza, dinamismo y responsabilidad (ibíd.: 333-334).

Maristany (2000), por su parte, sostiene que no hay que suponer que la revolución industrial mejora la situación de la mujer, por el contrario -según este autor, que puntualiza en la clase media-dicha situación, empeora. Pues ahora la mujer cuenta con más puestos de trabajo disponibles, pero muchos de ellos son para ocupar lugares donde los varones no dan abasto suficiente. "Podría decirse que recién en el siglo XX y sobre todo después de la Segunda Guerra las condiciones cambian. La mujer entre las dos guerras sigue siendo un objeto de sexo, aunque sin duda con más libertad de la que tuviera antes de la Primera Guerra."17

Al igual que Ruiz Giménez Arrieta, -quien sostiene que a las mujeres se las excluyó del área pública, bajo el argumento de su ausencia "natural" de las cualidades necesarias para moverse en ese plano-; Tickner (1998) resalta que se ha sugerido que "están más cómodas tratando con asuntos domésticos, como el bienestar social que son más compatibles con sus habilidades de crianza." ${ }^{18}$ Estas afirmaciones van en el mismo sentido de la "contradicción estructural" que señala Evans: "al mismo tiempo que se pensaba que las mujeres eran débiles e histéricas, éstas tenían que mantener familias numerosas y realizar abundante trabajo físico." 19

Sin embargo, a pesar de los prejuicios históricos que pesaron sobre las mujeres, éstas han demostrado: a) la inexistencia de aquella condición innata o "destino biológico" (Federici, 2010:26) respecto a su pertenencia/inclinación al ámbito del hogar y la maternidad; y, b) su interés y capacidad para desempeñarse en los asuntos públicos, del mismo modo que los varones. Respecto a este segundo enunciado, nos interesa pensar en el rol de la mujer en la arena política y, más específicamente, tomando decisiones en el plano internacional.

Por lo anterior, en primer lugar, se hace imprescindible preguntarnos cuál es el vínculo entre las relaciones internacionales y los géneros. Birgit Locher (1998) afirma que las primeras se presentan no sólo como neutrales, sino también como totalmente asexuadas. Desde la mirada de la autora - a la que nosotros adherimos- ha sido este error conceptual el

\footnotetext{
${ }^{17}$ Ibídem. 77.

${ }^{18}$ Ibídem. 429. Traducción nuestra

${ }^{19}$ Ibídem. 70
} 
que ha llevado a que ni siquiera el auge de los movimientos feministas en todo el mundo, fuera capaz de convencer a los internacionalistas sobre la importancia de abordar "la cuestión de la mujer":

...mientras en la psicología, sociología y otras ciencias sociales se le presta aunque sea una atención marginal a las cuestiones de las desigualdades entre los sexos y sus repercusiones en la investigación científica, en Relaciones Internacionales (RI) desde hace tiempo reina el criterio de que la situación entre los sexos representa un aspecto no solo irrelevante para el análisis de los fenómenos internacionales, sino también impropio (Locher, 1998: 40-41).

A pesar de ello, sobran los motivos por los que el género debería ser analizado desde la mirada de los Estados. Las mujeres como botín de guerra, por ejemplo, es un concepto y práctica que tiene sus orígenes en tiempos inmemorables y que aún en la actualidad se presenta como moneda corriente en los conflictos armados: desde las Cruzadas, la conquista de América, las dos guerras mundiales; pero también en disputas más recientes como las ocurridas en Kenia, Ruanda, Bosnia, Uganda, Sierra Leona, Turquía, Túnez, Angola, Pakistán, Birmania, etc. En todos esos casos y en tantos otros, la posesión, violación, mutilación o asesinato de las mujeres por parte del ejército/bando vencedor, ha representado un símbolo de victoria.

En una línea de análisis análoga, Rubin (1986), releyendo a Lévi-Strauss y Freud enfatiza la crítica hacia un sistema que emplea mujeres como materia prima y las moldea domesticadas como producto. En este sentido, la autora reconoce la facilidad para encontrar ejemplos etnográficos e históricos del tráfico de mujeres; ya que sostiene que éstas "son entregadas en matrimonio, tomadas en batalla, cambiadas por favores, enviadas como tributo, intercambiadas, compradas y vendidas." ${ }^{20} \mathrm{Y}$ aclara que si bien es cierto que también existe el tráfico de varones, éste es (o era) como esclavos, campeones de atletismo, siervos o alguna otra categoría social que no estuviera ligada al género en sí. En contraposición, Rubin remarca que "las mujeres son objeto de transacción como esclavas, siervas y prostitutas, pero también simplemente como mujeres." ${ }^{21}$

Los intercambios señalados previamente reflejan un sistema en que las mujeres no tienen pleno derecho sobre sí mismas (Rubin, 1986). Así, los vencedores de cualquier conflicto bélico atraviesan airosos los territorios conquistados, los escenarios donde

\footnotetext{
${ }^{20}$ Ibídem. 111.

${ }^{21}$ Ibidem. 111.
} 
batallaron, pero también -como parte simbólica de reafirmar esa preponderancia- se apoderan de las mujeres de sus adversarios; a veces incluso frente a la mirada de éstos. "Ha sido constitutivo del lenguaje de las guerras, tribales o modernas, que el cuerpo de la mujer se anexe como parte del país conquistado. La sexualidad vertida sobre el mismo expresa el acto domesticador, apropiador, cuando insemina el territorio-cuerpo de la mujer", sostiene Segato (2013:10).

El avance corporal del soldado ante aquellas víctimas parecería representar la última prueba de su fuerza superior, del triunfo (vil) de su masculinidad. Del siguiente modo lo explica Susan Brownmiller, en su estudio "Contra nuestra voluntad":

La guerra proporciona a los hombres el perfecto apoyo psicológico para dar rienda suelta a su desprecio por las mujeres. La misma virilidad de los militares (el poder brutal de las armas que manejan, el lazo espiritual que une a los combatientes, la disciplina masculina de órdenes dadas y acatadas, la propia lógica de las jerarquías), les confirman a los hombres lo que sospechan desde siempre; es decir, que las mujeres son periféricas, irrelevantes dentro del mundo que cuenta, espectadoras pasivas de la acción central (ibíd., 1975: 30).

Sobre estos reiterados episodios de denigración al género femenino, máxime en el ámbito de los conflictos armados, Riera Madurell (2006) cuestiona que las mujeres "no tuvieron nada que ver con la toma de las decisiones que las arrojaron a dicha situación; las decisiones las tomaron hombres y, en ningún caso, se tomaron contando con las mujeres"22.

Encausado con lo anterior, resulta pertinente retomar la importancia que tuvo como antecedente histórico en la prevención de la violencia de género, la Convención Interamericana para prevenir, sancionar y erradicar la violencia contra la mujer. La Convención de Belém do Pará - como es conocida popularmente--, pionera en el Continente por su especificidad, se propone desde su sanción en 1994 incluir la perspectiva de género en el diseño e implementación de diversas políticas públicas; ya que "reconoce e identifica claramente en su articulado el origen y la direccionalidad de la violencia que sufren las mujeres como producto de una organización social sexista en la cual el abuso y el maltrato contra las mujeres es el resultado de relaciones de poder históricamente desiguales entre hombres y mujeres." ${ }^{23}$ Un ejemplo de ello es que la mujer, de diversas formas y en

\footnotetext{
${ }^{22}$ Ibidem. 48.

${ }^{23}$ Fuente: www.inamu.go.cr/web/inamu/belemdopara
} 
diferentes épocas, fue comprada; situación que el varón padeció únicamente en la esclavitud. $^{24}$

Asimismo, urge recordar que el Estatuto de la Corte Penal Internacional, adoptado en Roma el 17 de julio de 1998, establece como crímenes de guerra en su artículo 8, inc 2: xxi) Cometer ultrajes contra la dignidad de la persona, en particular tratos humillantes y degradantes; xxii) Cometer actos de violación, esclavitud sexual, prostitución forzada, embarazo forzado (...), esterilización forzada y cualquier otra forma de violencia sexual que constituya una violación grave de los Convenios de Ginebra. El Estatuto busca poner fin a la impunidad de los autores de dichos crímenes, así como contribuir a la prevención de los mismos.

En esta instancia es necesario resaltar que aunque no será el tema de esta tesis el abordaje del rol de las mujeres en escenarios bélicos, sí consideramos necesario mencionarlo al inicio de esta investigación para evidenciar: por un lado, lo infundada de la postura de académicos y referentes de las Relaciones Internacionales que pretenden seguir invisibilizando y/o negando la importancia de abordar la situación de las mujeres en el ámbito internacional; problemáticas que no se reducen a la violencia física sino que abarca otras aristas como la feminización de la migración, la trata (con fines de explotación sexual, venta de órganos o como "mulas" de drogas) y la discriminación en distintos órdenes y jerarquías de la vida en sociedad. Por otro lado, las citas de los párrafos precedentes intentan crear un marco desde el cual comenzar a desentrañar en qué medida estos acontecimientos históricos y socio-culturales contribuyeron para que un número tan poco significativo de mujeres sean las que -en pleno siglo XXI- deciden en un mundo que pretende ser (y seguir siendo) construido, reglamentado y nombrado por varones. ${ }^{25}$

1.2. Normativa internacional sobre los derechos de las mujeres

A continuación, nombraremos y describiremos brevemente los principales instrumentos internacionales sobre derechos humanos de las mujeres. Esta compilación

\footnotetext{
24 Por ello, resulta paradójico que desde las representaciones simbólicas que tuvieron que ver con la Revolución Francesa, parecería ser que la libertad era/es siempre una mujer. Máxime si recordamos que la mujer de la antigüedad, para acceder a la libertad, elegía dos caminos: el ejercicio de la prostitución o el de hacerse sacerdotisa.

${ }^{25}$ María Cristina Chiriguini (2004:63) sostiene que "el que domina nomina, legitimando la jerarquización de las sociedades".
} 
responde a la necesidad de ilustrar de qué forma los Estados y la comunidad internacional tuvieron que hacerse eco de las desigualdades históricas a las que las mujeres venían siendo sometidas; incluso, por acción u omisión de ellos mismos. ${ }^{26}$

La Comisión Interamericana de Mujeres (CIM) fue el primer órgano intergubernamental que se creó para asegurar el reconocimiento de los derechos civiles y políticos de las mujeres. Establecida en 1928, está constituida por 34 Delegadas -una por cada Estado Miembro de la Organización de los Estados Americanos (OEA)- y se ha convertido en el principal foro de debate y de formulación de políticas hemisféricas en estos temas, en el marco de las Américas. Su misión es la de "incidir en la política pública a partir de un enfoque derechos para lograr la ciudadanía plena de las mujeres y la eliminación de la discriminación y la violencia de género" (Sitio oficial OEA).

Entre las normas sistemáticas establecidas por la CIM, podemos mencionar: las Convenciones Interamericanas sobre Nacionalidad de la Mujer (Uruguay, 1933), Concesión de los Derechos Políticos a la Mujer (Colombia, 1948), Concesión de los Derechos Civiles a la Mujer (Colombia, 1948) y la Convención Interamericana para Prevenir, Sancionar y Erradicar la Violencia contra la Mujer (Brasil, 1994). Esta última, conocida como “Convención de Belém do Pará", suscrita en el XXIV Periodo Ordinario de Sesiones de la Asamblea General de la OEA, advierte ya desde su Preámbulo la preocupación de los Estados parte porque la violencia contra la mujer es "una ofensa a la dignidad humana y una manifestación de las relaciones de poder históricamente desiguales entre mujeres y hombres".

Por lo anterior, la Convención Interamericana para Prevenir, Sancionar y Erradicar la Violencia contra la Mujer, establece en su artículo 5:

Toda mujer podrá ejercer libre y plenamente sus derechos civiles, politicos, económicos, sociales y culturales, y contará con la total protección de esos derechos consagrados en los instrumentos regionales e internacionales sobre derechos humanos. Los Estados Partes reconocen que la violencia contra la mujer impide y anula el ejercicio de esos derechos.

\footnotetext{
${ }^{26}$ Podemos encontrar análisis que indagan el tema de la ciudadanía desde la perspectiva de género en Kirkwood (1985) y Jelin (1997); pero mientras la primera lo hace desde la posibilidad histórica de la mujer de lograr su emancipación, Jelin enfatiza en aspectos que no responden al campo específico de la participación política femenina.
} 
En 1994 se celebró en Miami la Cumbre de las Américas, que dejó expresa la necesidad de fortalecer las políticas y los programas que mejoren y amplíen la participación de las mujeres en todos los ámbitos de la sociedad (Tema 18: "Fortalecimiento del papel de la mujer en la sociedad"). Ese mismo año, la Asamblea de Delegadas de la CIM aprobó su Plan Estratégico de Acción 1995-2000, que definió las estrategias a desarrollar para asegurar y afianzar el papel de la mujer hasta finalizar el siglo XX.

Por otro lado, la Convención Americana de Derechos Humanos "Pacto de San José de Costa Rica", del 22 de noviembre de 1969, estableció que los Estados se comprometían a respetar los derechos y libertades reconocidos en ella y a garantizar su libre y pleno ejercicio a toda persona que esté sujeta a su jurisdicción, sin discriminación alguna. Entre otros, reconoce los derechos políticos, cuyo artículo 23 establece que todos los ciudadanos deben gozar de los siguientes derechos y oportunidades:

a. de participar en la dirección de los asuntos públicos, directamente o por medio de representantes libremente elegidos;

b. de votar y ser elegidos en elecciones periódicas auténticas, realizadas por sufragio universal e igual y por voto secreto que garantice la libre expresión de la voluntad de los electores, y

c. de tener acceso, en condiciones generales de igualdad, a las funciones públicas de su país (Cursiva nuestra).

Asimismo, entre otras convenciones y declaraciones internacionales que designan valor e igualdad a la participación de la mujer en la vida pública, se pueden mencionar: la Declaración Universal de Derechos Humanos, que establece que toda persona tiene derecho a participar en el gobierno de su país; el Pacto Internacional de Derechos Civiles y Políticos, la Convención sobre los Derechos Políticos de la Mujer, la Declaración de Viena, el párrafo 13 de la Declaración y Plataforma de Acción de Beijing, las recomendaciones generales Nos. 5 y 8 con arreglo a la Convención, el Comentario general $\mathrm{N}^{\mathrm{o}} 25$ aprobado por el Comité de Derechos Humanos, la recomendación aprobada por el Consejo de la Unión Europea sobre la participación igualitaria de hombres y mujeres en el proceso de adopción de decisiones, y el documento de la Comisión Europea titulado "Cómo conseguir una participación igualitaria de mujeres y hombres en la adopción de decisiones políticas". 
En el marco de Naciones Unidas, es destacable que, en 1946, a pedido del Consejo Económico y Social (ECOSOC), se creó la Comisión de la condición jurídica y social de la mujer (CSW); que ya desde su origen solicitó participar en la redacción de la Declaración Universal:

El logro más conocido de sus delegadas fue convencer a los redactores de cambiar el artículo 1 que originalmente decía "todos los hombres nacen libres e iguales en dignidad y derechos..." para que se leyera "todas las personas nacen libres e iguales en dignidad y derechos". Aquellas primeras delegadas sabían muy bien el impacto excluyente del lenguaje androcéntrico", sostiene Facio (2011:7).

En una misma línea de pensamiento, Moreno (1991) afirma que el lenguaje refleja y consolida la preeminencia masculina: de este modo se comprende el motivo por el que en castellano, el uso de la palabra "hombre", se presenta como sinónimo de humanidad (masculina y femenina).

Además, en 1975 la Asamblea General proclamó el Año Internacional de la Mujer; circunstancia que marcó un hito, ya que a partir de esa fecha se incluyeron los asuntos relativos a la mujer en el programa de la Organización. De este modo, el Decenio de las Naciones Unidas para la Mujer (1976-1985) fue una iniciativa global orientada a examinar la condición y los derechos de la mujer y a colocar a ésta en puestos de adopción de decisiones en todos los niveles. El 18 de diciembre de 1979, la Asamblea aprobó la "Convención sobre la eliminación de todas las formas de discriminación contra la mujer" (CEDAW, por sus siglas en inglés). La misma entró en vigor como tratado internacional el 3 de septiembre de $1981^{27}$ y en la actualidad cuenta con la ratificación de 185 naciones.

En el preámbulo de aquél instrumento jurídico se reconoce explícitamente que "las mujeres siguen siendo objeto de importantes discriminaciones" y subraya que esa discriminación viola los principios de la igualdad de derechos y del respeto de la dignidad humana. En este sentido, la CEDAW establece no sólo una declaración internacional de derechos para la mujer, sino también un programa de acción para que los Estados Partes

\footnotetext{
${ }^{27}$ En octubre de 1999 fue adoptado el Protocolo Facultativo de la Convención sobre la Eliminación de Todas las Formas de Discriminación contra la Mujer por la Asamblea General de las Naciones Unidas. El mismo le otorga al Comité de Expertas la competencia para recibir y considerar denuncias por violaciones a los derechos consagrados en la Convención, a través de un mecanismo de comunicación o de un procedimiento de investigación.
} 
garanticen el ejercicio y goce de esos derechos. ${ }^{28}$ La CEDAW fue y sigue siendo el primer y más importante tratado sobre los derechos humanos de todas las mujeres.

En 1985, la “Conferencia Mundial para el Examen y la Evaluación de los Logros del Decenio de las Naciones Unidas para la Mujer: Igualdad, Desarrollo y Paz”, dio cauce a las Estrategias de Nairobi pensadas para el mejoramiento de la condición social de la mujer. Éstas se aplicarían hasta el año 2000.

Con la III Conferencia Mundial de la Mujer de Naciones Unidas (Nairobi, 1985), se observó la necesidad de articular estrategias de modo regional. Así, el 3 de julio de 1987 en San José de Costa Rica surge el Comité de América Latina y el Caribe para la Defensa de los Derechos de la Mujer (CLADEM); con el fin de mejorar la condición y situación sociojurídica de las mujeres en esta parte del continente. La CLADEM cuenta con estatus consultivo en la Categoría II ante las Naciones Unidas desde 1995 y, asimismo, goza de reconocimiento para participar en las actividades de la OEA desde el 2002.

En 1993, durante la Conferencia Mundial de Naciones Unidas sobre Derechos Humanos celebrada en Viena, se sienta un precedente al ser la primera vez que se reconoce que los derechos de las mujeres son derechos humanos. Es decir, tal como afirma Facio (2011:5), "no fue hasta finales del siglo XX que las mujeres alcanzamos la categoría de humanas para el derecho internacional".

En dicho marco, una de las Recomendaciones Generales adoptadas por el Comité para la Eliminación de la Discriminación contra la Mujer, fue la $N^{\circ} 8$ (1998):

El Comité para la Eliminación de la Discriminación contra la Mujer, Habiendo examinado los informes de los Estados Partes sometidos de conformidad con el Artículo 18 de la Convención, Recomienda a los Estados Partes que adopten otras medidas directas de conformidad con el Artículo 4 de la Convención, a fin de conseguir la plena aplicación del Artículo $8^{29}$ de la Convención y garantizar a la mujer, en igualdad de condiciones con el hombre y sin discriminación alguna, las

\footnotetext{
${ }^{28}$ Por el tema de esta investigación, consideramos relevante destacar el Artículo 7, de la Segunda Parte de la CEDAW, que establece que: Los Estados Partes tomarán todas las medidas apropiadas para eliminar la discriminación contra la mujer en la vida política y pública del país $\mathrm{y}$, en particular, garantizando, en igualdad de condiciones con los hombres, el derecho a: a) Votar en todas las elecciones y referéndum públicos y ser elegibles para todos los organismos cuyos miembros sean objeto de elecciones públicas; b) Participar en la formulación de las políticas gubernamentales y en la ejecución de éstas, y ocupar cargos públicos y ejercer todas las funciones públicas en todos los planos gubernamentales; c) Participar en organizaciones y asociaciones no gubernamentales que se ocupen de la vida pública y política del país.

${ }^{29}$ El artículo 8 se refiere a la participación de la mujer en todos los aspectos de las actividades de las Naciones Unidas y del sistema de las Naciones Unidas.
} 
oportunidades de representar a su gobierno en el plano internacional y de participar en las actividades de las organizaciones internacionales (Cursiva nuestra).

Por otro lado, al revisar la literatura especializada, no podemos dejar de destacar que existieron avances históricos en la inclusión de la perspectiva de género en la agenda internacional. La década de los 90 fue la época en que se conceptualizó el término "género" y su relación con el desarrollo; ya que se comprendió que el progreso no puede existir en un mundo sin igualdad de oportunidades y concesión de derechos para todos los seres humanos. En este sentido, la Conferencia de Beijing (1995), fue la Cuarta Conferencia Internacional de la Mujer $^{30}$ y ha sido un momento bisagra, ya que en ella se vieron resumidos los esfuerzos y las actividades realizadas a lo largo de cinco décadas. La de Beijing:

...puso de manifiesto un vastísimo acuerdo entre una gran mayoría de mujeres para reivindicar de forma decidida la consecución de la igualdad, entendida como fin de la marginación y la segregación histórica de que las mujeres han sido objeto en las sociedades patriarcales. (...)Y tal acuerdo (...) implicó además un consenso, un marco común de actuación en el nivel institucional, referente de todos los países en desarrollo y desarrollados que participaron. (López, 2005: 12).

La cuestión fundamental, que se destaca en la Plataforma de Acción de Beijing, es la disparidad entre la participación de jure y la participación de facto de la mujer en la política y la vida pública en general (es decir, entre el derecho y la realidad de esa participación). Así, además de resaltar en el artículo 13 la importancia de que la mujer pueda participar en “en los procesos de adopción de decisiones y el acceso al poder"; en el artículo 38 se afirma que los gobiernos se comprometen a aplicar la Plataforma de Acción y a garantizar que todas sus políticas y programas "reflejen una perspectiva de género".

En la Declaración del Milenio de Naciones Unidas, de septiembre de 2000, los Jefes de Estado y de Gobierno reunidos en Nueva York, establecieron que -a fines de alcanzar un mundo más pacífico, próspero y justo- "debe garantizarse la igualdad de derechos y oportunidades de hombres y mujeres" (art.6); "Promover la igualdad entre los sexos y la autonomía de la mujer como medios eficaces de combatir la pobreza, el hambre y las enfermedades y de estimular un desarrollo verdaderamente sostenible" (art.20); y "luchar contra todas las formas de violencia contra la mujer y aplicar la Convención sobre la eliminación de todas las formas de discriminación contra la mujer” (art 25).

\footnotetext{
${ }^{30}$ Las Naciones Unidas han organizado cuatro conferencias mundiales sobre la mujer, que se celebraron en Ciudad de México (1975), Copenhague (1980), Nairobi (1985) y Beijing (1995).
} 
El proyecto de integración de la perspectiva de género de la Organización de los Estados Americanos, llevado a cabo en coordinación con la CIM, tuvo como resultado el Programa Interamericano sobre Promoción de los Derechos Humanos de la Mujer y la Equidad e Igualdad de Género; cuya ejecución es responsabilidad de los gobiernos de los Estados miembros y la OEA. Entre los objetivos del Programa, se encuentran el de promover la participación plena e igualitaria de la mujer en todos los aspectos del desarrollo económico, social, político y cultural y de lograr la participación plena e igualitaria de la mujer en la vida política del país y en la toma de decisiones en todos los niveles.

Por último, consideramos necesario mencionar las Conferencias regionales sobre la Mujer de América Latina y el Caribe, que se constituyen en foros para el debate; a la vez que realizan evaluaciones periódicas de las actividades llevadas a cabo en cumplimiento de los acuerdos y planes regionales e internacionales sobre los temas de género. Como órgano subsidiario de la Comisión Económica para América Latina y el Caribe (CEPAL), identifica las necesidades de las mujeres, presenta recomendaciones y documentos. En el 2004, por ejemplo, con motivo de la Novena Conferencia Regional -Consenso de Méxicose planteó como meta central del Programa de Acción, acelerar el logro de la equidad de género y la total integración de las mujeres en el proceso de desarrollo, así como el ejercicio pleno de la ciudadanía en el marco de un desarrollo sustentable, con justicia social y democracia. ${ }^{31}$

\subsection{La igualdad de género: una prioridad del siglo XXI}

Entre los Objetivos de Desarrollo del Milenio -iniciativa de carácter global que se creó en el año 2000 a partir de la Declaración del Milenio en las Naciones Unidas firmada por 189 países; que identifica preocupaciones, valores y principios relacionados con el desarrollo- se encuentra el de "Promover la igualdad de género y el empoderamiento de la

\footnotetext{
${ }^{31}$ Para profundizar en la problematización de las mujeres en los organismos internacionales, recomendamos la lectura de Anzorena (2006), cuya tesis sostiene que con posterioridad a la IV Conferencia Mundial de la Mujer -Beijing, 1995- todas las declaraciones de los organismos internacionales comenzaron a apelar a la relevancia de la cuestión de género. Asimismo, Carvallo Ponce (2006), quien analiza la identidad femenina que propone la ONU; y Alberdi (2011), quien se detiene en los compromisos asumidos por ONU Mujeres.
} 
mujer". Éste, al igual que los otros objetivos y metas cuantificables, se previeron para ser alcanzados en el 2015. Sin embargo, aún resta mucho por avanzar.

Reafirmando lo anterior, Valdivieso (2014) sostiene que las feministas están desarrollando distintas estrategias en sus países "para avanzar en el proceso de despatriarcalización de las sociedades, de las relaciones de poder que las sustentan y de la política, como espacio en el que se desenvuelven las dinámicas de dominación, resistencia, conflictos y negociaciones" (ibíd.: 37). Así, los grupos y sectores que antes se pronunciaban por demandas de género intraestatales, en la actualidad forman parte de organizaciones con un alcance que trasciende sus fronteras y que conforman alianzas internacionales que persiguen la promoción de la igualdad en tiempos de globalización. ${ }^{32}$

Por otro lado, considerando que las políticas públicas ${ }^{33}$ son las que definen en dónde poner el foco, adónde se destinarán los recursos y qué se visibiliza; nos parece vital preguntarnos desde qué concepción de género parten estas decisiones. ¿Qué conceptualización de mujer/mujeres manejan en la tan pretendida equidad? En este sentido, es fundamental rastrear qué definición del "ser mujer" y del "ser varón" subyacen en los planteos y en las producciones de todas las instituciones, organismos o agencias que trabajan por la igualdad.

Si bien es cierto que los contextos cambian, las demandas siguen girando en torno al papel marginal que se les asigna a las mujeres en la sociedad y, específicamente, en la política; principalmente por la asociación varones/esfera pública y mujeres/esfera doméstica. Los espacios de toma de decisión siguen siendo -en un altísimo porcentajearena de los varones. John Stuart Mill decía ya en 1890: “....aquello de que las mujeres están excluidas es justamente para lo que más sirven, puesto que su vocación para el gobierno se ha probado y ha brillado en las circunstancias singulares en que pudieron demostrarla" (ibíd. 86).

\footnotetext{
32 Esta demanda también incluye la crítica al modelo heteronormativo: “...determinadas identidades y prácticas sexuales que aparecían estigmatizadas, no sólo encuentran ahora tolerancia e incluso cierto reconocimiento social, sino que las personas que las sustentan demandan su no exclusión de derechos civiles y de ciudadanía basándose en un principio de no discriminación a causa de la sexualidad" (Pichardo Galán, 2003).

Asimismo, las feministas lesbianas han denunciado que la heterosexualidad es un mecanismo primordial para el mantenimiento de la opresión patriarcal.

33 A las que entendemos como "fenómenos antropológicos en tanto contienen normas sociales, valores, principios de organización social y modelos de sociedad implícitos y explícitos (...) con capacidad para dotar de poder a unos grupos y silenciar a otros " (Gregorio Gil, 2012: 1209).
} 
El caso sudamericano marca un precedente único en la historia de la región: por primera vez y en la misma década, tres mujeres son elegidas democráticamente para encabezar el poder Ejecutivo de sus respectivas naciones. Cristina Elisabet Fernández en Argentina (2007), Dilma Vana da Silva Rousseff en Brasil (2011) y Verónica Michelle Bachelet Jeria en Chile (2006), constituyen un quiebre en esa tradición política patriarcal dominante. Esto nos lleva a preguntarnos en qué medida las cuestiones de género están desempeñando un papel relevante en los Estados; sobre todo considerando que éstos se presentan como sexualmente neutros (Anzorena, 2013:21). ${ }^{34}$

Si bien no es posible dar cuenta de una situación tan compleja y vasta en estas pocas páginas, procuramos realizar una selección representativa y general de obras literarias, autores/as-actores y hechos históricos para describir, al menos de forma ilustrativa, los puntos más sobresalientes de la conformación sociohistórica del rol de las mujeres: desde su condición de un ser definido casi como infrahumano hasta su transformación en las máximas representantes de sus Estados, decidiendo así el destino de millones de compatriotas.

\footnotetext{
${ }^{34}$ La autora también habla de la necesidad de “desnudar el sexo oculto del Estado” (Anzorena, 2013:19).
} 


\section{CAPÍTULO 2}

Marco teórico

La historia la hacen e interpretan los seres humanos, es decir, no puede ser considerada como un hecho objetivo; por el contrario, al tratarse de un constructo parcial y patriarcal, debemos considerar también sus omisiones: las grandes ausentes (calladas, negadas o ignoradas), en estas narrativas hegemónicas, fueron las mujeres. Ausencia literal y metafórica, ya que a ellas se les ha impedido conocer sus propias trayectorias y participar en la elaboración de sistemas simbólicos, filosóficos, científicos y legales, entre otros. ${ }^{35}$ Por supuesto, el mecanismo sistemático de invisibilización de las actividades y contribuciones de quienes representan a la mitad de la humanidad no puede ser considerado ingenuo.

Por lo tanto, esta investigación parte de entender al sexismo como la actitud que introduce la desigualdad y la jerarquización en el trato que reciben las personas sobre la base de la diferenciación sexual. Entonces, es importante señalar que nos adherimos a lo enunciado desde el programa 2015 de la materia "Metódos de investigación e intervención en estudios de género" de la Universidad de Huelva ${ }^{36}$, donde se hace una distinción entre sexismo benévolo y sexismo hostil. El primero, de acuerdo con el documento señalado, implica un conjunto de actitudes interrelacionadas hacia las mujeres que son sexistas, en tanto que las mujeres son consideradas de forma estereotipada y limitadas a ciertos roles, aunque puedan tener cierto tono afectivo para ellas.

El sexismo benévolo se basa en tres ideas: paternalismo protector, que asegura que el hombre debe cuidar y proteger a la mujer; diferenciación de género complementaria, que sostiene que las mujeres tienen por naturaleza muchas características positivas que complementan las de los varones; e intimidad heterosexual, que señala que existe una dependencia de los hombres ${ }^{37}$ respecto de las mujeres en ámbitos tales como la crianza de los/as hijos/as y la satisfacción de las necesidades sexuales.

\footnotetext{
${ }^{35}$ Como búsqueda y cuestionamiento, el feminismo filosófico pregunta por las "ausencias", como las llama Amorós, y da sentido a aquello que, por omisión, quedó de lado.

${ }^{36}$ A cargo de las Profesoras: Dra. Emilia Moreno Sánchez, Dña. Rosario Carrasco Tristancho y Dra. Beatriz Domínguez García. Doctorado en Estudios Interdisciplinares de Género, UHU (España).

${ }^{37}$ Hacemos la salvedad que en este apartado se utiliza la palabra "hombre/s", tal como aparece mencionado en el documento original al que se hace referencia. Este empleo no significa que, tal como se señaló previamente, se desconozcan los alcances ideológicos de dicho término al reforzar una visión androcéntrica de la humanidad.
} 
Por otro lado, el sexismo hostil remite a la actitud negativa basada en la supuesta inferioridad de las mujeres como grupo, que se articularía en las ideas de: un paternalismo dominante, que considera a las mujeres como más débiles, inferiores a los hombres y ello daría legitimidad a la figura dominante masculina; una diferenciación de género competitiva, que plantea que las mujeres son diferentes a los hombres y no poseen las características necesarias para triunfar en el ámbito público, siendo el ámbito privado el medio en el que deben permanecer; y una hostilidad heterosexual, donde se argumenta que las mujeres tienen un poder sexual (y reproductivo) que las hace peligrosas $\mathrm{y}$ manipuladoras para los varones.

Lo precedente nos lleva a analizar la barrera invisible resultante de un complejo entramado de estructuras en organizaciones dominadas por varones, que impide que las mujeres accedan a puestos importantes, como el denominado techo de cristal. Por ejemplo, los cargos de toma de decisión en la función pública, que son los que nos interesan a los fines de nuestra tesis, han sido siempre relegados para las mujeres. Se hace necesario entonces posicionarnos desde un marco interpretativo de la sociedad que fundamenta el análisis crítico de las desigualdades existentes entre géneros y propone alternativas para subvertirlo (Teoría crítica de género).

Ligado a lo anterior, hace casi tres décadas, Conway y otros (1987) reconocían que el estudio de género presenta tres grandes preguntas sobre la vida política:

1- ¿Cómo es que se desarrolló la cultura occidental para excluir a las mujeres de la actividad política formal?

2- ¿Cuáles han sido los estilos de acción política al alcance de las mujeres y cómo se comparan con los de otros grupos también privados de derechos ciudadanos? Y dado que el estilo da forma al sentido, ¿cómo han funcionado las mujeres que han sido líderes en relación con sus bases políticas?

3- ¿Cómo debemos entender el problema de la igualdad en un mundo de diferencias sexuales biológicas? ¿Cómo ha sido definido e implementado ese principio de igualdad con relación a esas diferencias?

Tal como los autores lo argumentan, responder a estos interrogantes nos obliga a conocer cómo fueron tratadas, qué pensaban y cómo se comportaban las mujeres; pero 
también requiere una exploración más profunda de las relaciones entre varones y mujeres, "así como el examen de actitudes culturales y prácticas políticas generales."38

En este sentido, las gestiones presidenciales de Fernández, Rousseff y Bachelet nos permiten reflexionar respecto de la cuestionada capacidad femenina para gobernar, hacia dentro y fuera de los Estados que presiden. Así, el interés particular de esta tesis radica en analizar si los discursos en política exterior que Cristina Fernández, Dilma Rousseff y Michelle Bachelet emitieron durante sus primeros gobiernos, en marcos bi y multilaterales, pueden ser leídos desde una perspectiva feminista de las Relaciones Internacionales, que apunte a perseguir avances y conquistas en la tan reclamada igualdad entre varones y mujeres.

Para trabajar las cuestiones previamente mencionadas, seleccionamos la perspectiva teórica del feminismo, ya que consideramos que nos permite visualizar al enfoque de género como una contribución valiosa para analizar y comprender las relaciones de poder en la política global y, específicamente en este caso, regional. Souto Zabaleta (2002) explica que la aproximación feminista en la disciplina de las Relaciones Internacionales (RI) -incorporada recién en la década de los ochenta- parte de una concepción de la realidad social construida y mediatizada por símbolos, mitos, y metáforas a través del lenguaje. "Se busca confrontar las estructuras dominantes a través de desafiar las prescripciones que establecen los roles de género, a partir de un análisis de las prácticas sociales establecidas para el mantenimiento de ciertas relaciones de poder" ${ }^{39}$, sostiene la autora.

Abordar un trabajo de estudio desde el feminismo, requiere una reformulación de los problemas a analizar, en términos de género. Dicho enfoque nos conduce a desnaturalizar las diferencias biológicas y a pensar en las construcciones sociales y relacionales como aquellas que definen los roles de género en cada sociedad. En esta instancia, nos parece relevante explicitar que entendemos por "roles de género" a las actividades, comportamientos, tareas o trabajos que cada cultura asigna a cada sexo. Éstos varían según las diversas sociedades y a lo largo de la historia, influidos por diversos factores como la economía, la religión o la etnicidad (Martín Casares, 2008:50).

\footnotetext{
${ }^{38}$ Ibídem. 3

${ }^{39}$ Ibídem., 72.
} 
Tal como afirma Evans (1997), por la complejidad de las tradiciones feministas, la palabra "feminismo" -en tanto forma de pensamiento crítico y acción política- exige una deconstrucción; sin embargo, hay algo que permanece inalterable y eso es "el principio organizativo central y crucial de que la diferencia sexual es una parte esencial de cualquier discusión dentro del mundo social o simbólico" ${ }^{\text {. }}$.

Asimismo, como nos encontramos con perspectivas feministas divergentes, es importante aclarar que no nos limitaremos a una sola corriente teórica; ya que a lo largo de esta investigación emplearemos un abanico complementario de autores que teorizan al género desde las RI y otras áreas de estudio. ${ }^{41}$ El marco teórico empleado aquí es ecléctico, no se restringe a la mirada específica de las RI, sino que la pretensión es la de reunir y conciliar bibliografía y definiciones de otras disciplinas afines, que asisten a nuestra propuesta, tales como la sociología, antropología, historia, comunicación y psicología social. De modo que, como venimos sosteniendo, la perspectiva de género es transversal al conjunto de las áreas del conocimiento.

Por otro lado, si bien no enfatizaremos en cuestiones económicas, sí rescataremos del enfoque del feminismo crítico la premisa de considerar al género como un elemento estructural que moldea prácticas y políticas -en términos materiales y simbólicos- en el mundo a través de las relaciones desiguales de poder entre varones y mujeres, "donde estas últimas tienen poco acceso a éste en diversos ámbitos como la política internacional" (Trujillo López, 2014: 463).

Por lo anteriormente afirmado, el punto focal del feminismo crítico se encuentra en la pregunta de cómo se pueden captar mejor las desigualdades entre los sexos, y al interior de ellos. En este sentido y de acuerdo con Locher (1998:10):

...un cambio fundamental fue el abandono de la categoría 'mujer' que caracterizaba al feminismo liberal y radical. En su lugar apareció el concepto de 'género', más general y extenso, que intenta tematizar las relaciones entre los sexos como un todo. El objeto de la perspectiva 'genérica' no es ya exclusivamente la mujer, sino también el hombre y la relación de un sexo con el otro.

En esta instancia, se hace indispensable establecer de cuál definición de género partimos. Ruiz Giménez Arrieta, tomando parte de una definición de Marysia Zalewski

\footnotetext{
${ }^{40}$ Ibídem., 22

41 Entre las principales tendencias dentro del feminismo, encontramos: liberal, radical, marxista, psicoanalítico, de color, postcolonial y eco-feminismo. Por este motivo, se habla de "feminismos", en plural.
} 
(1997), sostiene que dicho concepto se puede delimitar como "aquella «construcción social y cultural de las categorías de la masculinidad y la feminidad» que determina una atribución diferente de rasgos personales, actitudes, sentimientos, cualidades, conductas y actividades a las mujeres y los hombres." ${ }^{42}$ Dicha afirmación se apoya en la de una de las principales referentes históricas, Simone de Beauvoir (1989), quien argumenta sobre una feminidad socialmente constituida; postura que, en la opinión de Zerrilli (2008:39), “es un audaz intento de repensar 'la cuestión de la mujer' en términos de las restricciones internas y externas que pesan sobre el sujeto".

Por su parte, Scott (1986) no sólo aboga por la adopción del género como una categoría analítica, sino que además incorpora dos formas de pensar sobre el mismo: el género como diferencia y el género como poder. Estas dos maneras sintetizan la doble creencia sobre la que se asienta gran parte de la investigación feminista: por un lado, la idea de que las diferencias entre varones y mujeres han desempeñado un papel decisivo en la estructuración de las desigualdades sociales; y, por otro, la certidumbre de que el resultado de esas diferencias no es otro que la emergencia de relaciones de poder injustificadas. ${ }^{43}$

Teniendo en cuenta las consideraciones anteriores, nuestra hipótesis de trabajo es: Fernández, Rousseff y Bachelet, a través de sus políticas exteriores, quebraron discursivamente la ideología patriarcal; siendo la mandataria chilena quien puso más en evidencia dicha ruptura.

En suma, la justificación de la presente tesis consiste en reflexionar acerca de si los primeros gobiernos de estas Jefas de Estado representaron el inicio de una nueva etapa de avance de la mujer en la política regional o - por el contrario- son casos aislados que responden a las coyunturas históricas políticas que se evidenciaron en un momento particular de la historia de sus países.

\subsection{Problematización y perspectivas analíticas}

Durante siglos las mujeres en Occidente fueron pensadas en posiciones subordinadas a las de los varones, excluidas de los ámbitos de decisión y circunscriptas a las tareas domésticas y de crianza; de modo que para cuando se les permitió el acceso al

\footnotetext{
${ }^{42}$ Ruiz Giménez Arrieta, 2000: 325

${ }^{43}$ Rodríguez Manzano, 2001: 255
} 
conocimiento institucional y/o científico, la forma de éste había sido determinada por la visión masculina. Largos años y cientos de luchas después, comenzó a desentrañarse la trama: intelectuales y feministas de todas partes evidenciaron que la asignación de la esfera pública como propiedad de los varones, y de la esfera privada a las mujeres, era una construcción sociocultural impuesta que pretendía invisibilizar -bajo estereotipos y argumentos prejuiciosos de carácter religioso, moral y biologicistas- las relaciones de poder.

Para problematizar el debate, es interesante la postura de Tickner (1997), quien sostiene que características como poder, autonomía, racionalidad y público, están asociadas de modo estereotipado a la masculinidad; mientras que -sus opuestos- debilidad, dependencia, emoción y ámbito privado están relacionados a la feminidad. "Hay evidencia para sugerir que, ambos, mujeres y hombres, atribuyen un valor más positivo a las características masculinas." 44

Partiendo de la afirmación anterior, no es difícil imaginar los obstáculos que las mujeres han tenido que sortear para acceder y -aún más- liderar la arena publica en sociedades patriarcales, como las sudamericanas. Máxime si consideramos que por siglos mantuvieron poca o inexistente relación con el poder del Estado: "las mujeres per se fueron excluidas de la iglesia, el derecho y la política, las tres estructuras esenciales del poder público" (Evans, 1997:46).

El presente trabajo inicialmente se propuso partir del enfoque metodológico que planteó Kenneth Waltz en su obra "Man, the State, and War: a theoretical analysis" $(1959)^{45}$, para la distinción de tres imágenes en el estudio de la realidad internacional. Estos niveles de análisis son: las características psicológicas de los hombres de Estado; la estructura de los Estados; y el sistema inter-estatal. De este modo, según el autor, se logra la identificación de los factores internos (que conformarían la primera y segunda imagen) y externos (tercera imagen), que condicionan el comportamiento de los Estados y posibilitan la argumentación de su accionar en el plano global.

Tal como se ha evidenciado, tanto la política doméstica como la internacional deben constituirse como objeto de estudio a la hora de reflexionar sobre las relaciones exteriores

\footnotetext{
${ }^{44}$ Ibídem, 614. Traducción propia.

${ }^{45}$ Nótese que ya desde el nombre de su libro, Waltz concibe como sujetos y artífices de política internacional sólo a los varones; en sintonía con los planteos preponderantes de la época.
} 
de los países. Si nos referimos específicamente a América Latina, no podemos desconocer que las determinantes domésticas, -de acuerdo a Van Klaveren (1992) - son el sistema político, la estrategia de desarrollo; así como los factores culturales e históricos. Además, en dicha región, y comparándola con Europa, se observa una tendencia a que la personalidad, el liderazgo y el estilo personal, entre otras variables de la primera imagen, tengan un mayor peso relativo (Ledesma, 2007).

De manera análoga, Creus (2012) sostiene que:

...en el plano de lo fáctico el peso de los individuos y consecuentemente de sus ideas y creencias, puede verse potenciado por factores relativos a la estructura y organización del Estado -la denominada segunda imagen-. Tal es el caso de aquellos países con sistemas presidencialistas que habilitan y promueven la existencia de Ejecutivos fuertes, como ocurre por ejemplo en muchos países de América Latina. Estos concentran en sus manos buena parte del proceso decisorio, el cual tiende a ser sumamente restringido en aquellas cuestiones ligadas al manejo de las relaciones exteriores.

Por las limitaciones que encontramos en la propuesta de Waltz para extrapolar su metodología al análisis discursivo de las Presidentas, y por las características específicas que la presente investigación reviste, al posicionarse desde una perspectiva de género que busca "rescatar" la voz de mujeres como sujetos de conocimiento (y poder), decidimos considerar sólo la primera imagen waltziana (a la que, incluso modificamos, ya que no son “hombres", sino mujeres en el Estado).

Así, considerando la preponderancia del personalismo en los mensajes de las tres Presidentas, creamos un modelo basado en tres ejes analíticos para evidenciar cómo desde la primera imagen se transversalizan de forma discursiva las cuestiones de género. Dichos ejes son: a) "Yo como mujer"/ "Es un gobierno de mujeres"; b) "Es tiempo de pensar en las mujeres"/ "Queremos una sociedad más igualitaria"; y c) Sobre el ejercicio del poder y la toma de decisiones.

La decisión previamente señalada se sustenta en una de las afirmaciones que realiza Sandra Harding cuando, en 1987, se pregunta si existe un método feminista:

Las feministas argumentan que las epistemologías tradicionales excluyen sistemáticamente, con o sin intención, la posibilidad de que las mujeres sean sujetos o agentes del conocimiento, sostienen que la voz de la ciencia es masculina y que la historia se ha escrito desde el punto de vista de los hombres (de los que pertenecen a la clase o a la raza dominantes); aducen que siempre se presupone que el sujeto de una oración sociológica tradicional es hombre. Es por eso que han propuesto teorías epistemológicas alternativas que legitiman a las mujeres como sujetos de conocimiento. (p.14) 
Partiendo desde estas afirmaciones, es que nos proponemos indagar en los discursos de Fernández, Bachelet y Rousseff, durante sus primeras gestiones presidenciales. El corpus discursivo definido para esta investigación fue diferenciado: en los casos de Cristina Fernández y Dilma Rousseff, se analizaron la totalidad de los discursos transcriptos disponibles en la web, tanto en páginas oficiales (Casa Rosada y Palácio do Planalto) ${ }^{46}$ como en otros sitios relacionados (Portal do Brasil). El criterio de selección de los textos respondió a la búsqueda de mensajes presidenciales desarrollados por ambas mandatarias en los ámbitos bi y multilaterales durante los cuatro años correspondientes a sus primeros gobiernos.

Por otro lado, en el caso de Michelle Bachelet, la obtención del corpus discursivo estuvo limitada al hecho de que únicamente se tiene acceso a los discursos que la Jefa de Estado chilena emitió durante los días 21 de mayo de cada año, fecha en la que se conmemora el día de las Guerras navales, por la Guerra Pacífico. En dichas oportunidades, la funcionaria se ocupa de describir y enunciar las políticas públicas llevadas a cabo por su gobierno; las decisiones y acuerdos en el plano internacional; y las intenciones de su gestión, tanto en el presente como para el futuro. Por estas circunstancias, al ser sólo cuatro los mensajes presidenciales disponibles para analizar, se complementó el material con la realización de cuatro entrevistas en profundidad a personas vinculadas al gobierno de Bachelet. $^{47}$

Por otro lado, nos parece pertinente aclarar cómo entendemos ciertos conceptos desde los que partimos y que aún no han sido definidos. En primer lugar, si bien entendemos el concepto de patriarcado como "el sistema social basado en relaciones de dominación de los hombres sobre las mujeres" (Perea Ozerin, 2014:72) y el de cultura patriarcal, como "el conjunto de usos, costumbres, tradiciones, normas familiares y hábitos sociales, ideas, prejuicios, símbolos e incluso leyes que tratan de perpetuar la desigualdad entre hombres y mujeres" (Ortiz Hedesa, 2013: 7); consideramos interesante y valioso para nuestros fines el aporte de representantes del psicoanálisis al estudiar y desarrollar lo que se entiende como

\footnotetext{
${ }^{46}$ Palácio do Planalto, Presidencia da República (Brasil): http://www2.planalto.gov.br Casa Rosada, Presidencia de la Nación (Argentina): http://www.casarosada.gob.ar

${ }^{47}$ Respecto a las entrevistadas y otras cuestiones metodológicas, se amplía en el capítulo 4.
} 
ideología patriarcal. De acuerdo con Coria (2006), las ideas predominantes de esta ideología:

...giran alrededor de la suposición básica de la inferioridad de la mujer y la superioridad del varón. Esta suposición básica lleva a plantear las diferencias entre los sexos como una diferencia jerárquica. En esta jerarquía los varones se instalan en el nivel superior y desde allí detentan el poder, ejercen el control y perpetúan un orden que contribuye a consolidar la opresión de las mujeres. Esta jerarquización de las diferencias justifica y avala la dominación de la mujer por parte del varón. La suposición básica de la superioridad masculina se apoya en teorías biologistas, naturalistas y esencialistas. ${ }^{48}$

Además, del mismo modo que Coria (2006) sostiene que la ideología patriarcal promueve una división sexual del trabajo; Osborne (2005) afirma que "se crea la ideología -y la realidad- de las esferas separadas, los hombres para lo público y las mujeres para lo doméstico y la crianza de la prole." ${ }^{49}$ El feminismo revela la separación y dialéctica entre dichas esferas; dejando al descubierto las resistencias culturales que intervienen cuando, por ejemplo, una mujer desea acceder a algún ámbito considerado tradicionalmente masculino. El caso más concreto es el de cargos jerárquicos en partidos políticos. ${ }^{50}$

Ligado a lo precedente, cabe destacar que la Red Internacional de Información sobre Mujeres y Política, determinó en uno de sus Informes (mayo del 2010), -y en base a una investigación realizada en América Latina- que los desafíos que debe afrontar la mujer que pretende ingresar a la esfera pública y política, pueden resumirse en: el predominio en los partidos políticos de la región de una cultura patriarcal; los sistemas electorales discriminatorios hacia las mujeres; las medidas de acción positiva para la participación femenina que son cumplidas "formalmente" y, en ocasiones, transgredidas implícita y explícitamente; y las limitaciones en el acceso al financiamiento para campañas electorales.

Asimismo, cuando hablamos de estratificación de género, nos referimos a las desigualdades entre varones y mujeres, reflejando la jerarquización social y la dominación masculina existente en la mayoría de las sociedades. Esto, a su vez, se asocia con el concepto de identidad de género de la mujer, sobre lo que Cervantes Carson (1994) sostiene tres tesis principales, a las cuales nos adscribimos:

\footnotetext{
48 Ibidem., 20

${ }^{49}$ Ibídem., 214

${ }^{50}$ Esta problemática está asociada a la cultura política, que la entendemos como "la forma en que el poder y la autoridad son entendidos y practicados", en términos de las tradiciones de los miembros (Cohen, 1979: 48).
} 
a) Las desigualdades sociales entre el hombre y la mujer no están biológicamente determinadas, sino socialmente construidas.

b) Las mujeres comparten una misma condición opresiva por el hecho de vivir en una sociedad estructurada patriarcalmente, dentro de una cultura que legitima este patriarcado de manera permanente. Sin embargo, la opresión que vive cada mujer manifiesta variaciones y diferencias importantes, de acuerdo con la clase social a la que pertenece y al lugar que ocupa dentro de la estructura desigual de oportunidades.

c) Las mujeres construyen su identidad genérica basándose en factores vivenciales comunes y en experiencias simbólicas compartidas. El análisis de la naturaleza y la relación entre estos elementos fundamentales nos permite reconocer que existen patrones en el proceso de estructuración de la identidad de género que no dependen de la adscripción de clase, aunque se encuentran inevitablemente afectados por ella.

Por otro lado, y en gran medida donde reside la importancia de lo que esta investigación se propone, el desempeño de tres mandatarias en el ámbito de la política internacional, supone el desafío de "leer" a representantes de un sector históricamente excluido (las mujeres) desempeñándose en un terreno que parecía vedado para su accionar. Pues, tal como afirma Riera (2006: 47): "en un campo especifico y de tanto poder como es el de la política exterior y de seguridad, las mujeres, todavía muy raramente, podemos participar de las decisiones políticas importantes".

En consecuencia, hace falta enfatizar que entendemos la política exterior tal como la define Hill (2003:3); es decir, como "la suma de las relaciones externas oficiales conducidas por un actor independiente (usualmente un Estado) en las relaciones internacionales". A esta consideración, nos parece pertinente sumarle el aporte de Lasagna (1996), quien sostiene que la política externa está condicionada por el régimen político, "puesto que es fruto de interacciones que se llevan a cabo de acuerdo con unas reglas, estructuras y valores que emanan de él.",51

De forma análoga, Colacrai y Lorenzini (2010:9) afirman que:

${ }^{51}$ Ibídem., 50 
...la dimensión que las acciones gubernamentales cobran y su capacidad para influir y modelar las acciones en Política Exterior van mutando de acuerdo con las épocas, los diferentes momentos de un Estado, y suelen estar influidas, en parte, por el tipo de régimen político que asume el Estado. De este modo, inferimos que la identidad buscada en materia de política exterior, expresa: por un lado, el modo de percibir el mundo que tiene el Estado y, por otro, su autopercepción.

Las aseveraciones precedentes - pensadas desde una perspectiva centrada en el género- son congruentes con lo afirmado por Locher (1998), quien argumenta que dicho análisis exige "abolir la separación entre lo individual, lo político-interior y lo internacional, niveles que desde el punto de vista feminista sólo pueden observarse en su interdependencia". ${ }^{52}$ Justamente nuestra tesis se propone pensar a cada Presidenta, en el contexto doméstico del país que representaron y en el marco de sus discursos en la política externa. Por ello, los interrogantes que guiaron este estudio fueron: ¿Existe una ruptura del statu quo -al menos, a nivel discursivo- para alcanzar objetivos que persigan el empoderamiento y la valorización de la mujer como hacedora de política exterior? ¿Pueden detectarse particularidades propias del género femenino en las agendas internacionales establecidas por estas lideresas?

Por último, y convencidos que es justamente desde los feminismos desde donde podemos analizar e interpretar la construcción de una matriz cultural y conceptual que da soporte a una ideología patriarcal; nos interesa teorizar de forma esquemática porqué nos referimos a "feminismos", en plural.

\subsection{Historización del movimiento feminista}

Si bien el feminismo representa un compromiso político y social, que implica un cuestionamiento a las relaciones asimétricas de poder, las distintas olas del movimiento feminista nos permiten evidenciar cómo este posicionamiento se fue (re) definiendo en cada etapa histórica. Aquí vale aclarar que no existe una única periodización, ya que son diversas las conceptualizaciones feministas que se pronuncian al respecto; de acuerdo con la época e incluso con las diversas acepciones que adquieren dentro de cada período. De ahí que hablemos de los feminismos, en vez de un feminismo.

\footnotetext{
${ }^{52}$ Ibídem., 12
} 
De Miguel (1995), por su parte, distingue entre feminismo premoderno, moderno y contemporáneo. El primero, situado en el Renacimiento, propone un nuevo paradigma de ser humano y la necesidad de la educación, a pesar de ello, no incluye a las mujeres y en el tema de la educación inspiró el debate acerca de la naturaleza y los deberes de los sexos.

Por otro lado, el feminismo moderno coincide con las luchas por el voto femenino y se inicia con la obra de Poulain de la Barre y los movimientos de mujeres durante la Revolución Francesa. De esta etapa se destacan: por Francia, Olympe de Gouges, Mme. Roland, Théroigne de Mericourt, Etta Palm y Claire Lacombe; y por Inglaterra, Mary Wollstonecraft y las integrantes del salón Bluestocking Society, tal como Elizabeth Carter, Lady Mary Wortley Montagu y Anne Blackburne.

Finalmente, el feminismo contemporáneo se distingue por ser un feminismo institucional y se inicia a partir de las obras de Simone de Beauvoir y de Betty Friedan; quienes a su vez sirven de referencia al neofeminismo, en el que destacan los feminismos de corte liberal, radical, socialista y los feminismos de la diferencia. De Miguel (1995), además, sostiene que el feminismo contemporáneo se caracteriza por la crítica al uso monolítico de la categoría 'mujer' y las implicaciones de la diversidad de situaciones que atraviesan las mujeres.

Otro modo de distinción y organización de las etapas del feminismo es la que expondremos brevemente a continuación:

La primera ola del movimiento se inició a mediados del siglo XIX y concluyó hacia el final de la Primera Guerra Mundial. Esta etapa se caracterizó por las luchas por la consecución del voto femenino, en especial en países como Inglaterra y Estados Unidos. Así, el feminismo comienza a desarrollarse como una teoría capaz de explicar la organización sociocultural.

La construcción de una determinada identidad femenina, basada en estereotipos procedentes de las múltiples disciplinas que intervinieron en su definición (filosofía, religión, psicología, artes y letras), ha generado una resistencia que se ha expresado en diversas manifestaciones históricas, ya desde la Edad Media. Esa crítica, en este primer feminismo, podemos visualizarla en la obra de Mary Wollstonecraft, Vindicación de los 
Derechos de la Mujer, de 1792. 53 "Finalmente, se justifica la aparición del movimiento sufragista como respuesta a la exclusión de las mujeres del nuevo concepto de ciudadanía que surge de las revoluciones ilustradas del siglo XVIII, particularmente la francesa”, afirman Cuder Domínguez y otras ${ }^{54}$.

La segunda ola del feminismo -o "feminismo contemporáneo"- se inicia tras la segunda guerra mundial, con un escrito fundamental, El segundo sexo (1949), de Simone de Beauvoir. La autora propone en ella un nuevo orden en el que la mujer entra a formar parte del mundo de las personas activas, frente al viejo orden en el que las mujeres eran pasivas. La mujer así se masculiniza para escapar del efecto debilitador y de pérdida de poder característico de la feminidad como condición de la otredad. Para de Beauvoir el proyecto feminista definitivo consiste en rechazar esta condición (Evans: 78-79).

La famosa frase "la mujer se hace, no nace", abrió el debate para demostrar que las mujeres -como seres femeninos- son producto de la socialización. Contra este argumento, tenemos que oponer la afirmación de "la biología es el destino", que sostuvieron - desde la psicología, y como absolutos ahistóricos y aculturales- autores como Lacan, Kristeva y otros.

La publicación en 1963 del libro The feminine Mystique, de Betty Friedan es otra obra significativa de esta etapa; allí se reivindica la autonomía personal y se denuncia la ideología de la femineidad, que induce a muchas mujeres a aceptar, como destino, su rol de madre y ama de casa ${ }^{55}$. Además, dos consignas claves surgen en esa época: "lo personal es lo político" y "el compañerismo femenino es poderoso". Algunos eslóganes llevaban

\footnotetext{
${ }^{53}$ En su libro Wollstonecraft cuestiona los conceptos rousseaunianos y la sociedad cortés, que han convertido a las mujeres en meros objetos de deseo. La ética que la autora propone se basa en una educación que logre emancipar a las mujeres, que les permita desarrollarse como seres racionales y que este posicionamiento no sea diferente al de los varones. De allí su dedicación en la lucha por obtener los derechos civiles y políticos para la mitad excluida de la población.

${ }^{54}$ Programa oficial 2013-2014 de la materia "Introducción al pensamiento feminista y a la historia de las mujeres”. Dictado por las Dras. Pilar Cuder Domínguez, Encarnación Lemus López y Sonia Villegas López. Universidad de Huelva, España.

${ }^{55}$ La Organización Nacional para las Mujeres, fundada por Friedan en el año 1966 en Estados Unidos, funciona bajo los postulados del feminismo liberal, que ha definido la situación de las mujeres como "desigualdad". Tal como expresa Evans (1997: 22): "Ha sido la toma de conciencia de la diferencia, de las experiencias radicalmente diferentes entre el mundo de las mujeres y de los hombres, la que ha proporcionado al feminismo occidental contemporáneo su primer gran grito de guerra de finales de los sesenta".

En los setenta, "las feministas empezaron a hacer preguntas acerca de la supuesta responsabilidad 'natural' de las mujeres en el cuidado de los hijos, los ancianos y los enfermos, y también acerca de su exclusión 'natural' de todo lo relacionado con el poder real social y político" (Evans, 1997: 100-101).
} 
implícita la idea de que las mujeres estaban universalmente oprimidas y explotadas y que sólo a través de una toma de conciencia de esta situación común podrían cambiar las estructuras que las oprimían. Esta posición teórica se la llama "feminismo radical", que utiliza herramientas teóricas del marxismo y el psicoanálisis. ${ }^{56}$

En los primeros años de los setenta muchos de los males de Occidente se reunían bajo el término "patriarcado". El movimiento radical consideraba que sin la eliminación de éste no se podía concebir una verdadera autonomía e igualdad; ya que estaba instalado en el imaginario social que, en todas las culturas, los hombres eran propietarios del mundo público y que a través de esta preponderancia definían los roles femeninos.

La tercera ola del movimiento feminista podemos ubicarla a comienzos de los años '90. Un mundo globalizado, que había transitado el cambio de la modernidad a la posmodernidad, condujo al replanteamiento de los conceptos de nacionalidad, etnia y ciudadanía. Este nuevo escenario de fronteras porosas demuestra la imposibilidad de construir un feminismo universal. Así, se empieza a cuestionar la pretensión de incluir tantas diferencias bajo el término de "mujer", como si sólo existiera un solo modo hegemónico de serlo. ${ }^{57}$

En este contexto, se comprende que la realidad de las mujeres varía de acuerdo al contexto social, cultural, económico, religioso y étnico. Las historiadoras feministas socialistas, como Anna Davin, Linda Gordon y Barbara Taylor, habían demostrado la dificultad de considerar una sola visión o programa feminista. La fragmentación que el feminismo evidencia deja atrás las antiguas convicciones de unidad; a pesar de ello, cabe aclarar que existen ciertos temas -como el aborto-, a través del cual las mujeres siguen organizándose, independientemente de la cuestión racial o clasista.

Entonces, el feminismo debe ser redefinido; es decir, tiene que ser deconstruido para permitir la diferencia y diversidad entre las mujeres, casi tanto como entre éstas y los

\footnotetext{
56 "Estar allí" fue el papel más importante que interpretó una generación entera de mujeres, en la década del '70. Ellas fueron: por Gran Bretaña, Sheila Rowbotham, Sheila Jeffreys, Verónica Beechey y Juliet Mitchell; por Estados Unidos, Kate Millet, Shulamith Firestone, Adrienne Rich y Audré Lorde; y por Francia, Hélène Cixous y Luce Irigaray.

57 En una fecha tan temprana como 1977, se empezó a hablar sobre el problema de la categoría "mujeres". Ver: Felicity Edholm, Olivia Harris y Kate Young, "Conceptualising Women”, pp.101-30.
} 
varones. "Diferencia" y "diversidad" se convirtieron en los noventa en sinónimos de feminismo. ${ }^{58}$

\subsection{La mujer en la sociedad y en la política regional}

La histórica triada de discriminación-opresión-explotación, que afectó no sólo a las mujeres, sino también a otros grupos (negros, migrantes, judíos, homosexuales, etc.), comenzó a cuestionarse masiva y universalmente. Se entendió entonces que lo hegemónico y lo subalterno no eran status asignados por la naturaleza o alguna deidad; sino por las pujas simbólicas y materiales que resuenan dentro y fuera de las sociedades.

En Chile Matilde Brandau Galindo ${ }^{59}$ expuso con su tesis "Derechos civiles de la mujer" (1898) la situación de las mujeres en distintos países de Europa, así como en Argentina y en su propia nación de origen. Allí describe que, de acuerdo a la legislación chilena, por el sólo hecho de contraer matrimonio, la mujer se hace incapaz jurídicamente, quedando inhabilitada para ejecutar derechos civiles "por sí sola hasta los actos más insignificantes de la vida civil" ${ }^{, 60}$. Su argumento principal para reclamar por la misma capacidad civil que los varones, fue -al igual que Stuart Mill en 1869- que "no existe motivo alguno en virtud del cual pueda privarse a la mitad del jénero ${ }^{61}$ humano de los derechos que, sin traba alguna, se reconocen a la otra mitad"62.

Por su parte, las autoras Coelho y Baptista (2009), destacan las discusiones ocurridas durante la elaboración de la primera Constitución republicana brasilera, en 1891: “La asamblea constituyente debatió y vetó el sufragio femenino. Los que argumentaban

\footnotetext{
${ }^{58} \mathrm{Al}$ respecto, Evans afirma (1995:104): "Las mujeres de clase trabajadora -argumentaban- más bien deberían desear estar fuera de la población activa antes que formar parte de ella, ya que, a diferencia de las mujeres de clase media, no podían acceder a los empleos en las profesiones o en las oficinas. Igualmente, las mujeres negras rechazaban como un todo el feminismo de las blancas: Hazel Carby en Gran Bretaña, y Angela Davis en Estados Unidos estaban entre las que formulaban difíciles preguntas sobre los diferentes grados de privilegio y/o explotación que se hacía posible a través de sistemas sociales que estaban basados no sólo en divisiones sociales sino en divisiones raciales también".

${ }^{59}$ Brandau Galindo, Matilde (ca 1870-1948) ingresó a la Facultad de Leyes de la Universidad de Chile en 1893. Años más tarde y gracias a su tesis "Derechos civiles de la mujer", se convertiría en la segunda mujer en obtener una Licenciatura en Leyes y la quinta en concluir los estudios universitarios. Dedicó su carrera profesional a los liceos femeninos, convencida que la educación era el camino para lograr la igualdad entre los géneros.

${ }^{60}$ Ibídem., 30.

${ }^{61}$ sic.

${ }^{62}$ Ibídem., 104.
} 
contrariamente se referían, por ejemplo, a la inferioridad femenina, tomado por algunos como "natural" lo que, evidentemente, no era compartida por todos los miembros"63.

En Argentina ya desde 1910 se comienza a hablar de "feminismo", ligado al concepto de emancipación de la mujer. Así, durante el Primer Congreso Femenino Internacional en la República Argentina ${ }^{64}$, se sostenía que:

Como emancipación significa libertad e independencia, claro está que la tendencia del feminismo es independizar al sexo femenino del masculino, a cuya autoridad se encuentra sujeto. La mujer se siente, pues, oprimida y dañada en sus derechos por el hombre, y de ahí que, desengañada, levanta su enérgica protesta y proclama su emancipación, esperando hallar en ella la salud para su injusta situación. (Camacho y Bueno, 1910: 260).

Atento a estos reclamos, desde 1915 el ex Diputado nacional por el Partido Socialista de los Trabajadores, Alfredo Palacios, presentó ante la Cámara, sin éxito, varios proyectos que consideraban la posibilidad de otorgar a la mujer una paridad de derechos civiles con los varones. En ese sentido y dentro de la misma ideología partidaria, la joven que se convertiría en un símbolo del movimiento feminista argentino, Alicia Moreau de Justo ${ }^{65}$, tuvo como preocupación permanente el acceso de las mujeres al sufragio libre. Finalmente, éste se hizo ley en Argentina en el año 1947, cuando el peronismo -tomando la propuesta realizada por el socialismo décadas atrás-, comprendió el valor político de dicha conquista social.

En Brasil, en los inicios del siglo XX, lidera los movimientos sufragistas Berta Maria Júlia Lutz, quien en su viaje a Europa por estudios, descubre y se acerca al feminismo y la campaña sufragista británica y estadounidense. En 1918 se licenció en Ciencias por la Universidad de la Sorbona de París y regresó a su país. Cuatro años después, junto a otras feministas, creó la Federación Brasileña sobre el Progreso Femenino y organizó el Primer Congreso Internacional Feminista, del 20 al 22 de diciembre de 1922; cuyo principal

\footnotetext{
${ }^{63}$ Ibídem., 88-89. Traducción propia.

${ }^{64}$ Este Congreso fue organizado por la Asociación "Universitarias Argentinas”, los días 18, 19, 20,21 y 23 de mayo de 1910 y se celebró en Buenos Aires.

${ }^{65}$ Dirigió la publicación, "Nuestra Causa", que funcionó como órgano de difusión de las ideas de la Unión Feminista Nacional. Durante la última dictadura militar argentina, brindó apoyo a la lucha de las Madres de la Plaza de Mayo. En 1984 fue elegida la Mujer del Año y la Universidad de Buenos Aires le entrega un premio como Médica del Siglo. Al año siguiente, la declaran presidenta honoraria de las Primeras Jornadas de Mujeres Socialistas.
} 
objetivo fue reivindicar el derecho al voto de las brasileñas, que lograrían 10 años más tarde.

Sobre las limitaciones de acceso a cargos políticos por parte de las mujeres, Evans (1997: 42 y 75) expresa:

los estudios culturales feministas han mostrado que el modo en que las mujeres son representadas está repleto de cuestiones acerca del poder relativo de los sexos (...) En Occidente, en los años ochenta y noventa, hubo pocos cambios significativos en el número de mujeres en posiciones de poder y autoridad social y política. A pesar de que la cantidad de mujeres en trabajos pagados varió bastante, no se veía en ningún país que este cambio se hubiera extendido a una mayor participación en la toma de decisiones por parte de las mujeres.

Ligado a lo anterior, según algunas autoras (Vargas, 2002; Facio, 2001; Guzmán y Bonan Jannotti, 2008), en América Latina se desarrollaron los feminismos como movimientos políticos desde la década de los setenta -contra los regímenes dictatoriales de la época- y ya para los ochenta, la demanda de las mujeres por el lugar periférico que ocupaban en sus sociedades, se había extendido a todos los países de la región. "Es cierto que no empezamos luchando por los derechos de las humanas en esa etapa, pero la forma política en que las madres utilizaron la maternidad, fue el inicio del cuestionamiento a la separación entre la esfera privada y la pública", afirma Facio (2001:19); en alusión a lo que en Argentina se conoció como Madres de Plaza de Mayo.

Durante los '80 los debates internos dentro del movimiento feminista latinoamericano estuvieron relacionados "con la importancia relativa de los factores económicos y sociales -en comparación con los culturales e ideológicos” para analizar el papel secundario de la mujer (Stolen, 2004:24). El enfoque materialista en los estudios de género, influenciado por el marxismo estructural, dominaba en América Latina. La principal preocupación era "comprender y erradicar el capitalismo, detectando los mecanismos por los cuales la subordinación y explotación de las mujeres (...) contribuía a la reproducción de las abusivas relaciones de clase." 66

Así, hacia la mitad de los ochenta fue aceptado que el estado legitimaba una visión patriarcal de las mujeres. "El estado daba por supuesto que las mujeres eran económicamente dependientes de los hombres, que estaban 'naturalmente' mejor dotadas

${ }^{66}$ Ibídem., 24 
para cuidar de otros y que eran 'buenas' (las que merecían la protección del estado) o ‘malas' (las que tenían que ser castigadas por el estado)” (Evans, 1997:59).

En el Cono Sur, la recuperación de la democracia tras años de gobiernos autoritarios, les permitió a las mujeres negociar sus demandas; lo que derivó en que varias de sus reivindicaciones se incorporaron en las nuevas constituciones democráticas, como las de Brasil en 1988, Paraguay en 1992 y la reforma constitucional argentina, en 1994. La vuelta a las urnas en Sudamérica implicó además la ampliación de los espacios públicos y la diversificación de actores sociales y problemáticas (Guzmán, 2011). Como resultado, países como Argentina adoptaron la legislación de cuotas de género. ${ }^{67}$

Alentadas por las Naciones Unidas y la Organización de Estados Americanos, las nuevas democracias adoptaron políticas de promoción de la igualdad. Así, "las mujeres latinoamericanas obtuvieron grandes progresos durante los 90: legislación sobre violencia doméstica, planes de oportunidades y programas que apuntaban a las fuentes de pobreza específicas de género" (Franceschet, 2006: 15). Las invisibilizadas de siempre comenzaban a tener voz y ser consideradas en escenarios de neoliberalismo exacerbado y replanteo de viejos paradigmas.

Pero, ¿qué pasaba con los derechos políticos de estas mujeres? Si bien el acceso al sufragio ya era una realidad, en esta nueva etapa se empieza a pensar y cuestionar en quienes ocupan los cargos de poder. Es decir, se comienza a problematizar cada vez más seriamente porqué la toma de decisiones a nivel estatal está asociada a sujetos masculinos. La praxis política ha sido protagonizada a lo largo de la historia por numerosas mujeres que desmontaron en infinitas ocasiones el mito del desinterés femenino por los asuntos públicos. Sin embargo, tal como sostiene Carosio, "la cultura patriarcal está instalada en la subjetividad" (2012:14), tanto en varones como en mujeres; situación que contribuye a la efectiva reproducción de esta visión.

La primera pregunta que nos surge ante el escenario que venimos describiendo sería: ¿Es viable la construcción de sociedades más justas en la región mientras sigue en

\footnotetext{
${ }^{67}$ Entre la literatura académica relacionada a la aplicación del sistema de cuotas de participación política como mecanismo de acción afirmativa para las mujeres, debemos destacar el análisis de: Sagot Rodríguez (2010) sobre la situación en Costa Rica; el de Fernández Ramil (2008), sobre el caso chileno y el de Macías Lovera (2011), sobre la repercusión de esta medida en el subcontinente latinoamericano. En una línea similar de pensamiento, varios de los autores que integran los libros editados por Ríos Tobar (2006; 2008), ponen en cuestión la implementación de las cuotas de género en distintos países del Centro y el Sur de América, sosteniendo que la efectividad de éstas ha sido diversa en los disímiles Estados donde se han aplicado.
} 
vigencia la ideología patriarcal? Guzmán (2011) nos dice que las distintas dinámicas coyunturales en cada país han repercutido en respuestas diferenciadas: apertura o restricción de oportunidades "para que las mujeres se constituyan en actores sociales y políticos e incorporen sus problemas en las agendas públicas e institucionales". 68

Pero, ¿qué sucedió cuando Fernández, Rousseff y Bachelet asumieron su cargo como mandatarias de Argentina, Brasil y Chile respectivamente? Ramil y Oliva Espinosa (2012) resaltan la paradoja que, a pesar del impacto democratizador que implica la llegada de una mujer al Poder Ejecutivo, esta situación no siempre se expresa en avances sustantivos en la transformación de instituciones políticas que permitan mejorar la calidad de la democracia en sus sociedades.

${ }^{68}$ Ibídem., 11 


\section{CAPÍTULO 3}

La concreción del problema en los casos de Argentina, Brasil y Chile

La política sudamericana ha sido siempre dominio masculino. Desde la Independencia de países como Argentina (1816), Chile (1818) y Brasil (1822), hasta bien avanzado el siglo $\mathrm{XX}$, los espacios de toma de decisión en esas latitudes pertenecieron a los varones.

Como hecho destacado, cabe mencionar el caso de Argentina, donde la figura de Eva Duarte durante la primera Presidencia de su marido, Juan Domingo Perón (1946 a 1952, año en que "Evita" fallece como consecuencia de cáncer), tuvo un rol destacado. Aunque la empática actriz nunca asumió ningún cargo formal como funcionaria del gabinete de su marido, su accionar político -como primera dama, pero también como presidenta del Partido Peronista Femenino y de la Fundación Eva Perón- fue reconocido por admiradores y detractores.

$\mathrm{Su}$ carisma, cualidad que le permitió convertirse en la "abanderada de los descamisados", la convirtieron en una lideresa política de gran influencia. En este sentido, en el discurso denominado "Mujeres y poder. Transformaciones, mitos y realidades en los procesos populares y democráticos. La experiencia Argentina" ${ }^{69}$, pronunciado el día 12 de noviembre del 2016 en Ciudad de México, la Diputada Nacional del Frente para la Victoria por la Provincia de Buenos Aires, Juliana Di Tullio ${ }^{70}$, afirmó:

\footnotetext{
${ }^{69}$ Pronunciado en el marco de la Conferencia Internacional "El impulso del empoderamiento político de las mujeres en la toma de decisiones". Evento organizado por el Partido de la Revolución Democrática a través de la Secretaría de Relaciones Internacionales del Comité Ejecutivo Nacional, el día 12 de noviembre del 2016 en la Ciudad de México.

${ }^{70}$ Del 2003 al 2005 fue Embajadora de la Representación Especial para Temas de la Mujer en el ámbito internacional del Ministerio de Relaciones Exteriores, Comercio Internacional y Cultura de la República Argentina. Ha sido Delegada Titular en la CIM de la OEA, Delegada Titular en organizaciones de NNUU; ha sido Delegada Titular del Mercosur, en la reunión especializada de Ministros y Mujeres del Mercosur; y, como Embajadora, ella ha impulsado la creación de la Comisión de Equidad de Género de la Sociedad Civil, que es un espacio de información e intercambio entre el Estado, organizaciones sociales, organizaciones no gubernamentales, con el fin de lograr procesos de integración política, económica y social en el Mercosur, donde éstos contemplen la perspectiva de género. Ella se ha ocupado de generar en esta etapa de trabajo, una comisión ad hoc para el seguimiento de la Plataforma de Acción de Beijing, en la Conferencia Mundial de las Mujeres. Di Tullio ha sido Diputada ya tres veces, desde el año 2005 es la representante de las mujeres del Frente para la Victoria en la Argentina. Este partido impulsó la candidatura primero de Néstor Kirchner, Presidente de la Argentina; y después de Cristina Fernández de Kirchner, también ex Presidenta de la República Argentina. (Fuente: Presentación de Di Tullio, en el marco de la Conferencia Internacional "El impulso del empoderamiento político de las mujeres en la toma de decisiones"; Ciudad de México, $12 / 11 / 2016)$.
} 
...desde el mito fundante (del partido Peronista), Eva Perón es como un símbolo de una mujer con mucho poder - no sólo en nuestro país, sino en el mundo-- y es como un faro para todas las mujeres que somos parte de este gran espacio político. También de la ex Presidenta Cristina Fernández quien en su discurso de asunción presidencial-, dice: "bueno...yo, seguramente me va a ser más difícil porque soy mujer. Lo voy a admitir acá públicamente. Y seguramente Evita se lo hubiera merecido más que yo, pero bueno, me tocó a mí serlo".

3.1. Política exterior previa a la asunción de las mandatarias

¿Por quiénes estaba representada y conducida la política exterior sudamericana antes que asumieran como mandatarias Fernández, Rousseff y Bachelet?

Además de que los cargos de máxima representación habían estado históricamente ocupados por varones ${ }^{71}$, los Ministerios de Relaciones Exteriores y Embajadas también eran terreno masculino.

$\underline{\text { República Argentina }}$

El caso argentino es curioso porque, tras la última dictadura cívico-militar y el regreso de la democracia, el Presidente elegido Raúl Ricardo Alfonsín tuvo dos Cancilleres: Dante Mario Antonio Caputo (10 de diciembre de 1983 - 26 de mayo de 1989) y Susana Ruiz Cerutti (26 de mayo de 1989 - 08 de julio de 1989). Si bien cabe destacar la presencia de una mujer en la Cancillería, también es cierto que Cerutti estuvo poco más de un mes en ese espacio.

Los encargados del Ministerio de Relaciones Exteriores y Culto argentino que siguieron fueron todos varones: durante los gobiernos de Carlos Saúl Menem (19891995/1995-1999), fueron Domingo Felipe Cavallo (1989-1991) y Guido Di Tella (19911999). En el caso de la gestión de Fernando de la Rúa (1999-2001), su Canciller fue Adalberto Rodríguez Giavarini.

\footnotetext{
${ }^{71}$ La excepción es, en el caso argentino, María Estela Martínez, popularmente conocida como "Isabelita" o "Isabel Perón". Compañera de fórmula de su marido, se convierte en el año 1973 en la primera vicepresidenta mujer; y, tras la muerte de Perón en 1974, asume la Presidencia hasta su derrocamiento en manos militares, el día 24 de marzo de 1976. Ese golpe de estado sería el inicio formal de la dictadura -autodenominada Proceso de Reorganización Nacional- y que se extendería hasta 1983.

El otro caso sudamericano fue el de Lidia Gueiler Tejada, elegida Presidenta de Bolivia por el Congreso Nacional el 16 de noviembre de 1979; convirtiéndose así en la primera mujer Presidenta de ese país desde la fundación de la República. También fue Diputada durante dos períodos, Cónsul en Alemania Occidental y representó a su Patria en la Comisión Interamericana de Mujeres en Estados Unidos.
} 
Tras la escandalosa salida del Presidente De la Rúa, y de la terrible crisis política, social y económica que atravesaba Argentina, en el lapso comprendido entre el 20 de diciembre del 2001 al 2 de enero del 2002, desfilaron por el Ejecutivo: Ramón Puerta, Adolfo Rodríguez Saá y Eduardo Camaño. En esa etapa el Canciller fue José María Vernet. Luego asumió como Jefe de Estado Eduardo Alberto Duhalde (2 de enero del 2002 al 25 de mayo del 2003), quien tuvo como Ministro de Relaciones Exteriores, Comercio Internacional y Culto de su gobierno provisional a Carlos Federico Ruckauf.

Durante el gobierno de Néstor Kirchner (2003- 2007), sus Cancilleres fueron Rafael Antonio Bielsa (2003-2005) y Jorge Enrique Taiana (2005-2007). Este último, continuó al frente del Ministerio durante la gestión de presidencia de Cristina Fernández, hasta que en el 2010 presentó su renuncia tras una acusación de la mandataria en la que lo trataba de desleal. La carta de declinación a su cargo, se refiere a "diferencias" y "falta de apoyo" a su gestión en la Cancillería. ${ }^{72}$

\section{$\underline{\text { República Federativa de Brasil }}$}

Fernando Henrique Cardoso fue Presidente de Brasil desde 1995 hasta el 2002; sin embargo, en los años previos a su asunción, se desempeñó como Ministro de Relaciones Exteriores (1992-1993) y luego como Ministro de Hacienda (1993-1994). Estos antecedentes lo llevaron a ejercer un rol activo en política exterior durante sus mandatos: la denominada "diplomacia presidencial”. Luiz Felipe Lampreia, un diplomático de carrera, asumió las Relaciones Exteriores.

El siguiente mandatario elegido para gobernar fue el candidato del Partido de los Trabajadores (PT), Luiz Inácio Lula da Silva, quien gobernó por dos períodos consecutivos. Este líder sindicalista representaba la necesidad de transformación que algunos sectores del pueblo brasileño estaban buscando en las estructuras sociales. El concepto de mudança (transformación) fue unos de los lemas de la primera campaña presidencial lulista; cambios que afectarían la esfera interna, económica y política, pero también el plano internacional:

(la) elección del asesor presidencial para temas de relaciones internacionales (profesor Marco Aurelio Garcia, durante muchos años secretario de relaciones internacionales

\footnotetext{
${ }^{72}$ Ver: Nota del diario Clarín (18/06/2010), “Una frase de Cristina molestó a Taiana y lo llevó a presentar la renuncia a la Cancillería". (On line). Disponible en: http://www.clarin.com/politica/Presidenta-renuncio-sorpresivamente-canciller-Taiana_0_SJK7FnlCD7g.html
} 
del PT), primeros viajes exteriores del presidente (a su entorno regional, Argentina y Chile, y a Estados Unidos, en diciembre del 2002) (...), o la elección como ministro de Exteriores -quizás para compensar la elección de un asesor ajeno a la carrera, que a menudo había sido elegido entre el elenco de Itamaraty- de Celso Amorim. (Grasa Hernández, 2004: 97)

Entre las características más resonantes de la política exterior brasilera, debemos destacar: la existencia de una Constitución abarcadora, que hace alusión a derechos, principios y normas de la realidad internacional; un Ministerio de Relaciones Exteriores o Cancillería (Itamaraty), reconocido mundialmente por su solidez y profesionalización; su rol de potencia media semiperiférica, con un fuerte liderazgo en América Latina; y una política exterior tradicional que apunta a relaciones multilaterales, por un lado, y con Estados Unidos, por el otro.

Celso Luiz Nunes Amorim, perteneciente al ala izquierda del PT, fue Ministro de Relaciones Exteriores de Lula durante sus ocho años de gobierno (2003-2010). Durante el primer mandato de Dilma Rousseff, y a partir de la renuncia de Nelson Jobim ${ }^{73}$ por discrepancias con el gobierno de la mandataria, se convierte en Ministro de Defensa del país.

Fueron varias las declaraciones públicas que Jobim realizó en contra de su Jefa de Estado; pero -y en virtud del énfasis en la mirada de género de esta tesis- no podemos dejar de destacar el ataque que realiza en la revista Piauí a funcionarias con cargos relevantes:

trazaba un perfil nada elogioso de dos de las ministras más importantes del Gobierno, escogidas personalmente por Rousseff: la de la Casa Civil (Presidencia), Gleisi Hoffmann, que sucedió al ministro Antonio Palocci, acusado de corrupción, y la de Relaciones Institucionales, Ideli Salvatti. De esta última, Jobim confesó que es "flaca" y de Hoffmann que "ni siquiera conoce Brasilia". (El País, 5/08/2011).

\section{$\underline{\text { República de Chile }}$}

\footnotetext{
73 "Se trata del tercer ministro, después del de la Casa Civil, Antoni Palocci, y del de Transportes, Alfredo Nascimento, que deja el puesto con Rousseff, tan solo siete meses después de su toma de posesión. Los tres pertenecían al anterior Gobierno del Lula da Silva, que había pedido a su sucesora que los mantuviera en su nuevo gabinete". Diario "El País", 5 de agosto del 2011. Disponible en: http://internacional.elpais.com/internacional/2011/08/05/actualidad/1312495201_850215.html
} 
El caso chileno es un caso particular, porque el ex Presidente Ricardo Froilán Lagos Escobar (2000-2006) ${ }^{74}$ contó en su mandato con dos mujeres fuertes en puestos de gran responsabilidad: Soledad Alvear Valenzuela (PDC) como Ministra de Relaciones Exteriores y a Michelle Bachelet Jeria (Socialista) en Salud. Ésta última sería nombrada como Ministra de Defensa Nacional en marzo del 2002, reemplazando a Mario Fernández Baeza (PDC).

La abogada Alvear Valenzuela ya contaba en su historial con otros cargos de importancia: durante el gobierno que encabezó Patricio Aylwin Azócar, se desempeñó como Ministra Directora del Servicio Nacional de la Mujer; más tarde, en la gestión de Eduardo Frei Ruiz-Tagle lideró la Reforma Procesal Penal como titular de la cartera de Justicia.

Ambas mujeres fueron separadas de sus cargos en septiembre del 2004, con el objetivo de que concentraran su atención en las inminentes elecciones primarias que se llevarían a cabo en la Concertación y en las cuales eran precandidatas partidarias. De este modo, Bachelet fue sucedida por Jaime Ravinet de la Fuente y Alvear por Ignacio Walker Prieto, ambos del PDC.

Finalmente, la votación - prevista para el 31 de julio del 2005- no llegó a realizarse porque la que se convirtiera en la primera mujer en ocupar el cargo de Ministra en Relaciones Exteriores en la historia chilena, renunció a su postulación e incentivó a cerrar filas tras la imagen de Michelle. Finalmente, Bachelet venció en las elecciones presidenciales celebradas a dos vueltas, el 11 de diciembre de 2005 y el 15 de enero de 2006, frente al candidato de la RN, Sebastián Piñera Echenique.

Por su parte, también en el 2006, Alvear gana las elecciones internas de la Democracia Cristiana, convirtiéndose en la primera mujer presidenta del partido; función que llevó a cabo por dos períodos consecutivos.

Respecto a la política exterior chilena, Chaves y Pávez (2016) sostienen que en las dos décadas que van de 1990 a 2010 ha sido -en muchos aspectos- constante,

\footnotetext{
${ }^{74}$ El 11 de marzo de 2000 Lagos tomó posesión del Palacio de la Moneda con un mandato sexenal (el último de esa característica, ya que en agosto del 2005 el Congreso votó por la reducción del período presidencial de seis a cuatro años sin posibilidad de reelección consecutiva); convirtiéndose en el primer presidente socialista en 27 años y en el tercero de la Concertación en la última década.
} 
independientemente del partido gobernante ${ }^{75}$. Esta cualidad señala un posicionamiento que pondera el alcance de los intereses nacionales, por sobre las diferencias ideológicas de la política doméstica. Se pasó de un país con un posicionamiento internacional aislado durante los años del régimen militar (1973-1990), por la de una nación con inserción mundial creciente (Portales, 2011).

Los autores también señalan el cambio que se produce en la política exterior a partir de que Bachelet asume en el Palacio de la Moneda:

Así, recién desde el 2006, América del Sur comienza a tener para la política exterior chilena una importancia geopolítica como región en sí: la adhesión de Chile a UNASUR o CELAC son ejemplos de ello. Sin embargo, aquél acercamiento no significó que Chile dejara de tener un buen trato hacia el resto de los países con quienes negociaba (...) De hecho, a pesar de haber sido la Presidenta Bachelet asimilada a la ola de gobiernos progresistas que surgieron en la región durante la segunda mitad del siglo pasado y principios de éste; la mandataria decidió no unirse a acuerdos de índole política y cercanos al llamado "socialismo del siglo XXI", como la Alianza Bolivariana para los Pueblos de Nuestra América (ALBA). (Chaves y Pávez, 2016: 22).

La política exterior del primer gobierno de Michelle, ha pretendido y logrado tener un acercamiento en las relaciones bilaterales con los países latinoamericanos, pero desde una postura que en varias oportunidades ha sido bastante criticada: mirando desde afuera, con algún elemento "latinoamericano", aunque no "latinoamericanista" (Fermandois \& Henríquez, 2005:73). La idea de integración aperturista a la economía mundial, que tiene entre sus socios a aliados extra-regionales, fue algo difícil de digerir para América Latina.

En el año 2008, la revista estadounidense Forbes ubicaba a Michelle Bachelet en el puesto 25 entre las 100 mujeres más influyentes del mundo (Funk, 2009).

3.2. Historia personal de las presidentas como dirigentes políticas.

\footnotetext{
${ }^{75}$ Cabe destacar que desde marzo de 1990 hasta marzo del 2010, la Coalición que estuvo en el Ejecutivo fue la de la Concertación. La diferencia fueron los partidos: Patricio Aylwin Azócar, Demócrata Cristiano; Eduardo Frei Ruiz- Tagle, Demócrata Cristiano; Ricardo Lagos Escobar, Partido por la Democracia; y Michelle Bachelet Jeria, Socialista.
} 


\subsubsection{Muñeca brava}

Cristina Elisabet Fernández nació en Tolosa, partido de La Plata, el 19 de febrero de 1953; con un padre -Eduardo Fernández- colectivero que falleció en 1982 y una mamá Ofelia Wilhelm- representante sindical. Además, "tiene una hermana menor, Giselle, y dos hijos con Néstor Kirchner: Máximo, que nació en 1977, y Florencia, de 1990” (Halperín, 2009: 82).

Respecto a su formación de grado, Fernández cursó sus estudios de abogacía en la Facultad de Ciencias Jurídicas y Sociales de la Universidad Nacional de La Plata. De acuerdo a la página oficial de la ex mandataria ${ }^{76}$ : fue justamente en esa institución donde “inició su militancia política en el Frente de Agrupaciones Eva Perón (FAEP), que luego se fusionó con la Federación Universitaria por la Revolución Nacional (FURN) para constituir la Juventud Universitaria Peronista de la Universidad de La Plata”.

En 1975 se casó con Néstor Kirchner, con quien compartieron militancia en la JUP. Tras el golpe de estado de 1976, ambos decidieron mudarse a Río Gallegos, ciudad natal de Kirchner. Desde allí, la pareja formó un estudio jurídico y se dedicó a la actividad privada como abogados. Con el retorno del régimen democrático, Cristina volvió a participar activamente en el Partido Justicialista junto a su marido, "quien fue electo intendente de Río Gallegos en 1987 y gobernador de Santa Cruz en 1991 y reelecto en dos oportunidades" $" 77$.

Fernández fue triplemente electa como Diputada Provincial en Santa Cruz: en 1989, en 1993 y en 1995. Éste último año, además, ingresó al Senado Nacional representando a la provincia patagónica:

En 1997 renunció a su cargo de senadora para ser electa diputada nacional y en 2001 fue electa otra vez senadora, siempre por la misma provincia. (...) A partir de 2003, durante la presidencia de su marido Néstor Kirchner, representó al país en diversos foros internacionales (...) En las elecciones legislativas del 23 de octubre de 2005 fue elegida senadora de la provincia de Buenos Aires por el Frente para la Victoria, mandato durante el cual se desempeñó como presidenta de la Comisión de Asuntos Constitucionales del Senado. (Página oficial CFK)

Sobre la etapa en que la ex mandataria permaneció en el Congreso, Halperín (2009) destaca los múltiples enfrentamientos que tenía Fernández con sus compañeros de

\footnotetext{
${ }^{76}$ Nos referimos a la página: www.cfkargentina.com

${ }^{77}$ Ibídem.
} 
comisiones y bloque; y que, según el autor, le costaron la denominación de "mujer rebelde" o -como la bautizarían algunos sectores del periodismo gráfico-, "muñeca brava":

Cuando ella se negó a apoyar el proyecto de creación del Consejo de la Magistratura, el presidente del bloque, Augusto Alasino, se cansó y decidió expulsarla de las comisiones de las que formaba parte. No eran pocas: Coparticipación Federal de Impuestos; Asuntos Administrativos y Municipales; Relaciones Exteriores y Culto; Asuntos Penales y Regímenes Carcelarios; Educación; Familia y Minoridad, y Economías Regionales. (Ibíd., 77)

En 1994, Fernández participó de los debates que terminaron autorizando la reelección presidencial; circunstancia que habilitó a Carlos Menem para que se presentara a un segundo mandato. Por esas cosas del destino, sería este cambio en el principal código normativo lo que posibilitaría que en octubre del 2011 Cristina pudiera ser reelecta en Argentina como Jefa de Estado.

En mayo del 2003, el candidato Menem -quien aspiraba a una tercera gestión gubernamental- renunció a la carrera presidencial, evitando el ballotage que iba a enfrentarlo con Néstor Kirchner. De este modo, éste último se convirtió en presidente y la senadora Fernández en primera dama. Durante el 2005, Cristina viajó a países influyentes y se reunió con importantes funcionarios como representante del gobierno kirchnerista. Además, asumió como Senadora, pero esta vez por la provincia de Buenos Aires.

La "primera ciudadana", como quería que la nombraran, estaba abocada a los temas parlamentarios, así como también a los de la justicia y los Derechos Humanos. En este sentido, su relación cercana con las Madres y Abuelas de Plaza de Mayo es innegable. Asimismo, se le atribuye un cambio de paradigma respecto al ingreso de funcionarias en la gestión pública: “Aconsejado por su esposa, Kirchner fue el primer presidente en designar a dos mujeres en la Corte Suprema de Justicia (Carmen Argibay y Elena Highton de Nolasco) y el primero en darle perfil femenino a dos ministerios siempre dominados por hombres. Felisa Miceli fue ministra de Economía y Nilda Garré, ministra de Defensa" (Halperín, 2009: 80).

El 19 de julio de 2007, Cristina lanzó su postulación oficial a la presidencia en el Teatro Argentino de La Plata. El 28 de ese mes se presentó a quien sería su compañero de fórmula: el radical Julio César Cleto Cobos, gobernador de la provincia de Mendoza. Tal como afirmamos en el Documento de Trabajo No 10 del IRI, esta disidencia ideológica que 
al principio de sus mandatos muchos vieron como enriquecedora, porque suponía compartir cierto espacio de poder con un representante del partido opositor históricamente de mayor peso, con el tiempo supondría un obstáculo para la Jefa de Estado. En especial, con la famosa votación de la Resolución $125^{78}$. (Chaves, 2015)

Cristina fue la sucesora política de su marido, Néstor Kirchner; y, aunque su lema de campaña fue "El cambio que recién comienza", lo que quedó demostrado luego en su gestión fue la continuidad de acciones en la dirección de su antecesor, tanto en la política doméstica como en la externa (Chaves, 2015). En este sentido, Simonoff (2008) afirma:

Por la división de tareas históricas de esa sociedad política mientras Néstor Kirchner, le había tocado siempre estar en cargos ejecutivos, Cristina Fernández ocupó legislativos. Eso moldea los estilos de ambos donde el primero, aunque terminante posee cierto criterio pragmático, la segunda es más ideológica, por eso concluimos que desde su propia historia, nada indicaba un cambio rotundo, como el que se deseaba y anunciaba.

El 28 de octubre de 2007, Fernández obtuvo el 44\% de los votos; el doble de lo que había logrado Néstor Kirchner en el 2003. De este modo vencía a su máxima oponente política -Elisa Carrió- y se convertía en Jefa de Estado de Argentina. La primera mujer presidenta elegida por el voto popular; que, además, incorporó a otras mujeres en cargos importantes, como a las ministras Alicia Kirchner, Nilda Garré, Débora Giorgi y Graciela Ocaña.

En el caso de Cristina, debe reconocerse que fue y es una mujer fuerte que siempre se hizo oír, con una histórica militancia y una personalidad que la condujo a constituirse como un cuadro político. Sin embargo, también es necesario considerar que su condición de “esposa del Jefe de Estado", la benefició en su acceso al poder. Esto se evidencia, por ejemplo, en que al interior del partido peronista, en esos tiempos representado casi

\footnotetext{
${ }^{78} \mathrm{El}$ proyecto de ley sobre un nuevo sistema de retenciones móviles a la exportación, que iban a aumentar o disminuir de acuerdo con la evolución de los precios internacionales de la soja fue anunciado por el entonces Ministro Lousteau en marzo del 2008. A raíz de este anuncio, las organizaciones que reúnen al sector empresario de la producción agropecuaria declararon paros, cortes de rutas, cierres patronales y la interrupción de las exportaciones. La situación en el país se agudizó y llegó a haber desabastecimiento en muchas ciudades, porque la medida afectó el comercio nacional e internacional. Hacia fines de abril, el impulsor de la 125, Lousteau, renunció y fue reemplazado por Carlos Fernández. "El 17 de julio, el proyecto se trató en la Cámara Alta. La votación terminó empatada con 36 votos, y quien debió decidir fue el vicepresidente, Julio Cobos. Sus palabras sellaron, en parte, el tono del futuro del gobierno a partir de ese momento: 'Yo creo que la Presidenta de los argentinos me va a entender. Que la historia me juzgue. Pido perdón si me equivoco. Mi voto es no positivo'. La resolución 125 pasó a ser historia. Enseguida el gobierno la derogó, y si bien el conflicto ha continuado (...), esos cuatro meses marcaron la gestión de Cristina Fernández más que cualquier cosa" (Halperín, 2009: 88).
} 
exclusivamente por el "Frente para la Victoria", no hubo debate interno sobre las candidaturas presidenciales; sino que primó la elección y el impulso explícito que brindó el entonces Presidente Néstor Kirchner a su esposa como sucesora natural.

Finalmente, lo anterior nos conduce a reflexionar sobre esta cuestión de compartir el poder en términos conyugales como una característica del peronismo, desde una mirada histórica. En palabras de Di Tullio ${ }^{79}$ :

...ella (Fernández) fue acompañando a Néstor Kirchner a poder concretar ese sueño de ejercer la Presidencia de la República, en el año 2003, donde en esta unidad de concepción entre Néstor y Cristina en términos políticos... -y en esto sí es casi como un revivir esa corpórea alianza entre Perón y Evita-, Cristina acompañó ese proceso para que Néstor Kirchner sea electo Presidente de los argentinos y las argentinas.

\subsubsection{La elegida de Lula}

Dilma Vana Rousseff nació el 14 de diciembre de 1947 en Belo Horizonte, capital del estado de Minas Gerais; donde creció junto a sus hermanos Igor y Zana Lúcia. Hija de Pedro Rousseff, un inmigrante búlgaro que se dedicaba a la poesía y ejercía como abogado; y de Dilma Jane Silva, maestra de escuela, oriunda de Río de Janeiro.

De acuerdo al Centre for International Affairs Barcelona (CIDOB), el padre de Dilma, cuyo nombre eslavo original era Petur Rusev, había estado afiliado al Partido Comunista en Bulgaria, donde quedó viudo de su primera esposa, con quien tuvo un hijo. Una vez en Brasil, hizo carrera profesional en San Pablo, para luego establecerse con su esposa brasilera en Belo Horizonte; donde trabajó para la Compañía Siderúrgica Mannesmann.

A sus 14 años perdió a su padre y ya desde esa joven edad comenzó a interesarse por cuestiones sociales y políticas. En 1964 ingresó en el Colegio Estatal Central, donde comenzó a participar en el movimiento estudiantil de la Organização Revolucionária Marxista-Política Operária (POLOP), “un grupo de extrema izquierda, surgido de sendas

\footnotetext{
79 Discurso pronunciado en el marco de la Conferencia Internacional "El impulso del empoderamiento político de las mujeres en la toma de decisiones". Evento organizado por el Partido de la Revolución Democrática a través de la Secretaría de Relaciones Internacionales del Comité Ejecutivo Nacional, el día 12 de noviembre del 2016 en la Ciudad de México.
} 
disidencias juveniles de los partidos Comunista (PCB), Socialista (PSB) y Trabalhista (PTB), y que se sumergió en una disputa interna sobre la estrategia a seguir para expulsar a la dictadura y avanzar hacia la creación de un Gobierno de tipo socialista”. (Ibíd.)

Los sectores discutían si el derrocamiento de los militares, quienes habían depuesto al presidente electo João Goulart, debía hacerse por la vía política o a través de la lucha armada. En 1967, ya como alumna en la Facultad de Economía de la Universidad Federal de Minas Gerais, Rousseff se incorporó al Comando de Liberación Nacional (COLINA), movimiento revolucionario que organizó múltiples asaltos a entidades bancarias y atentados. Ese mismo año se casó por civil con un compañero de militancia, el periodista Cláudio Galeno Linhares; de quien se separó al poco tiempo.

En la organización Dilma era el enlace con los sindicatos, la instructora ideológica y editora del periódico clandestino O Piquete (CIDOB). Condenada por la dictadura de su país, fue detenida y torturada por casi tres años (1970-1972) en el presidio Tiradentes en San Pablo; donde la sometieron a "golpes y descargas eléctricas, dirigidas por oficiales cuyos nombres ella denunció posteriormente, en las vistas judiciales que siguieron a la restauración democrática. También le practicaron tortura psicológica, como una simulación de fusilamiento" (CIDOB).

Liberada de la cárcel, se fue a vivir a Porto Alegre en 1973 e ingresó en la facultad de Economía de la Universidad Federal de Rio Grande do Sul. En 1975, empezó a trabajar como pasante en la Fundación de Economía y Estadística (FEE), órgano del gobierno de Rio Grande do Sul, y obtuvo el grado universitario en economía en 1977. En 1990, vuelve a la FEE como presidente de la institución. (Palácio do Planalto, 31/12/2014) ${ }^{80}$

Fue durante su época de activista política contra la estructura militar cuando conoció al abogado Carlos Franklin Paixão de Araújo, con quien mantuvo una relación de más de tres décadas y con quien tuvo a su hija Paula, en 1976.

A principios de los 80, colabora con el ex-gobernador Leonel Brizola para fundar el Partido Democrático Trabalhista (PDT) en Rio Grande do Sul; además, asesora a la bancada del PDT en la Asamblea Legislativa y, de la mano del alcalde Alceu Collares, de su mismo partido, asume la Secretaría Municipal de Hacienda en Porto Alegre. Más tarde,

\footnotetext{
${ }^{80}$ http://www2.planalto.gov.br/presidencia/presidenta/perfil/presidenta-dilma-rousseff-1
} 
en 1993, cuando Collares fue elegido gobernador, la asigna como Secretaría Estadual de Energía, Minas y Comunicación, donde permanecerá hasta que:

...en 1999, Olívio Dutra toma posesión como gobernador electo en una coligación PTPDT y, en el 2000, Dilma se afilia al Partido dos Trabalhadores (PT). En el 2001, afecta al país (una) grave crisis de suministro de energía y el Rio Grande do Sul es uno de los pocos estados de la federación en no sufrir apagones. Acreditada por su desempeño en la Secretaría durante la crisis, el presidente electo Luiz Inácio Lula da Silva la invita, a fines del 2002, para participar del equipo de transición que prepararía el siguiente Gobierno Federal. Con la toma de posesión de Lula, se convierte en ministra de Minas y Energía. (Palácio do Planalto, 31/12/2014)

Durante dos años (2003 al 2005), Rousseff ocupará el cargo de Ministra en esa área tan estratégica, dirigiendo profundas modificaciones en "leyes y normas técnicas que rigen las relaciones del Estado con las empresas del sector). Además, preside el Consejo de Administración de Petrobrás, introduce el biodiesel en la matriz energética brasileña y crea el programa Luz para Todos”. (Palácio do Planalto, 31/12/2014)

El 21 de junio del 2005 fue nombrada Jefa de la Casa Civil, para coordinar la labor de la totalidad del gabinete ministerial. Asimismo, Dilma asumió la dirección del Consejo de Directores de la empresa estatal petrolera Petrobras y de iniciativas como el Programa de Aceleración del Crecimiento y el de habitación popular "Mi Casa, Mi Vida". También, desde su rol de economista, integró la Junta Presupuestaria del Gobierno. En este contexto, fue elegida por el presidente Lula da Silva para ser su sucesora presidencial por el Partido de los Trabajadores en las elecciones del $2010^{81}$. Tal como en el caso de Fernández en Argentina, el padrinazgo de su antecesor fue crucial en la conformación de Dilma como una lideresa capaz de acceder al poder. La selección y el apoyo público de Lula, la figura emblemática y más poderosa del Partido de los Trabajadores, fueron decisivos para que una mujer presidiera Brasil.

Es decir, a pesar de atesorar una trayectoria política de casi tres décadas -aunque orientada a puestos de desempeño técnico y no de elección popular-, Dilma aparece como una figura dependiente de su mentor masculino. Ríos Sierra (2017:79) advierte que fueron dos los elementos que se utilizaron para afectar negativamente a Rousseff, en la campaña presidencial previa a su primer gobierno:

\footnotetext{
${ }^{81}$ Vanguardia.com, 1/11/2010; Palácio do Planalto, 31/12/14.
} 
De un lado, el referido Instituto de Investigación Social Datafolha, publicaba un informe, a finales de 2010, en el que señalaba que más del 40\% de los brasileños, afirmaba que, con independencia de quien fuese el candidato, votarían por el designado de Lula a suceder con su mandato presidencial (Gómez y Fernandes, 2012). Por otro lado, como se recoge en el trabajo de Gandin (2012), Dilma Rousseff aparece en toda la campaña y la propaganda electoral junto a Lula da Silva, lo cual construye una imagen de coresponsabilidad al frente de los éxitos y logros del Partido de los Trabajadores obtenidos en Brasil desde 2001.

El 3 de abril del 2010, Dilma deja el Gobierno Federal para lanzarse como candidata a fin de ocupar el Ejecutivo. Finalmente, el 31 de octubre de 2010, Rousseff fue elegida Presidenta de la República Federativa de Brasil, con más de 55,7 millones de votos (56,05\%); derrotando en segunda vuelta al socialdemócrata José Serra. "Es la primera mujer a llegar al Palacio del Planalto, como ya había sido la primera mujer secretaria de Hacienda de Porto Alegre, la primera secretaria estadual de Energía, la primera ministra de Minas y Energía, y la primera jefa de la Casa Civil”. (Palácio do Planalto, 31/12/14)

\subsubsection{La pediatra socialista}

Verónica Michelle Bachelet Jeria nació el 29 de septiembre de 1951, con siete meses de gestación, en el Hospital de Carabineros en Santiago. Era la segunda de los hijos de un matrimonio compuesto por una mamá -Ángela Jeria-, que fue Jefa de Presupuesto en el Departamento de Finanzas de la Universidad de Chile, y un papá que era teniente de la Fuerza Aérea de ese país. Cada tres o cuatro años, a Alberto Bachelet lo destinaban a distintas bases. "Yo nací en un mundo militar, viví en un mundo militar, viví toda mi vida en unidades militares. Mis tíos sociales eran los militares. Mis amigos eran los hijos de los militares", recordaba Michelle en el documental La hija del general, del año $2006 .{ }^{82}$

Estuvieron unos años en Estados Unidos, donde habían trasladado a su padre y fue justamente en Washington donde conoció la segregación racial y el debate sobre la Guerra de Vietnam. Regresaron a Santiago en noviembre de 1973 y enseguida se reintegró al Liceo

\footnotetext{
${ }^{82}$ En: Castillo y Montes, 2013: 39.
} 
No1 Javiera Carrera. Ya en la Facultad de Medicina de la Universidad de Chile, en 1970, Michelle daba sus primeros pasos en la política y la juventud de izquierda. Aún careciendo de carnet del partido, se convirtió en jefa política de esa Escuela Superior y en secretaria de la quinta comuna distrital de la Juventud Socialista.

Teniendo como líder a Carlos Lorca Tobar, cabeza del sector moderado de su partido, Michelle “es designada como responsable de la formación política de la organización. Enseña materialismo dialéctico y teoría de partidos a los comunales de la colectividad y a los obreros que solicitan adoctrinamiento. Poco a poco se transforma en una figura habitual en la sede de la JS (Juventud Socialista)" (Castillo y Montes, 2013: 84).

Por su parte, Alberto Bachelet fue destinado al puesto de Jefe de la Dirección Nacional de Abastecimiento y Comercialización (DINAC), cuya labor principal era la lucha contra el mercado negro y el acaparamiento de productos, "lo que iba a costarle la odiosidad de la oposición y finalmente la vida" (Michele Bachelet, en: Subercaseaux y Sierra, 2005: 50). Con el gobierno de Allende, la sociedad chilena comenzó a dividirse; separación que también podía evidenciarse en la familia de Michelle; sobre todo, desde que su padre empezó a participar en el gobierno de la Unidad Popular.

Los que siguieron fueron una sucesión de hechos desafortunados. Entre ellos, el suicidio de Salvador Allende Gossens y el encarcelamiento -por parte de las Fuerzas Armadas- del general Bachelet, a quien acusaban injustificadamente. En ese contexto, Michelle se mudó de la Facultad de Medicina al hospital José Joaquín Aguirre, donde se instaló como paciente para su protección. Sería luego de un mes y medio que padre e hija se reencontrarían. Michelle retomó sus tareas políticas y comenzó una relación con Jaime López, Secretario de Organización del Partido Socialista; quien en diciembre de 1975 caería preso y sería torturado para que delatara compañeros/as. Hasta la actualidad se desconoce su paradero y se encuentra en condición de desaparecido. ${ }^{83}$

Después de tres etapas de arresto (en los recintos de la Fuerza Aérea, en su domicilio y en la cárcel pública) y de un extenso interrogatorio que incluyó torturas en la Academia de Guerra Aérea, el papá de Michelle tuvo un infarto y falleció a los cincuenta

\footnotetext{
${ }^{83}$ En el Partido Socialista “existe la certeza de que, después de sufrir torturas, López comenzó a colaborar con la DINA y se convirtió en un traidor”. (Ibídem. 50)
} 
años, el 12 de marzo de 1974. Pero las adversidades para esta familia no se detuvieron con la muerte del general y la indiferencia de sus ex compañeros de armas:

La DINA había concentrado su acción represiva en el Movimiento de Izquierda Revolucionaria (MIR). Una compañera de universidad de Ángela, militante de esa organización, cayó presa y en medio de las sesiones de tortura a que fue sometida dio su nombre y el de Michelle, además de los nombres de muchos otros. (Subercaseaux y Sierra, 2005: 80)

En enero de 1975 fueron arrestadas en su departamento de Avenida Vespucio y trasladadas a Villa Grimaldi; "donde las separaron y las empezaron a interrogar, preguntándole por personas del Partido Socialista" (ibíd.81). Allí Michelle tiene recuerdos del modo en que "parrillaban" a sus compañeras de celda como método de tortura, y cómo ella les curaba las heridas a su regreso. En una entrevista en el 2004, admitió haber sido torturada, así como también haber recibido amenazas de que iban a matar a su mamá (Castillo y Montes, 2013: 120).

Desde Villa Grimaldi las llevaron a Cuatro Álamos, de donde luego de dos semanas la soltaron sin decirle nada. Su madre pudo salir de la prisión después de un mes y juntas pudieron irse a Australia; gracias a la gestión de su hermano Alberto, quien logró que el gobierno australiano las pidiera como asiladas políticas. Michelle estuvo allí dos meses y se fue a la República Democrática Alemana, adonde la seguiría su madre. Desde el exilio, ambas colaborarán con la oposición a la dictadura chilena y serán activistas de las denuncias de violaciones en derechos humanos del régimen pinochetista. La más joven, además, "está a cargo del boletín del secretariado exterior de la Juventud Socialista en Berlín, donde escribe extensos artículos" (Castillo y Montes, 2013: 132).

En diciembre de 1977 Michelle se casa en Potsdam con Jorge Dávalos, un compatriota, también exiliado y estudiante de Arquitectura. A los pocos meses nace su primer hijo, Sebastián. Dos años después regresan a Chile, al igual que Ángela. Sobre esa época de retorno, Michelle relató en 1990 a la Comisión Rettig que siempre tuvieron "los teléfonos intervenidos, además de llamadas en que nos insultaban” (ibíd. 127). Michelle volvió a la Escuela de Medicina y se recibió en 1983. Con una beba de meses -Francisca-, cursando la especialidad en Pediatría y con otras presiones, el matrimonio se terminó separando a comienzos de 1985. 
En la década del 80 la dictadura volvió a mostrar sus garras. Como consecuencia, en agosto de 1983 surgió la Alianza Democrática, integrada por la Democracia Cristiana, el Partido Republicano, el Radical, el Socialista, el Social Demócrata y la Unión Socialista Popular. En esa época Michelle formaba parte del Partido Socialista -y empezaba a brindar apoyo de forma clandestina a su dirección-; pero a la vez trabajaba en la Protección a la Infancia Dañada por los Estados de Emergencia, colaboraba con la Vicaria de la Solidaridad, la Comisión Chilena de Derechos Humanos, la Fundación de Ayuda Social de las Iglesias Cristianas y la Corporación de Promoción y Defensa de los Derechos del Pueblo. (Subercaseaux y Sierra, 2005; Castillo y Montes, 2013)

En octubre de 1988, Augusto Pinochet perdió el plebiscito nacional, que lo habilitaría a continuar en el poder por ocho años más. Luego de este hecho histórico, la vida de Mica - como la llamaba su padre-, toma un nuevo matiz:

Integra el Partido Amplio de Izquierda Socialista, una coalición instrumental que reúne al PC, al PS Almeyda, a la Izquierda Cristiana y al MIR. Desde fuera de la Concertación, comienza a trabajar por el triunfo del democratacristiano Patricio Aylwin, quien se convierte en el primer presidente después de la dictadura. Asume el 11 de marzo de 1990. Entonces, Michelle Bachelet comenzará un lento camino desde la marginalidad de la izquierda hacia la institucionalidad de La Moneda" (Castillo y Montes, 2013: 140-141).

Con la vuelta a la democracia, además, cambió de trabajo. Comenzó en el Ministerio de Salud, primero en el Servicio de Salud Metropolitano y más tarde haciéndose cargo del programa nacional de SIDA. Allí conoció a Aníbal, un médico del que terminó enamorándose. A los tres años nació Sofía, la menor de sus hijos. Luego se separaron y Michelle volvió a quedar sola, con los tres niños, y trabajando primero como asesora y más tarde como Ministra.

En 1995 integra el Comité Central de su partido y en 1996 acepta ser su candidata en las municipales, aunque pierde. Ese año también comienza a cursar un Máster en la Academia Nacional de Estudios Políticos y Estratégicos (ANEPE), dependiente del Ministerio de Defensa. Asimismo, en 1997 se traslada por un año a la Academia Nacional de Estudios Políticos y Estratégicos y en Defensa Continental de Washington, convencida de que "desde el poder, los militares entendían el lenguaje de la fuerza y el poder" y que era "necesario colocarse en ese lugar, aprender su lenguaje y sus códigos" (Subercaseaux y Sierra, 2005: 131). 
Finalmente, en el 2002 el Presidente Lagos la designa en un cargo poco común para las mujeres, convirtiéndola en la primera ministra de Defensa no sólo en la historia de Chile, sino en la de América Latina. La asignación de Bachelet fue:

...en el mismo gabinete que incluía a Soledad Alvear como ministra de Relaciones Exteriores. Resulta significativo que estos dos últimos ministerios, los más tradicionalmente masculinos, hayan quedado a cargo de dos mujeres, un desafío importante a las ideas acerca del rol femenino en el ámbito político. (Franceschet, 2006: 15)

Ambas funcionarias comenzaron a tener altos niveles de popularidad, hasta que llegaron a posicionarse como candidatas a la Presidencia por la Concertación. Sin embargo, Alvear terminó renunciando a la lucha por el puesto en su partido, tras comprobar la ventaja que Bachelet demostraba sobre ella en las encuestas. Su retirada fue en junio del 2005 y desde entonces, apoyó la campaña de su entonces compañera.

Sobre el paso al costado que dio la entonces representante por la Democracia Cristiana en las elecciones primarias para definir a la candidata de la Concertación, Ximena $\mathrm{Jara}^{84}$ recuerda la siguiente anécdota:

...cuando cada una estaba haciendo su campaña para las primarias, en algún momento le preguntan a Ricardo Lagos Presidente, quién de las dos quiere que gane las primarias. Entonces él dice "yo soy el Presidente..." y trata de salir por arriba y no responde, ¿no? "Yo creo que las dos tienen grandes condiciones..." En fin, una respuesta muy correcta. Y entonces el periodista lo presionó: "pero usted va a votar por alguien, ¿va a decir por quién va a votar?” Entonces, él le dice: “yo tengo mi corazón”. Y eso fue suficiente porque él es un socialista, y entonces lo que él quería decir era "yo no puedo votar contra mi corazón. Yo soy un socialista y voy a votar por el Socialismo". Eso todo se sobreentiende y se entiende como un espaldarazo a Bachelet. Le duele mucho a Soledad Alvear, pero se entiende que Ricardo Lagos también cree que la que naturalmente tiene que ser la jefa es Michelle Bachelet. Y entonces, al poco tiempo, Soledad Alvear desiste de ir a las primarias, baja su candidatura.

Finalmente, en enero del 2006 y en segunda vuelta electoral, Bachelet triunfa por sobre el candidato de la "Alianza por Chile", Sebastián Piñera. La mandataria obtuvo el $53,49 \%$ de los votos. Como otra de las paradojas del destino, en el año 2006 Bachelet regresará a Alemania, pero esta vez como Presidenta de su país. Quien la recibirá será otra mujer política: la canciller Ángela Merkel.

\footnotetext{
${ }^{84}$ En: Entrevista realizada en Santiago de Chile, el 20 de agosto del 2015.
} 
En definitiva, podemos inferir que la médica socialista proveniente del sector público llega al Ejecutivo con una importante acumulación de poder simbólico: se constituyó como una lideresa distinta a los liderazgos masculinos que la habían precedido en términos de cercanía con los/las ciudadanos/as; y, a la vez, por su propia formación política, profesional y su historia de vida, demostraba mucha seguridad y capacidad para llevar adelante las riendas del Estado. Su paso por el Ministerio de Salud, donde se comprometió a terminar en 90 días con las filas de los consultorios de la salud primaria, la acercaron a la gente. Cuando no logra cumplir ese objetivo al cien por ciento, aunque sí en un altísimo porcentaje, ella presenta una renuncia que no es aceptada por el Presidente Lagos por considerar que ella hizo un trabajo impecable. La opinión pública considera justo el gesto del mandatario y Bachelet "empieza a estar en la boca de la gente en la medida que empieza a prosperar o mejorar el sistema de salud...Bachelet empieza a ser una mención espontánea". 85

En esta misma línea, el paso de Bachelet como Ministra de Defensa, representó un quiebre para la historia política latinoamericana; ya que constituyó un antecedente revolucionario en términos de género. Pero, además, lo que no es menos importante, representó un acercamiento y reconciliación en términos sociales entre distintos sectores de la ciudadanía chilena. Del siguiente modo lo relata Jara $^{86}$ :

...fue tremendamente relevante porque ella era hija de un general asesinado en dictadura. Por lo tanto, se cerraba el círculo...y ella volvía como mandamás de todas las Fuerzas Armadas, pero también de aquella que le había quitado la vida a su padre; por lo tanto, era como un círculo de amor que se cerraba (...) todas las piezas calzaban en términos de vivencia personal, de gestos de género, de capacidades y de vivencia íntima; entonces ahí todo se cristaliza en una mujer que es "iguau, esta mujer es potente!", no sólo es una buena doctora, no sólo es Ministra de Salud...no sólo tiene una gran historia de este lado, sino que además tiene esta otra gran historia...y ahí entonces sale a la luz que ella estuvo detenida en Villa Grimaldi, con su madre (...) (Y, además, luego se supo que) su madre vivía en el mismo edificio que su torturador y que se habían encontrado en el ascensor. Y que la madre y ella iban juntas y en lugar de decirle algo, lo habían saludado.

Por lo anterior y como veremos en las siguientes páginas, Bachelet llega a La Moneda con mayor autonomía política y legitimización de género respecto a sus pares sudamericanas. El aval de Lagos la ayuda a convertirse en Jefa de Estado, pero no tiene el

\footnotetext{
${ }^{85}$ Ibidem.

${ }^{86}$ Ibídem
} 
peso decisivo que puede evidenciarse en el caso de Cristina y Dilma respecto a sus antecesores y mentores partidarios. Por ello, podríamos asegurar que Bachelet va cobrando peso como figura política por sí misma y gracias al mérito de su desempeño en distintos ámbitos estatales. Empezada su gestión, se desprenderá de la imagen de Lagos e imprimirá su impronta personal como mandataria. 


\section{CAPÍTULO 4}

\subsection{Modelo metodológico para el análisis discursivo}

La primera aclaración que debemos hacer respecto al universo de análisis que empleamos para esta investigación es que fue diferenciado: en los casos de Cristina Elisabet Fernández y Dilma Vana da Silva Rousseff, se analizaron la totalidad de los discursos transcriptos disponibles en la web, tanto en páginas oficiales (Casa Rosada y Palácio do Planalto) ${ }^{87}$ como en otros sitios relacionados (Portal Brasil y Página oficial de CFK). El criterio de selección de los textos respondió a la búsqueda de mensajes presidenciales desarrollados por ambas mandatarias en los ámbitos bi y multilaterales, durante los cuatro años correspondientes a sus primeros gobiernos, y que dieran cuenta de la transversalización del género en sus palabras.

Asimismo, cabe aclarar que se decidió incluir entre los discursos analizados los correspondientes a la toma del cargo como Presidentas de sus Naciones, en los respectivos Congresos, por considerarse un hecho histórico que mujeres asuman los Ejecutivos de su países. Además, en el caso de Rousseff, se incluyó en el análisis un mensaje de la mandataria en el marco de una celebración de graduación en el Instituto Río Branco, por considerar interesante para esta investigación el énfasis que la mandataria pone al expresar que quiere un Brasil con más Diplomáticas.

Por otro lado, en el caso de Michelle Bachelet, la obtención del corpus discursivo estuvo limitada al hecho de que únicamente se tiene acceso a los discursos que la Jefa de Estado chilena emitió durante los días 21 de mayo de cada año, fecha en la que se conmemora el día de las Guerras navales, por la Guerra Pacífico. En dichas oportunidades, la funcionaria se ocupa de describir y enunciar las políticas públicas llevadas a cabo por su gobierno; el accionar, las decisiones y acuerdos en el plano internacional; y las intenciones de su gestión, tanto en el presente como para el futuro. Por estas circunstancias, al ser sólo cuatro los mensajes presidenciales disponibles para analizar (uno por año), se complementó el material con la realización de cuatro entrevistas en profundidad a personas vinculadas al gobierno de Bachelet o al estudio del mismo.

\footnotetext{
${ }^{87}$ Palácio do Planalto, Presidencia da República (Brasil): http://www2.planalto.gov.br Casa Rosada, Presidencia de la Nación (Argentina): http://www.casarosada.gob.ar
} 
Durante el mes de agosto del año 2015, en el marco de un viaje a Santiago de Chile para la concreción de este trabajo de campo, se realizaron entrevistas a las siguientes funcionarias: Paulina Díaz Pérez y Lorena Henríquez, del área Dirección de Gestión del Ministerio de Relaciones Exteriores de Chile; Claudia Godoy Caroca, responsable del ex Servicio Nacional de la Mujer (actualmente, Ministerio de la Mujer y la Equidad de Género); y Ximena Jara, Jefa de Contenidos de Presidencia del primer y segundo gobierno de Michelle Bachelet.

Por lo anterior, queda en evidencia que se ha conformado un vasto corpus de análisis, a fin de establecer si las Presidentas Fernández, Bachelet y Rosusseff, a través de sus discursos en ámbitos de la política internacional, quebraron $-\mathrm{o}$ pusieron en crisisdiscursivamente la ideología patriarcal.

Para responder dicho objetivo, se elaboró un modelo de análisis basado en la conformación de tres ejes centrales. Vale la pena aclarar que la delimitación y denominación de dichos ejes responden a ideas fuerza que se reiteran en los mensajes presidenciales considerados y que nos permiten visibilizar la presencia de una perspectiva feminista en lo que integraría la primera imagen waltziana ("la lideresa" de Estado, en nuestra propia adaptación): a) "Yo como mujer"/ "Es un gobierno de mujeres"; b) "Es tiempo de pensar en las mujeres"/ "Queremos una sociedad más igualitaria"; y c) Sobre el ejercicio del poder y la toma de decisiones.

Dicho modelo nos permitió recuperar lo central de la trayectoria de cada Jefa de Estado en relación con estos tres ejes y establecer, además de las particularidades de cada una de las gestiones, similitudes y diferencias entre éstas. En este capítulo en particular y en el siguiente, recuperaremos las expresiones presidenciales correspondientes a los ejes a) y b), para empezar a demostrar cómo las mandatarias utilizaron la cuestión de género en sus discursos para marcar cierto quiebre en la tradicional política latinoamericana. Mientras que en el último capítulo cruzaremos esta información con lo arrojado por el eje c).

Finalmente, urge aclarar que en los fragmentos de los discursos que expondremos en los ejes, las cursivas han sido empleadas por nosotros/as; con el objetivo de resaltar de forma explícita los conceptos y las nociones principales a las que quisimos hacer referencia en cada caso. 
4.2. "Yo como mujer"/ "Es un gobierno de mujeres"

Las conclusiones que se desprenden del análisis de los fragmentos que conforman el primer eje, son:

\subsubsection{Las mandatarias como amenaza de un statu quo patriarcal}

En primer lugar, las tres Presidentas tienen la convicción de que se enfrentan a un sistema históricamente dominado por varones y que, por ese motivo, habrá resistencias ante la ruptura que ellas representan. En este sentido, no podemos obviar el conocimiento que las funcionarias tienen sobre una ideología patriarcal imperante en sus sociedades de origen. Así, se desprende de las palabras de Cristina Fernández que -a pesar de esos prejuicios machistas- ella considera tener la fuerza, el valor y la fortaleza necesaria para asumir las responsabilidades que acarrean su cargo de autoridad nacional. La mandataria atribuye la inspiración de estas cualidades al ejemplo y admiración que siente por Eva Duarte de Perón y por las Madres y Abuelas de Plaza de Mayo:

También -porque saben, que la sinceridad es uno de mis datos proverbiales- sé que tal vez me cueste más porque soy mujer, porque siempre se puede ser obrera, se puede ser profesional o empresaria, pero siempre nos va a costar más. Estoy absolutamente convencida. Pero creo tener la fuerza para poder hacerlo y además el ejemplo, el ejemplo no solamente de Eva que no pudo, no pudo, tal vez ella lo merecía más que yo, el ejemplo de unas mujeres que con pañuelo blanco se atrevieron donde nadie se atrevía y lo hicieron. Ese era el ejemplo de ellas, de las Madres y de las Abuelas. ${ }^{88}$

...hay que estar sentado acá para saber lo que es gobernar un país y la República Argentina, hay que estar sentado acá o sentada, lo cual además, si no solamente estás sentado, sino que además estás sentada, lo que implica también una cuestión de género, es un poquito más dificil todavía y no quiero victimizarme porque no es mi costumbre. ${ }^{89}$

La diferencia de Fernández con Bachelet es que mientras la primera expresa los condicionantes del género en la política a título personal ${ }^{90}$; la segunda lo hace desde un

\footnotetext{
${ }^{88}$ En: Acto de Asunción del mando en el Congreso de la Nación ante la Asamblea Legislativa; 10/12/2007

${ }^{89}$ En: Apertura del $127^{\circ}$ Período ordinario de sesiones realizado ante la Asamblea Legislativa en el Honorable Congreso de La Nación, 9/03/2009.

${ }^{90}$ Incluso es interesante ver cómo Fernández resalta la cuestión de género por el hecho de recibir obsequios de Presidentes: "Yo quiero agradecerle la presencia a Evo, a toda su Comitiva y además quiero contarles algo - esto pasa porque soy una Presidenta, si hubiera sido un presidente estas cosas no pasarían- quiero contarles que esto que ustedes me ven hoy aquí, estos dos hermosos aros y este collar, es un obsequio, esto es plata
} 
cambio profundo a nivel estatal, donde se pondera la creación inédita de un gobierno paritario. De este modo, de los textos analizados, se desprende como afirmación de la médica socialista que su gestión se compromete a hacer cumplir los derechos de la mujer, entendiendo que no es por ausencia de capacidad que éstas no ocupan otros cargos o puestos de jerarquía; sino por falta de oportunidades reales:

¡Quién lo hubiera pensado! Hoy le habla a este Congreso Pleno una mujer Presidenta. Aqui están mis diez Ministras y mis quince Subsecretarias. Aqui está, como lo prometí durante la campaña, el primer gobierno paritario de toda nuestra historia. (...) Una sociedad más inclusiva, que no discrimina y que no olvida a quienes se quedan atrás. Estoy aquí como mujer, representando la derrota a la exclusión de que fuimos objeto tanto tiempo. ${ }^{91}$

Mi gobierno apoyará del modo más decidido el ejercicio efectivo de los derechos de la mujer (...) Dos cosas son igualmente ciertas. Las mujeres tienen la capacidad de salir adelante. Pero también necesitan mayores oportunidades para incorporarse al mundo moderno. Predicamos con el ejemplo. El gobierno paritario es el principio y no el fin del camino. ${ }^{92}$

También queremos promover la participación de la mujer. Basta mirar alrededor: Una testera llena de hombres, pero al frente, una mujer. Por qué digo esto, lo digo como un ejemplo que demuestra que nosotras tenemos la capacidad para ganar elecciones cuando tenemos la oportunidad para competir y el problema es que esas oportunidades no siempre se dan. ${ }^{93}$

Pero por cierto que la democracia es también más inclusiva y ciudadana cuando la mujer participa de ella. Nunca antes había adquirido tanta relevancia el tema de la equidad de género en todas nuestras políticas. Esa misma cuenta se puede ver en que la mujer ya no es un sector de la política pública. La mirada de mujer está presente en todas las politicas, de manera transversal, en salud, en seguridad social, en emprendimiento, en educación, en todos los ámbitos. ${ }^{94}$

boliviana, auténtica plata boliviana. En: Acto de apertura de ofertas económicas para el gasoducto Noroeste argentino, con la presencia del Presidente de la República de Bolivia, Evo Morales, 25/01/2008.

"Presidente: antes que nada quiero agradecerle el honor que me ha dispensando el gobierno y el pueblo del Ecuador con este collar que tiene para nosotros, los argentinos, un doble valor. Primero, la demostración del afecto, de los lazos de amistad políticos e históricos que unen a ambos pueblos, pero además este collar entregado por segunda vez a una mujer en toda la historia del Ecuador, reviste para nosotros los argentinos también un valor muy especial, porque ha sido otorgado solamente a dos mujeres. Yo he tenido el honor, el inmenso honor, tal vez el inmerecido honor de ser la segunda mujer y la primera fue María Eva Duarte de Perón. Hay cosas que constituyen verdaderos golpes al corazón y este es uno de ellos". En: Firma de convenios con Ecuador, 21/4/2008

${ }^{91}$ En: Congreso de la Nación de Chile, 21/5/2006.

${ }^{92}$ Ibídem

${ }_{93}^{93}$ En: Congreso de la Nación de Chile, 21/5/2008.

${ }^{94}$ Ibídem 
Por último, podemos ver cómo Dilma Rousseff, durante la $66^{\mathrm{a}}$ Apertura de la Asamblea General de las Naciones Unidas, subraya que el hecho de que por primera vez en la historia de ese organismo una voz femenina abra el debate general, representa una mayor democracia e igualdad del sistema. Asimismo, notamos en su corpus discursivo la alusión a su logro como una conquista colectiva (similar a como lo expresa Bachelet), con todas las mujeres del mundo y -asimismo- la idea de tenacidad como cualidad del género femenino:

Por primera vez en la historia de la ONU, una voz femenina abre el debate general. Es la voz de la democracia y la igualdad se está expandiendo esta plataforma, que se ha comprometido a ser el más representativo del mundo. Es con humildad personal, pero con el justificado orgullo, que viven este momento histórico. Comparto esta emoción con más de la mitad de los seres humanos en este planeta que, como yo, han nacido mujer, y que con tenacidad, están ocupando su lugar en el mundo. Estoy segura de que, señoras y señores, este será el siglo de las mujeres. ${ }^{95}$

Además de mi amada Brasil, también estoy aqui en representación de todas las mujeres en el mundo. Mujeres anónimas, las que tienen hambre y no pueden alimentar a sus hijos; aquellas que sufren de enfermedades y no pueden ser tratadas; las que sufren violencia y son discriminados en el empleo, la sociedad y la vida familiar; aquellas cuyo trabajo en el hogar crea generaciones futuras. Uno mi voz a las voces de las mujeres que se atreven a luchar, que se animaron a participar en la vida política y la vida profesional. ${ }^{96}$

De nuevo una voz femenina abre el debate en la Asamblea General de la ONU. Para muchos, las mujeres somos la mitad del cielo, pero queremos ser la mitad de la tierra, y tener la igualdad de derechos y oportunidades, libre de todas las formas de discriminación y violencia, capaces de construir su emancipación, y con ella contribuir a la plena emancipación de todos. ${ }^{97}$

\subsubsection{Características socialmente valoradas atribuidas al género femenino}

Fernández menciona en sus mensajes presidenciales los conceptos de "capacidad", "sinceridad" y "pasión" como atributos femeninos. Éstos serían la definición de su accionar gubernamental. Asimismo, la noción de "ciudadana" - a veces acompañada por la aclaración de "latinoamericana" -, la liga discursivamente al respeto a las libertades, a las igualdades y a la defensa de los derechos humanos tanto en su país de origen, como en la

\footnotetext{
${ }^{95}$ En: $66^{\mathrm{a}}$ Apertura de la Asamblea General de las Naciones Unidas; 21/9/2011.

${ }^{96}$ En: ONU, 21/9/2011.

${ }^{97}$ En: Apertura de la $67^{\text {a }}$ Asamblea General de las Naciones Unidas; 25/09/2012.
} 
región y el mundo. A estas cualidades se le sumaría la del diálogo y mesura, características que también atribuye a las mujeres y que queda perfectamente ilustrada en las frases extraídas de su discurso en la Cumbre Extraordinaria de la UNASUR, del 28 de agosto del 2009, donde además se registra cierta complicidad de género con Michelle Bachelet:

...porque en definitiva los hombres por allí en momentos difíciles y no quiero hacer una cuestión de género, por favor -acá me sonrie Michelle Bachelet desde su lugarsuelen tener por alli, por su propia estructura cultural tal vez reacciones un poco...acá me apunta la Dra. Bachelet: "la testosterona", pero bueno, reacciones un poco más fuertes. ${ }^{98}$

$\mathrm{Y}$ quiero agradecer profundamente la presencia de todos ustedes aquí $\mathrm{y}$ comprometerme, como siempre lo he hecho en mi vida y en mi práctica política, a hacer las cosas con toda la capacidad, con toda la sinceridad y con toda la pasión de que somos capaces nosotras, las mujeres. Quiero decirles además que me siento no una argentina aquí en el MERCOSUR, me siento una latinoamericana, hermana de mis hermanas uruguayas, brasileras, paraguayas, bolivianas, mexicanas, chilenas, en fin, una ciudadana. A mí me gusta llamarme ciudadana porque nos da una categorización universal, la del respeto por las libertades, por las igualdades y por la defensa irrestricta de los derechos humanos, que es nada más y nada menos que respetar la condición humana. ${ }^{99}$

Por otro lado, resulta curioso evidenciar que Fernández atribuye a su condición de mujer su necesidad de que los acuerdos firmados en el marco de convenios bi o multilaterales, tenga plazos y objetivos claros:

También es importante hoy el compromiso de los dos países para comenzar el primer emprendimiento hidroeléctrico binacional en toda la historia con plazo. Quiero contar para los que no saben qué son los "plazos", que fue una idea que tuve en la primera visita, que a las mujeres nos gusta establecer plazos, y yo le quería dar mucha operacionalidad a la integración. ${ }^{100}$

Fue mi primer viaje cuando fui electa presidenta y allí pudimos articular una forma de funcionamiento de reuniones semestrales que comenzamos a inaugurar en este período, en la cual dada mi condición de mujer también sugerí que los acuerdos y todo aquello que firmáramos tuviera plazos con objetivos claros, por estas cosas que tenemos las mujeres, que siempre estamos pidiendo plazos y cuándo se van a hacer las cosas. Es una cuestión casi de género, que afortunadamente fue comprendida por mi colega de

\footnotetext{
98 En: Cumbre Extraordinaria de la UNASUR, 28/08/2009. Esta anécdota se da en el marco de un conflicto limítrofe: la demanda de respeto a la soberanía nacional por parte de la República de Colombia y, a la vez, la demanda de seguridad de las Repúblicas de Ecuador y de Venezuela al Presidente Uribe.

${ }^{99}$ Palabras de Cristina Fernández en Acto de Asunción como Presidenta del Mercosur, 18/12/2007.

${ }^{100}$ Palabras de Cristina en el almuerzo con el Presidente Lula; 8/09/2008
} 
la República del Brasil, y pudimos articular este funcionamiento que comienza en este primer acuerdo que estamos firmando hoy con puntos claros, concretos y objetivos. ${ }^{101}$

En ese sentido, es notorio advertir cierta similitud discursiva con Fernández, cuando Bachelet se refiere en el 2008 a los logros en materia de protección social desarrollados por su gestión, sosteniendo que lo hicieron cumpliendo "paso a paso, plazo a plazo, el itinerario trazado" 102 cuando fue candidata a la Presidencia.

Por otra parte, la pediatra chilena busca la reivindicación de las mujeres en expresiones que identifican la "fuerza" como atributo femenino, característica empleada para definir el modo en que llevó adelante su programa de gobierno: "He puesto toda mi fuerza, como he dicho tantas veces fuerza de mujer, para llevar adelante el proyecto de progreso y justicia social que la mayoría de los chilenos anhela" ${ }^{\prime 103}$.

Se hace evidente, a través de sus palabras, el orgullo que le produce el haberse convertido en la primera sudamericana que accedió al poder por la decisión popular. Respecto a su elección, Lorena Henríquez, de la Dirección de Gestión del Ministerio de Relaciones Exteriores de Chile, afirmó:

...hay un factor personal de ella, que logra históricamente, en una época donde los partidos políticos tenían una baja valoración por hechos de corrupción y un montón de cosas que se habían dado...luego ella aparece como una persona de carisma personal y que logra captar votos que el propio partido político no logra captar. ${ }^{104}$

Por su parte, Rousseff, en un modo cercano al expresado por su par chilena, se refiere a la fuerza de la mujer como un atributo especial para superar cualquier problemática. También reconoce en el valor o coraje, el cariño, el cuidado de otros/as y en la sinceridad, valores femeninos:

En portugués, las palabras tales como la vida, el alma y la esperanza son de género femenino, y las mujeres son también otras dos palabras muy especiales para mí: el valor y la sinceridad. ${ }^{105}$

No voy a descansar mientras existan brasileños sin alimentos en la mesa, mientras existan familias en el desaliento de las calles, mientras haya niños pobres abandonados

\footnotetext{
${ }^{101}$ En: Almuerzo ofrecido en honor del presidente de la República Federativa del Brasil, Luiz Inacio Lula Da Silva; 22/02/2008.

102 Bachelet en el Congreso de la Nación, 21/5/2008.

${ }^{103}$ Michelle Bachelet en el Congreso chileno, 21/5/2007.

${ }^{104}$ Entrevista realizada en el Ministerio de Relaciones Exteriores; Santiago de Chile, 18 de agosto del 2015.

${ }^{105}$ En: 66 ${ }^{\mathrm{a}}$ Apertura de la Asamblea General de las Naciones Unidas; 21/9/2011.
} 
a su propia suerte. La confraternización de las familias se da en el alimento, en la paz, y en la alegría. ¡Es éste el sueño que voy a perseguir! ${ }^{106}$

Y es con este coraje que voy a gobernar el Brasil. Pero mujer no es solamente coraje. Es cariño también. Cariño que dedico a mi hija y a mi nieto. Cariño con el cual abrazo a mi madre, que me acompaña y me bendice. Es con este inmenso cariño que quiero cuidar de mi pueblo, y a él dedicarle los próximos años de mi vida. ${ }^{107}$

Rousseff define como "osadía del voto popular" el hecho de que su pueblo haya elegido como Presidente primero a "un hombre del pueblo, un trabajador", como Luiz Inácio Lula da Silva y luego a una mujer, como es su caso. Esta analogía podría ser comparada con la que hace Cristina Fernández de Kirchner cuando en algunos discursos del año 2009 sostiene que su elección en Argentina y la de un afroamericano en Estados Unidos señalan un cambio de patrón a la hora de que los pueblos elijan a sus dirigentes, el “despertar de la región”. Este “despertar” lo entendemos en relación a los patrones hegemónicos de género, clase social y étnico/nacionales asociados a la dirigencia política.

Además, al igual que en el caso de Bachelet, se evidencia en Rousseff un discurso de logro común y de engrandecimiento del género. Es decir, ella se encarga de destacar que asume como representante del colectivo femenino de su Nación y asegura que su interés no es particular, sino que su intención es la de allanar el camino para que otras puedan llegar al Ejecutivo:

Por la decisión soberana del Pueblo, será hoy la primera vez que la banda presidencial ciña el hombro de una mujer. Siento un inmenso honor por esta elección del Pueblo brasileño y sé del significado histórico de esta decisión. Sé, también, cómo es aparente la suavidad de la seda verde y amarilla de la banda presidencial, pues ella trae consigo una enorme responsabilidad frente a la nación. Para asumirla, está conmigo la fuerza y el ejemplo de la mujer brasileña. Abro mi corazón para recibir, en este momento, una centella de su inmensa energía. Y sé que mi mandato debe incluir la traducción más generosa de esta osadía del voto popular que, luego de llevar a la presidencia a un hombre del pueblo, un trabajador, decide convocar a una mujer para dirigir los destinos del país. Vengo para abrir las puertas para que muchas otras mujeres puedan también, en el futuro, ser presidenta; y para que -en el día de hoy- todas las brasileñas sientan el orgullo y la alegría de ser mujer. No vengo para enaltecer mi biografia; sino para glorificar la vida de cada mujer brasileña. iMi compromiso supremo, reitero, es honrar a las mujeres, proteger a los más frágiles y gobernar para todos! $!^{108}$

\footnotetext{
${ }^{106}$ En: Discurso de asunción, Congreso Nacional, Brasilia, 1/1/2011.

107 Ibídem.

108 Ibídem.
} 


\subsection{3. ¿Estado maternalista?}

Puede notarse en el discurso del 5 de diciembre del 2008 en Chile, que Fernández toma de las palabras de la Presidenta Bachelet los conceptos de "equidad" e "igualdad" para establecer que esas deben ser las directrices que guíen a los gobernantes a accionar en favor de sociedades más justas e inclusivas. En su relato, la abogada peronista se apoya en la imagen de su par chilena en su faceta de mamá, con su pequeña Sabrina sobre su regazo. Esta elección podría interpretarse como una capitalización del estereotipo de las madres como protectoras, sacrificadas, justas y afectivas.

Y junto a la democracia y la libertad -como recién señalaba Michelle-la lucha por la igualdad, por la equidad, que debe ser el verdadero objetivo que guie a todos los gobernantes, a todos los hombres y mujeres de buena fe para también contribuir, como ella señalaba, al proceso de paz; para que cuando un chico duerma como Sabrina lo hace en el regazo de su madre, lo haga con la tranquilidad de saber que tiene educación, que tiene vivienda, que tiene salud y que tiene seguridad, esto es lo que quieren argentinos, chilenos, latinoamericanos en general, porque esto es en definitiva lo que hace a la condición humana. ${ }^{109}$

En forma análoga a la de su par argentina, podemos observar que Bachelet asocia la imagen de las mujeres con los conceptos de sacrificio y esfuerzo: en el trabajo, en los ámbitos educativos y con sus familias. Estas características, muchas veces ligadas por los imaginarios sociales al rol materno, parecerían ser las que la mandataria socialista reconoce en ella misma, como protectora del pueblo chileno, que vela por su protección y bienestar. Sin dudas, esta idea se refuerza por el dato objetivo de que Michelle es progenitora y médica pediatra, esferas vinculadas subjetivamente con el amparo y la ternura. Ligado a esta visión, Lorena Henríquez sostiene que el encanto de la Presidenta:

...tiene que ver más con la imagen más materna que ella tiene. Imagen que se le criticó en su momento porque se le comparaba con el ex Presidente que la había antecedido, que era Ricardo Lagos - que era el tipo que golpeaba la mesa, que hablaba ronco, fuerte-, que cuando había algo que podía enturbiar, él aclaraba inmediatamente pegando un golpe de voz. Ella al contrario. Ella tiene esto de mover los afectos. Es una figura mucho más empática. Mucha gente decía "pero esta señora parece la mamá de la gente"...que tiene algo físicamente como acogedora, como que se ríe. ${ }^{110}$

\footnotetext{
${ }^{109}$ En: Firma de acuerdos con la República de Chile, en Monte Aymond; 5/12/2008.

${ }^{110}$ En: Ministerio de Relaciones Exteriores, Santiago de Chile; 19 de agosto del 2015.
} 
En forma similar, Claudia Godoy Caroca, Jefa del Departamento de Cooperación y Relaciones Internacionales del Servicio Nacional de la Mujer, coincide con Henríquez en comparar al Presidente Lagos, que "era una figura absolutamente de lo que significaba el patriarcado", de liderazgo fuerte, "autoritario", "acostumbrado a la cultura política" chilena; con los modos de ejercer el poder de Bachelet, a quien se la consideraba "la madre de Chile".

En relación a esto, Paulina Díaz Pérez, del área de la Dirección de Gestión del Ministerio de Relaciones Exteriores de Chile, sostuvo:

Es que yo creo que desde el punto de vista de la mujer la preocupación está en atender algo de lo que nadie se había preocupado (...) Cuando uno habla de este estado más materno, yo creo que la Presidenta Bachelet tuvo un enfoque de previsión social importante (...) Son iniciativas que han puesto como este concepto en la mira. Este concepto de protección del Estado maternalista; iniciativas que han ido en apoyo de quienes ella o el Estado consideran más vulnerables. (Santiago de Chile; 19/8/15)

Por último, reconocemos en las palabras de Dilma el concepto de ternura ligado al aspecto maternal que las tres Presidentas sudamericanas de alguna forma quisieron proyectar, comparando el cuidado de sus propias familias con la dedicación y asistencia a sus pueblos liderados.

Pero mujer no es solamente coraje. Es cariño también. Cariño que dedico a mi hija y a mi nieto. Cariño con el cual abrazo a mi madre, que me acompaña y me bendice. Es con este inmenso cariño que quiero cuidar de mi pueblo, y a él dedicarle los próximos años de mi vida. ${ }^{111}$

\subsubsection{Mujeres y algo más}

En otro orden, en su oratoria Fernández remarca la alegría que le produce ser la primera socia del MERCOSUR y sostiene el deseo de poder representar satisfactoriamente al género. De ahí su claro posicionamiento como vocera no sólo de las mujeres argentinas, sino de todas las de la subregión y el continente. En alusión a esto, hay una imagen que en varias ocasiones ella refuerza, y que hace alusión a una triple condición que sería el motor de su compromiso: ella como mujer, como latinoamericana y como militante política.

\footnotetext{
111 Ibídem.
} 
Hoy con usted hablaba de la responsabilidad de la mujer. Usted como yo pertenecemos a esa generación de militantes políticos donde no había diferencias entre mujeres y hombres en nuestras estructuras partidarias; es más, una mujer podía ser más importante que un hombre, de hecho muchas veces lo era dentro de las propias estructuras militantes. Es cierto que eso por allí no se repetía en los partidos tradicionales pero aquí estamos en marcha. También quiero decirle que me siento muy responsable del rol de género, pero más que del rol de género me siento responsable como militante de una causa que siempre ha abogado en la democracia, en el respeto a los derechos humanos, en el interés del pueblo (...) En eso estamos y es nuestro compromiso, primero como militante, luego como mujer y fundamentalmente, por sobre todas las cosas, como argentina y latinoamericana. ${ }^{112}$

"al lado de la mujer, que siempre ha tenido una fuerte inclinación por la historia de la humanidad, convive también la politica, que electa por los argentinos, tiene la responsabilidad de articular lazos de amistad y comerciales con tan importante Nación, como es Egipto" $" 113$

...la infinita e inmensa paciencia de poder escuchar a una mujer que no solamente vino a hablarles como Presidenta de los argentinos, sino como una militante política igual que ustedes de toda la vida". ${ }^{114}$

En el caso de Bachelet, discursivamente ella refuerza su condición de mujer y médica; profesión vinculada desde el imaginario social al cuidado y servicio hacia otros/as:

He procurado que todos los días sea verdad lo que dije tantas veces: "estoy contigo". $A$ través de los años que llevo al servicio de las personas, como médico, como ministra, como Presidenta, he constatado que para que un país llegue lejos, el gobierno y las personas deben estar cerca. He constatado que decir progreso es decir "todos" y "cada uno". ${ }^{115}$

Sin embargo, esta apelación a su profesión no siempre fue interpretada de forma favorable para la dirigente chilena. Refiriéndose al programa de gobierno que llevó adelante Bachelet y que tuvo una indiscutible perspectiva de género, Ximena Jara afirma:

...el comentario que se hacía cuando ella planteaba este programa, es que como ella era mujer, y era Pediatra y su tema eran los niños, entonces no sabía sino hablar de los niños. Sin comprender la potencia de una política que potencia a los niños desde chicos y que además empodera a las mujeres y la capacidad económica de ellas (...) como si ella hubiera sido una educadora de párvulos cachay que sólo tiene la capacidad de

\footnotetext{
${ }^{112}$ Almuerzo en honor al presidente de Brasil, Lula Da Silva, 22/2/2008.

${ }^{113}$ En: El Cairo, 20 de noviembre del 2008.

${ }^{114}$ En: el Parlamento español; 10/2/2009.

${ }^{115}$ En: Congreso de la Nación de Chile, 21/5/2009.
} 
pensar una cierta capacidad de cosas que son la extensión de su vida doméstica; que es lo que corresponde a una mujer. ${ }^{116}$

Finalmente, en el caso de Rousseff también surge, como en las palabras de Fernández, la figura de la mujer y militante petista; pero se le suma la de "torturada". Esta última imagen alude a su duro pasado, relacionado con la lucha contra la dictadura en su país. En este contexto, la mandataria brasilera reconoce ser una celosa guardiana de la democracia; pero también hace visible de forma discursiva su infranqueable fortaleza.

Como una mujer que fue torturada en la cárcel, sé lo importante que son los valores de la democracia, la justicia, los derechos humanos y la libertad. ${ }^{17}$

Quería decirles que dediqué toda mi vida a la causa de Brasil. Entregué mi juventud, como muchos aquí presentes, al sueño de un país justo y democrático. Soporté las adversidades más extremas infligidas a todos los que osamos enfrentar a la arbitrariedad. No tengo ningún arrepentimiento, tampoco resentimiento o rencor (...) Ésta, a veces dura jornada, me hizo valorizar y amar mucho más la vida y me dio, sobre todo, coraje para enfrentar desafíos aún mayores. ${ }^{118}$

\subsubsection{Irrupción en el Ejecutivo}

Asimismo, es importante destacar el énfasis que las mandatarias realizan cuando se pronuncian como las primeras mujeres en ocupar los Ejecutivos de sus respectivos países. Mientras en Fernández es una mención bastante recurrente, en el caso de las otras funcionarias sudamericanas es más esporádico. Algunos ejemplos del caso argentino, son:

...en mi carácter de primera mandataria mujer electa en la historia de mi país". ${ }^{119}$

...primera visita después de muchos años de un presidente, en este caso de una presidenta argentina, la primera mujer presidenta de la República Argentina, a la hermana República de Cuba. ${ }^{120}$

Me hubiera gustado, esta noche, mirar sus caras y observar a su nieta Presidenta de los argentinos, primera mujer Presidenta de la Nación Argentina, condecorada por $\mathrm{Su}$ Majestad, el Rey de España, de su España, la que nunca olvidaron y de que finalmente

\footnotetext{
${ }^{116}$ Entrevista realizada en Santiago de Chile, el 20 de agosto del 2015.

${ }^{117}$ En: ONU, 21/9/2011.

118 Discurso de asunción en el Congreso, Brasilia, 2011

${ }^{119}$ En: ONU, 23/9/2008.

${ }^{120}$ En: Clausura del Seminario "Oportunidades de Comercio, Inversiones y Negocios" entre la Argentina y Cuba; 20/1/2009
} 
nunca se fueron y estoy segura que se hubiera frotado los ojos y no lo hubieran podido creer". ${ }^{121}$

Y si se me permite, desafío a cualquier archivo, a cualquier memoria, a cualquier prueba, que no ha habido mayor libertad para hablar de las autoridades de un país que durante el gobierno de la primera presidenta mujer de la República Argentina. Tal vez el hecho de que estemos enviando estas leyes y podamos haber acordado, sea también -y perdóneme, no es una cuestión de género- que somos tres mujeres las que hoy estamos aquí, porque comentábamos con Lucía que es la primera vez que una mujer preside la Comisión Interamericana, es la primera vez que una mujer preside la Corte Interamericana y es la primera vez una mujer preside la República Argentina. ${ }^{122}$

Nunca, y como dije el otro día en la Comisión Interamericana de Derechos Humanos, desafío a cualquier archivo, a cualquier memoria, a cualquier registro que alguna vez haya habido tal grado de libertad -y les digo que me encanta- para hablar, criticar, oponerse a un gobierno como el que hubo durante la gestión de esta primera, como dijera el presidente de la Universidad, Presidenta mujer. ${ }^{123}$

Así que en esta visita que constituye la primera desde hace 15 años, y lo digo porque me lo han recalcado - se ríe nuestro Vicecanciller- en cada una de las entrevistas que teníamos con los distintos funcionarios, con la señora Presidenta, que también me siento muy honrada porque somos dos mujeres por primera vez presidentas, una de la República de la India y la otra de la República Argentina, feliz coincidencia que espero que se siga repitiendo, y es también una mujer la jefa del partido del gobierno, lo cual revela que la India es un país adelantado realmente. ${ }^{124}$

En los casos de Bachelet y Rousseff, rescatamos de sus discursos de asunción:

¡Quién lo hubiera pensado! Hoy le habla a este Congreso Pleno una mujer Presidenta. Aquí están mis diez Ministras y mis quince Subsecretarias. Aqui está, como lo prometí durante la campaña, el primer gobierno paritario de toda nuestra historia. (...) Una sociedad más inclusiva, que no discrimina y que no olvida a quienes se quedan atrás. Estoy aqui como mujer, representando la derrota a la exclusión de que fuimos objeto tanto tiempo. (Bachelet) ${ }^{125}$

Por la decisión soberana del Pueblo, será hoy la primera vez que la banda presidencial ciña el hombro de una mujer. Siento un inmenso honor por esta elección del Pueblo brasileño y sé del significado histórico de esta decisión. (Rousseff, Congreso Nacional, Brasilia, 2011)

${ }^{121}$ En: Palacio Real de Madrid; 10/2/2009.

${ }^{122}$ En: Treinta años de la visita de la Comisión Interamericana de Derechos Humanos a la Argentina, $11 / 09 / 2009$.

${ }^{123}$ En: Foro Líderes Mundiales, Universidad de Columbia; 21/09/2009.

${ }^{124}$ En: Cámara de Comercio de Mumbai; India, 15/10/2009.

${ }^{125}$ En: Congreso de la Nación de Chile, 21/5/2006. 


\section{CAPÍTULO 5}

5.1. "Es tiempo de pensar en las mujeres"/ "Queremos una sociedad más igualitaria"

En este segundo eje de nuestro modelo metodológico se ponderan expresiones que señalan la percepción de las tres Presidentas en base al quiebre de un sistema y escenario (nacional e internacional) que siga excluyendo y/o invisibilizando los aportes, voces y derechos de las mujeres. Dichos conceptos pueden ser interpretados dentro de los siguientes apartados:

\subsubsection{Representación femenina y visibilidad}

Se hace evidente la reivindicación que hace Fernández a la figura de las Madres y Abuelas de Plaza de Mayo por la fuerza de éstas; característica que la mandataria reconoce como natural de las mujeres cuando sienten amenazados/as a sus hijos/as y a la sociedad. En un sentido similar, reconoce el accionar heroico de una agrupación femenina que reclamaba frente a entidades bancarias y afirma que antes las mujeres eran muy anónimas y que cada vez serán más visibles. De esto último puede inferirse que la "visibilidad" responde tanto a términos cuantitativos (aumento de la cantidad de mujeres en la política nacional e internacional) como a niveles de impacto y recepción de lo que tenemos (las mujeres) para decir -y/o denunciar- en el espacio público:

...mujeres que con un pañuelo blanco en la cabeza enfrentaron lo que nadie se había atrevido en la República Argentina, la dictadura más sangrienta que tuvo lugar. Y lo hicieron mujeres que no venían de la política, mujeres como Estela, como Marta, la mayoría de ellas que nunca habian participado en ninguna actividad política y sin embargo, con la fuerza que solemos tener las mujeres cuando sentimos la agresión, no ya solamente sobre nuestros hijos sino sobre toda la sociedad, como una fortaleza y un valor inclaudicable salieron a la calle cuando nadie lo hacía. ${ }^{126}$

Había surgido inclusive una agrupación de mujeres -siempre las mujeres, perdónenme el tema del género- llamado "Mujeres en lucha" que cantaban el himno y se paraban frente a las tranqueras cuando los distintos bancos querían ir a rematar los campos. ${ }^{127}$

\footnotetext{
${ }^{126}$ En: París por la inauguración del Jardín Abuelas y Madres de Plaza de mayo; 7/4/2008.

${ }^{127}$ En: firma de convenios con el BID; 17/4/2008.
} 
...los hombres más famosos, las mujeres más anónimas, que construyeron la independencia de nuestros países hace 200 años. Éramos muy anónimas las mujeres en aquella época, ahora somos más visibles afortunadamente y cada vez lo vamos a ser más. Así que, a prepararse todos, por favor. ${ }^{128}$

En otro orden, también nos parece interesante introducir aquí algunos extractos del corpus discursivo de Fernández, donde la lideresa kirchnerista pretende dar cuenta de su extensa y escalonada trayectoria política hasta llegar a constituirse como la máxima representante de los/as argentinos/as. Es decir, se denota una intención de demostrar discursivamente que su carrera empezó "desde abajo". También en ese sentido iría su aclaración sobre que su paso por la Casa Rosada no estuvo determinado por ser la esposa del ex Presidente Néstor Kirchner:

Dieciocho años de mi vida política han transcurrido sentada en un escaño, como diputada provincial primero, como senadora nacional, como diputada nacional y luego nuevamente como senadora nacional antes de haber sido electa Presidenta de los argentinos. $^{129}$

...he hablado más con el corazón, con lo que pienso, con mis convicciones y con lo que me ha tocado vivir en estos años. Y cuando digo años no son años de gestión únicamente, no crean que empecé a trabajar en politica el día que asumí como Presidenta o el día que me casé con un señor que en ese momento no era Presidente, al contrario, vengo de muy joven, como muchos de ustedes, militando en política y esta transformación que viene experimentando el mundo es un debate apasionante. ${ }^{130}$

Por su parte, la Presidenta Bachelet critica la poca representación femenina en las esferas más altas de la política y a aquellos que pretenden justificar este hecho bajo el argumento de que son una minoría, cuando - en verdad- conforman la mitad de la población y el electorado.

Hemos de cambiar la ley, pero lo que hay que cambiar es bastante más que la ley. Nuestra democracia debe reflejar el país real y eso no está sucediendo en el caso de las mujeres (...) Pese a que a que a veces se habla de que hay que privilegiar a los grupos minoritarios y se habla de las mujeres, es una paradoja porque las mujeres son la mitad de los que nos miran desde las casas. Son la mitad de los que, ahora mismo, nos acaban de saludar alegremente en las calles. Son la mitad de los que están en las graderías, seguramente. Son más de la mitad de los que votan. Son la mitad del gabinete aquí presente y la Presidenta de la República es mujer. ;Y uno de los lugares

\footnotetext{
${ }^{128}$ En: cena con Bachelet en Punta Arenas, Chile; 5/12/2008.

${ }^{129}$ En: Parlamento español; 10/2/2009.

${ }^{130}$ En: Acto de designación a la República Argentina durante el año 2011 para presidir el grupo G-77; $28 / 9 / 2010$
} 
donde estamos representadas tan bien pero tan escasamente es aquí, en el Parlamento! ${ }^{131}$

La Ley de Partidos Políticos que enviaré al Congreso apunta en esa dirección. Necesitamos partidos fuertes, modernos, más transparentes, más participativos y - ¡por favor!-con más mujeres en sus directivas. ${ }^{132}$

Estoy cierta de que este estilo participativo será difícil de desterrar, porque en futuros gobiernos las personas exigirán ser escuchadas. Lo mismo puedo decir en relación de la participación femenina. ;No creo que sea posible ya en Chile tener un gabinete ministerial con dos o tres mujeres! El cambio cultural en este sentido es irreversible. $Y$ permitanme decirles que las mujeres sabemos ocupar espacios sin excluir a nadie. Chile es más grande cuando las mujeres también son protagonistas (...) Necesitamos perfeccionar nuestra institucionalidad democrática. Quisiera avanzar más en la reforma constitucional que introduce la iniciativa popular de ley o la participación política femenina. ${ }^{133}$

Asimismo, celebra la incorporación de mujeres en la Escuela Naval de la Armada de Chile, un ámbito tradicionalmente asociado a los varones $\mathrm{y}$, por lo tanto, a atributos masculinos. Este particular interés de Bachelet por las Fuerzas Armadas, como hemos descripto en su biografía como dirigente política, la ha llevado a formarse en Defensa y a liderar posteriormente ese Ministerio:

Además, por primera vez desde el nacimiento de la Escuadra Nacional, la Armada de Chile recibe a sus primeras mujeres cadetes navales. Y este es un tremendo orgullo porque yo empujé fuertemente para que esto fuera posible, y es una tremenda y excelente experiencia para las mujeres en la Escuela Naval. ${ }^{134}$

Por último, la mandataria afirma que su gobierno fue una bisagra en relación a la participación femenina en la política y otros sectores de decisión. Esto se debería tanto al ejemplo que su gobierno ha dado como por el cambio cultural que éste ha generado en la sociedad que ella preside. "¡No creo que sea posible ya en Chile tener un gabinete ministerial con dos o tres mujeres!”, afirmó en el 2009. En ese mismo contexto, sostuvo, como si fuera una cualidad del género, que "sabemos ocupar espacios sin excluir a nadie".

Respecto a nuestra consulta sobre la posibilidad de que la figura de Bachelet en la Presidencia fuera a facilitar la entrada de más mujeres en la política, las respuestas de algunas de nuestras fuentes fueron: Yo creo que es dificil que entre la mujer...se vislumbra también en la cantidad de hombres y mujeres que tenemos en las Cámaras,

\footnotetext{
${ }^{131}$ En: Congreso de la Nación, Chile, 21/5/2006.

132 En: Congreso de la Nación, Chile, 21/5/2008.

${ }^{133}$ En: Congreso de la Nación, Chile, 21/5/2009.

${ }^{134}$ En: Congreso de la Nación, Chile, 21/5/2007.
} 
pero sí siento un cambio. Yo siento que al ser ella mujer, ha permitido que la mirada vaya cambiando, porque tenemos la Presidenta del Congreso ${ }^{135}$. La elección anterior había dos candidatas a la Presidencia. ${ }^{136}$ (Díaz Pérez, 19/8/2015)

Ahora está la ley para premiar a aquél partido político con recursos que coloquen mujeres candidatas. Por lo menos que las coloquen como candidatas. No que las elijan, pero por lo menos que jueguen con la variable "mujeres" entre sus candidatos. Hasta hace poco decían "no, nosotros colocamos mujeres". Claro, pero las colocan en lugares donde saben que no van a ganar ninguna cosa. (Henríquez, 19/8/2015)

Por último, queremos destacar la distinción que hace Rousseff, en el marco de la reinauguración de la Embajada argentina en Brasil, a la entonces Ministra de Industria del vecino país, Débora Georgi. En este sentido, la mandataria brasilera se dirige a Georgi como una de las "mujeres que integran los gobiernos latinoamericanos". De este modo, queda implícito el hecho de que son varias las funcionarias que conforman los Estados en la región y que esta característica señalaría un cambio significativo respecto a los tradicionales protagonistas políticos en América Latina:

Felicitando a las mujeres que integran los gobiernos latinoamericanos, me gustaría saludar a Débora Giorgi, Ministra de la Industria de la República Argentina. ${ }^{137}$

Similar interpretación a la anterior puede darse en el discurso emitido en el Instituto Branco, donde manifiesta su deseo de que su país "tenga muchas Milenas"; refiriéndose a la participación femenina en la diplomacia nacional.

Y espero que todos los que estamos aquí, Presidentes, Diplomáticos, estudiantes, en fin, todos los que estamos hoy en día seamos capaces de permitir que este país tenga muchas "Milenas". ${ }^{138}$

Tal como sostienen Wicth y Cazarin, (2015:7): “La Presidenta, en muchos pasajes, a menudo deja en claro el deseo de ver a más mujeres trabajando en posiciones de poder" (Traducción nuestra).

\footnotetext{
${ }^{135}$ Se refiere a María Isabel Allende Bussi (hija del ex Presidente Salvador Allende), quien en el período 14/3/2013 al 11/3/2015 se desempeñara con el cargo de Presidenta del Senado; transformándose en la primera mujer en ostentar dicho puesto en Chile

${ }^{136}$ Dichas candidatas fueron: Verónica Michelle Bachelet Jeria (Partido Socialista) y Evelyn Rose Matthei Fornet, del Partido de la Unión Demócrata Independiente (UDI).

${ }^{137}$ En: Reinauguración de la Embajada de la República Argentina en Brasil, acompañada por Cristina Kirchner; Brasilia, 29/7/2011

${ }^{138}$ Milena Oliveira de Medeiros era una joven Embajadora que falleció en Guinea Ecuatorial, en ejercicio de su función como representante del Brasil. En: Acto de graduación de la clase 2010-2012 del Instituto Rio Branco, Brasilia; 20/4/2012
} 


\subsubsection{Lenguaje inclusivo}

Algo que tienen en común las tres funcionarias es que sostienen que se debe enfatizar en cuestiones de género desde el lenguaje. Es decir, el quiebre discursivo de la ideología patriarcal se presenta como necesario. En el caso de Fernández:

...señores y señoras empresarias de Argelia y de la República Argentina, no debemos olvidarnos nunca del género. ${ }^{139}$

Estaba sentada allí, como Primera Dama, le puedo asegurar que nunca supe que dos años y medio más tarde iba a estar aquí, hablándoles a todos ustedes como Presidenta de todos los argentinos. ${ }^{140}$

Presidenta de todos los argentinos. ${ }^{141}$

En efecto, la ex mandataria argentina evidencia un cambio de paradigma, donde "ellas" deben ser nombradas y visibilizadas en sus cargos jerárquicos; pero, además, polemiza sobre la dificultad de algunas personas -independientemente de su género- de incorporar este lenguaje inclusivo:

...creo que todos y todas, hay también que acostumbrarse a esa palabra, les cuesta a los hombres lo de "todas". Susan ${ }^{142}$, vos también lo debés saber, y a algunas mujeres les cuesta lo de "todas", pero es importante tener esta actitud y apertura para abordar los problemas con mucha responsabilidad. ${ }^{143}$

En el caso de Bachelet, podemos destacar los siguientes fragmentos:

Caminamos con el esfuerzo de todos, para que Chile tenga un rostro más humano. Tenga el rostro de las personas que lo habitan y lo hacen crecer. El rostro de 17 millones de chilenos y chilenas a quienes me debo y por quienes seguiré trabajando incansablemente. ${ }^{144}$

Los cobardes que agreden a las mujeres o los hijos, seguramente no aprueban mi gestión como Presidenta, porque conmigo les ha ido mal. ${ }^{145}$

\footnotetext{
${ }^{139}$ En el marco de firma de acuerdos con Argelia, 17/11/2008.

${ }^{140}$ En: Ayuntamiento de Madrid; 9/2/2009.

${ }^{141}$ En: $66^{\circ}$ Asamblea General de las Naciones Unidas, Nueva York; 21/9/ 2011.

${ }^{142}$ Aquí la Presidenta Fernández hace alusión a Susan Segal, Presidenta del Consejo de las Américas.

${ }^{143}$ En: Council of Americas; Nueva York, 25/09/2008.

${ }^{144}$ En: Congreso Nacional, Chile, 21/5/2009.

145 Ibídem.
} 
Es justamente sobre el uso del lenguaje inclusivo en el caso de la mandataria chilena, que la Jefa de Contenidos de Presidencia, Ximena Jara, sostiene:

Ahí empieza la transformación. Y ella empieza en el discurso, cuando asume, una de las primeras cosas que hace, además de garantizar la paridad ministerial, es que ella cambia el lenguaje. Entonces, ella no habla más de amigos, sino de "amigos y amigas", de los "chilenos y las chilenas"; entonces, se transforma en una burla porque obliga a hablar muy largo. (...) Pero es imperativo para ella hacer un cambio en el discurso. Y entonces ella además, pasa a ser "Presidenta" y no "Presidente". Y si tú lo piensas, no hay ninguna razón para que ella sea Presidenta porque Presidente es una forma no marcada. Ella podría ser la Presidente Bachelet, pero se elige la forma femenina aún cuando léxicamente no sea lo correcto, se elige "Presidenta" porque marca el cambio $^{146}$.

Por último, en el caso de Rousseff, encontramos -al igual que en el caso de las otras dos mandatarias- la alusión a varones y mujeres de su patria, en este caso con las frases "brasileños y brasileñas” durante su discurso de asunción:

Dije, al comenzar en este discurso, que gobernaré para todos los brasileños y brasileñas. Y voy a hacerlo. Pero es importante recordar que el destino de un país no se resume a la acción de su gobierno. Es el resultado del trabajo y de la acción transformadora de todos los brasileños y brasileñas. ${ }^{147}$

Asimismo, es importante destacar que en el marco de discursos bi y multilaterales, no sólo utiliza un lenguaje inclusivo para referirse a sus ciudadanos/as; sino también para dirigirse a otras autoridades extranjeras: "hombres y mujeres brasileñas" "148; "Señora Presidenta y señores presidentes"149; "saludar a las señoras y señores jefes de misión diplomática", "señores y señoras embajadores"150 ; “Señoras y Señores Jefes de Estado y de Gobierno"151; "Señoras y señores Presidentes y Presidentas del Mercosur" "152; entre otros.

Respecto al lenguaje de la Jefa de Estado, Cazarin y Wicth (2015:105) afirman que:

...ella también refuerza su sexo a través del cambio de la vocal "e" por la "a" en el final de la palabra presidenta que en la lengua portuguesa es indicadora del género femenino. Dicha actitud puede ser entendida como una forma ideológica de empoderar y reforzar la participación política en la política. (Traducción y cursiva nuestra)

\footnotetext{
${ }^{146}$ Entrevista realizada en Santiago de Chile, el 20 de agosto del 2015.

${ }^{147}$ En: Discurso de asunción, Brasil, 1 de enero del 2011.

${ }^{148}$ En: ONU, 21/9/2011.

${ }^{149}$ En: XLII Cumbre de Jefes de Estado del Mercosur; 20/12/2011.

${ }^{150}$ En: Instituto Rio Branco; 20/4/2012.

${ }^{151}$ En: Cuba, 27/1/14.

${ }^{152}$ En: XLVII Cumbre del Mercosur; 17/12/2014.
} 


\subsubsection{Posicionamiento contra la discriminación}

En otro orden, respecto a algunas acusaciones que pesan sobre las mujeres que se interesan por la política, las mandatarias responden de diversos modos. Fernández contesta que -habiendo presenciado ciertas escenas de peleas entre varones dirigentes - las mujeres son las más racionales. Y además, critica que siempre las están "poniendo a prueba”; y denuncia en sus mensajes las discriminaciones de las que son víctimas las que están en puestos de poder y toma de decisión; sobre todo por parte de los medios de comunicación:

...siempre nos han acusado -y discúlpenme un planteo de género-a las mujeres de que se nos vuelan los pájaros y que por alli tenemos cierto grado de histerismo cuando tenemos algunas cuestiones, pero quiero decirles a algunas escenas que por alli nos tocan ver, nos convierten a las mujeres tal vez en las personas más racionales de este planeta. Discúlpenme con la cuestión de género, pero nos la debíamos porque siempre nos están poniendo a prueba y siempre tenemos que dar muestras y pruebas de que podemos ser mejores que los hombres. Creo que en algunas cosas estamos demostrando que, en algunas cosas, somos un poco mejores que algunos hombres. ${ }^{153}$

Las discriminaciones se dan hasta muchas veces hacia las mujeres que tal vez ocupamos lugares en los sistemas de poder y también hay un comportamiento diferente hacia esa mujer que forma parte de un sistema de poder que cuando son los hombres los que forman parte de ese sistema de poder. El otro día me tocaba ver escandalizada a la prensa internacional por el escote de una importante política europea. Nunca vi a nadie escandalizado por la calvicie, por ejemplo de ningún importante presidente o político. Como ustedes verán amigas y amigos, no es un problema ni siquiera de feminismo o machismo. Es apenas de mediocridad (...) y creo que las mujeres tal vez seamos las que podamos dar con mayor fuerza este desafio, porque también muchas veces somos víctimas de esa falta de intelecto, de inteligencia $y$ esa mayoría por momentos agobiante y aplastante de mediocridad que parece rodear hoy al mundo contemporáneo. ${ }^{154}$

Por su parte, Bachelet, se refiere a que su presencia es un síntoma del fin de una época de prejuicios hacia la mujer. Ella se presenta como fuerte y trabajadora, pero resalta de forma permanente en sus discursos que su labor es tan valiosa como la de otras mujeres chilenas:

Traigo, más que nunca, una certeza en el espíritu: la certeza de que este sitio en el que me ha puesto la democracia ha permitido derribar prejuicios que ya no encuentran

\footnotetext{
${ }^{153}$ En: XX Cumbre de Jefes Estado del Grupo de Río en Santo Domingo; 7/3/2008.

${ }^{154}$ En: Acto de Apertura del Seminario "La mujer y la Alianza de Civilización, oportunidades y desafíos", realizado en el Palacio San Martín, en coordinación con autoridades españolas y portuguesas; 28/04/2008.
} 
albergue en nuestro Chile. ¡Aquí está una mujer chilena, respondiendo día a día al mandato de la patria! Y lo digo como mujer de esta tierra, como tantas que cada día, sola o acompañada, guían, sostienen y protegen a quienes aman. Lo digo sabiendo que esta es una herencia compartida por tantas mujeres chilenas que trabajan por su país y que se esfuerzan por que todos juntos avancemos hacia el desarrollo. ${ }^{155}$

Un país sin exclusiones exige que las mujeres ejerzan en plenitud la ciudadanía, en todas sus facetas. Chile aún vive la experiencia diaria de discriminaciones y de segregación. ${ }^{156}$

Chile será un país más desarrollado, justo y democrático cuando dejen de existir las poderosas barreras para la integración de las mujeres al trabajo, la cultura, la economía y la vida pública. Sin la presencia activa de la mujer no podremos derrotar la pobreza ni ser un país más competitivo. ${ }^{157}$

Por último, Rousseff utiliza la visibilidad que denota su figura como lideresa de su país en el Consejo de Seguridad en Naciones Unidas, para posicionarse como vocera de otras "anónimas" en el mundo y exigir igualdad de derechos y oportunidades respecto a los varones. Con todo, afirma que: son "capaces de construir su emancipación, y con ella contribuir a la plena emancipación de todos" (ONU, 2012). Esta frase de la mandataria nos remite a una trama de fortaleza, pero también de justicia social.

\subsubsection{Cambio(s) y equidad de género}

Las tres funcionarias se refieren a un cambio sociocultural significativo, que hizo posible el ascenso de ellas a los poderes Ejecutivos de sus países. Fernández lo asocia a la movilidad social de su país y a un escenario regional donde parecerían empezar a romperse por parte de los pueblos americanos, patrones patriarcales y racistas:

...que todos puedan tener la esperanza del progreso en sus vidas, una movilidad social ascendente que fue lo que caracterizó al espacio político en el cual milito desde muy joven y que permitió, por ejemplo, que quien hoy les habla, hija de trabajadores, pudiera acceder a la universidad y pudiera ser hoy Presidenta de la República. Esto era impensable en la Latinoamérica donde se consagraban únicamente las élites y donde, además, cuando no lograban consagrarse por el voto popular, recurrían al golpe militar. ${ }^{158}$

\footnotetext{
${ }^{155}$ En: Congreso de la Nación, Chile, 21/5/2009.

${ }^{156}$ En: Congreso de la Nación, Chile, 21/5/2006

157 Ibídem.

${ }^{158}$ En: una Iglesia Jesuita en Quito, 21/4/2008. Esta última frase debe interpretarse en dos sentidos: por un lado, en el contexto en el que ella siempre se refiere a sus orígenes como hija de trabajadores, y -en
} 
...bienvenida a Dilma, que la estamos esperando con mucho afecto y cariño, y también con mucho amor para reparar cosas que suceden cuando las mujeres decidimos incursionar en los puestos más altos de la política. Parece que somos bien vistas de diputadas, senadoras, ministras de educación, o sea de samaritanas, enfermeras o maestras; ahora cuando queremos disputar el poder arriba ya ahi nos encuentran que el rulo tal, qué habrá hecho cuando era jovencita, qué si le gusta cuál o quién, ya estamos acostumbradas. Y nos va a hacer mucho bien incorporar a una compañera del género porque la verdad que me siento un poquito sola, allá Alicia Ríos de la CEPAL me mira y asiente. Realmente quiero en este sentido y si me permiten terminar esta intervención con un reconocimiento al género, en la figura también de quien va a presidir a partir del $1^{\circ}$ de enero un país tan importante, no solamente para nosotros sino a nivel global como es el Brasil, de la compañera Dilma Rousseff. ${ }^{159}$

Resulta interesante notar cómo la mandataria asocia lo sucedido en su patria con lo acontecido en el norte del continente, para argumentar que se está atravesando por una etapa de cambio cualitativo; así, vincula el hecho de que una mujer -como es su caso- haya sido elegida Presidenta de Argentina y un afroamericano haya sido elegido Presidente de Estados Unidos. Ambas elecciones, de acuerdo a las expresiones que se desprenden del corpus analizado, "revelan que las sociedades han cambiado antes que sus dirigencias" y que estamos ante el "despertar de una región":

La participación de mujeres en lugares históricamente reservados a los hombres, la llegada de un afroamericano a un lugar donde también era impensable que esto sucediera, revelan que las sociedades han cambiado antes que sus dirigencias. ${ }^{160}$

Si alguien hace 10 años me hubiera dicho que yo iba a estar aquí en la Universidad de La Habana, como presidenta de los argentinos, inaugurando esta cátedra, en el día que en Estados Unidos, además, eligieron su primer presidente afroamericano, yo lo hubiera mirado y hubiera dicho 'este hombre o esta mujer, quien dice esto se ha vuelto loco' (...) no voy a hacer en esto una cuestión de género, pero significa esencialmente el despertar de toda una región. ${ }^{161}$

En otro orden, la abogada originaria de la ciudad de La Plata, resalta la honra que le significa convertirse en la primera socia mujer del proceso de integración regional más destacado de Sudamérica; es decir, el Mercado Común del Sur:

consecuencia- alejada de las élites; $y$, por otro, donde hace alusión a que la única mujer que la precedió en el cargo de Jefa de Estado argentina -María Estela Martínez- no fue respetada en su investidura por haber llegado al poder de forma circunstancial (por la muerte de su marido, Perón, quien era el Presidente) y no por la decisión ciudadana.

${ }^{159}$ En: XL Cumbre del Mercosur, 17/12/2010.

${ }^{160}$ En: Casa de América en la Reunión Tribuna Iberoamericana; España; 10/2/2009.

${ }^{161}$ En: Disertación en el Aula Magna de la Universidad de La Habana; 20/1/2009. 
...me siento muy honrada de ser la primera socia mujer del MERCOSUR, realmente espero representar bien el género y quiero, en este sentido, decir que no me siento representante únicamente de las mujeres argentinas, sino de las uruguayas, de las brasileras, de las paraguayas y también de las venezolanas. ${ }^{162}$

Por su parte, Bachelet señala el cambio simbolizado en su elección como Jefa de Estado, como una oportunidad histórica para alcanzar un cambio profundo en términos de igualdad. Por ello, realiza una permanente interpelación a las chilenas, afirmando que su designación es en verdad un logro colectivo que representa el inicio de una etapa donde las mujeres cobran protagonismo y gozan de sus derechos para el ejercicio de una ciudadanía plena. Además, la médica socialista se ocupa de denunciar las barreras de género que se les impone para acceder a los más altos cargos del Estado y critica el rol de los partidos políticos:

Sé que mi presidencia ha marcado un nuevo tiempo para las mujeres. Un nuevo tiempo de oportunidades y participación en los más diversos ámbitos de la sociedad. Mi gobierno tomó la decisión de poner fin a las barreras a las mujeres en los altos cargos del Estado. Y tomamos la decisión de ser activos en esta materia porque las mujeres no pueden seguir esperando a que las instituciones se adecuen a los tiempos que vivimos. Hemos visto como las mujeres se integran en todo el quehacer nacional (...) Queremos que los partidos políticos -todos- reconozcan el lugar que les corresponde a las mujeres en sus estructuras internas y sobre todo en las candidaturas a los municipios y al Parlamento. Cada día más mujeres aspiran a lo más alto. Cada día se hace más difícil aceptar la discriminación y los prejuicios sobre nuestras capacidades. ${ }^{163}$

Y yo quiero decirles a las mujeres de Chile: la igualdad dejó de ser un sueño. Llegamos para quedarnos en la política, en el trabajo, en la empresa. ${ }^{164}$

Por otro lado, la Jefa de Estado chilena tiene como destinatarias privilegiadas de sus discursos a las mujeres trabajadoras y madres de su Nación. En esa línea, se refiere -incluyéndose-a la doble jornada que hacen en sus trabajos y hogares. Por este motivo, su lenguaje apunta a reivindicar el valor de éstas en la sociedad, en la democracia y como protagonistas de las múltiples políticas públicas que su gestión ideó para buscar soluciones a determinadas temáticas, como la ampliación de la cobertura escolar y de salud; la ley de amamantamiento; el apoyo a las progenitoras

\footnotetext{
${ }^{162}$ En: Cumbre del Mercosur, 19/12/2007.

${ }^{163}$ En: Congreso de la Nación, Chile, 21/5/2007.

164 Ibídem.
} 
que desean continuar con sus estudios; la reforma previsional; la igualdad de remuneración entre varones y mujeres, entre otras:

Se asoma también un tiempo de mujeres y hombres, como nunca antes en nuestro país. Cosechamos hoy una larga siembra. (...) el tesón y el sacrificio de miles y miles de mujeres en todo el país que se esfuerzan por sacar a sus familias adelante, por trabajar, por estudiar. ${ }^{165}$

Para las mujeres la situación es similarmente desigual. Sólo el 37 por ciento tiene un empleo fuera de casa, y todos sabemos lo mucho que además trabajamos en la casa. (...) Tenemos que hacer algo ya. Promoveremos la jornada parcial y el teletrabajo. Ampliaremos dramáticamente la cobertura pre escolar, para que las mujeres trabajen tranquilas, en la seguridad que sus hijos estarán bien atendidos. ${ }^{166}$

Llegamos donde las trabajadoras, llegamos donde las temporeras. Llegamos (...) para apoyar a las madres que desean continuar sus estudios. Llegamos, incluso, donde madres privadas de libertad. ${ }^{167}$

Nos hemos preocupado especialmente de la mujer trabajadora. Hoy son miles las que pueden trabajar más tranquilas porque sus hijos acceden a sala cuna. ${ }^{168}$

Aprobamos la Ley de Subcontratación, la Ley de Amamantamiento, que permite que todas las madres tengan opción a ese derecho tan básico como es amamantar a sus hijos. ${ }^{169}$

...cuando pensamos la Reforma Previsional tuvimos siempre en mente los problemas específicos de las mujeres, cuyas pensiones fueran sustantivamente más bajas o que ni siquiera tenían pensión. Y ahora tenemos una reforma que beneficiará, enorme y mayoritariamente, a las mujeres (...) Y pido, muy formalmente también, al honorable Congreso el pronto despacho del proyecto de ley de brecha salarial. ¡Cómo va a ser justo que una mujer que tiene el mismo trabajo que tiene un hombre gane menos que el hombre! Debemos promover que a igual función, igual remuneración entre hombres y mujeres. Como ven, vamos avanzando y seguiremos avanzando en los derechos de la mujer. $^{170}$

Creamos en tal sentido 20 mil nuevos cupos en el programa de capacitación laboral para mujeres que han estado desempeñándose como trabajadoras dependientes, pero que necesitan apoyo estatal para reconvertirse en independientes o emprendedores. ${ }^{171}$

\footnotetext{
${ }^{165}$ En: Congreso de la Nación, Chile, 21/5/2006.

${ }^{166}$ Ibídem.

${ }^{167}$ En: Congreso de la Nación, Chile, 21/5/2007.

${ }^{168}$ Ibídem.

${ }^{169}$ En: Congreso de la Nación, Chile, 21/5/2008.

${ }^{170}$ Ibídem.

${ }^{171}$ En: Congreso de la Nación, Chile, 21/5/2009.
} 
...el Congreso aprobó el proyecto de brecha salarial, que va a promover algo muy sentido por todos y todas: que hombres y mujeres de nuestra patria por igual trabajo reciban igual salario. ${ }^{172}$

Por último, en el caso de Rousseff, en el año 2014 y en el marco de la asunción de Michelle Bachelet a su segundo mandato gubernamental en Chile, Dilma se expresa mostrándose orgullosa de que tres mujeres (ellas y Cristina Fernández), sean las máximas autoridades de los Ejecutivos en países de América del Sur. En ese sentido, sostiene que la región avanza no solamente en términos de mejoramiento económico, sino también de igualdad de género; y reconoce que en esta materia ha sido fundamental el rol que Bachelet cumplió como Directora Ejecutiva de ONU Mujeres (2010-2013):

Es emblemático que nos encontramos hoy con nuestra querida Presidente Cristina Kirchner, tres mujeres de países de América del Sur. Nuestra región se mueve hacia adelante, no sólo en términos de crecimiento económico y el desarrollo social y humano, sino también y sobre todo que presiden la igualdad de género. Igualdad que Michelle tanto nos ayudó a promover, cuando se desempeñó como Directora Ejecutiva de ONU Mujeres. (...) "Cuando una mujer entra a la política, cambia la mujer; cuando muchas mujeres entran a la politica, cambia la política."173

Asimismo, la ex mandataria petista valora y reconoce que la gestión del Secretario General Ban Ki-moon le brinda un lugar de relevancia a los derechos humanos de las mujeres; comprendiendo que el alcance de la igualdad entre las personas es uno de los principios fundamentales de las sociedades democráticas, así como un indicador del grado de desarrollo alcanzado por dicho sistema socio político:

En mi país, las mujeres han sido fundamentales para la superación de las desigualdades sociales. Nuestros programas de distribución de ingresos tienen como figura central a las madres. Ellas tienen el cuidado de los recursos que permiten a las familias el invertir en la salud y la educación de sus hijos. Pero en mi país, al igual que todos los países, aún es necesario hacer mucho más por la valoración y la afirmación de las mujeres. Para hablar de ello, saludo al Secretario General Ban Ki-moon, por la prioridad que se da a las mujeres en su gestión de las Naciones Unidas. Saludo en particular a la ONU Mujeres y su Directora Ejecutiva, Michelle Bachelet. ${ }^{174}$

\footnotetext{
172 Ibídem.

${ }^{173}$ En: Asunción del segundo gobierno de Michelle Bachelet en Chile; 11/3/2014.

${ }^{174}$ En: 66 Apertura de la Asamblea General de las Naciones Unidas; 21/09/2011.
} 


\section{CAPÍTULO 6}

\subsection{Lideresas del sur}

Como expusimos en los capítulos anteriores, lo que se desprende de los ejes a) "Yo como mujer"/“Es un gobierno de mujeres", y b) "Es tiempo de pensar en las mujeres"/ "Queremos una sociedad más igualitaria”, analizados en los casos de las tres mandatarias sudamericanas es que la perspectiva de género se encuentra siempre presente en los discursos que emiten tanto en los Congresos Nacionales (en los contextos de asunción a sus cargos) como en los ámbitos bi y multilaterales. El apelativo de "mujer", el posicionamiento de representar a las mujeres de sus países (sobre todo en los casos de Bachelet y Rousseff) y de gobernar con ciertos rasgos que se le atribuye al género femenino, representan una constante en el corpus seleccionado.

Sin lugar a dudas, la tendencia auto-referencial, en sistemas que podríamos catalogar de presidencialistas, nos conducen a pensar en el peso de la primera imagen waltziana. De aquí nuestra insistencia en analizar las creencias, ideas y personalidades de las Presidentas. O sea, los componentes de la primera imagen; arrojados por los ejes a), b) y c).

A continuación desarrollaremos el tercer eje de nuestra propuesta metodológica. Es decir, c) Reflexiones sobre el ejercicio del poder y la toma de decisiones. Los fragmentos seleccionados ilustrarán cómo se ven ellas mismas respecto al desarrollo de sus propios liderazgos. Esto nos permitirá saber si se posicionan desde rasgos distintivos -atribuibles al género- para ejercer el poder y desempeñarse en política exterior.

En relación con la segunda imagen waltziana (estructura y organización del Estado), podemos asegurar que en ninguno de los tres casos se registran cambios en el régimen político, dado que continúan siendo democráticos y en todos los casos las mandatarias suceden a Presidentes del mismo espacio partidario. Lo anterior responde a la siguiente información: Cristina Fernández sucede a Néstor Kirchner, del Frente para la Victoria; Verónica Michelle Bachelet Jeria sucede a Ricardo Lagos Escobar, del Partido Socialista; y Dilma Vana Rousseff sucede a Luiz Inácio Lula da Silva, del Partido de los Trabajadores.

En consecuencia, la modificación más significativa que puede evidenciarse es la asunción por el voto popular de tres mujeres como Jefas de Estado y la incorporación que ellas hacen de otras mujeres en puestos de poder (sobre todo, Ministerios). 
6.2. Reflexiones sobre el ejercicio del poder y la toma de decisiones

\begin{abstract}
"Cuando una mujer llega a la política, cambia la mujer. Cuando muchas mujeres llegan a la política, cambia la política". Pero no era el caso, no era la situación. Para ninguna de las tres mandatarias.

Ninguno de los tres países era realmente un país súper igualitario... y apenas llegaron, se les empieza a medir los atributos de liderazgo, ¿no? $Y$ ellas tienen que responder a atributos de liderazgo tipicamente masculinos ${ }^{175}$.
\end{abstract}

Ximena Jara, Jefa de Contenidos de la Presidencia de Michelle Bachelet.

\title{
6.2.1. Construcciones colectivas y disposición para el diálogo
}

En el caso de Cristina Elisabet Fernández, ya desde su discurso de asunción presidencial, se refiere a "construcciones colectivas" y no a triunfos personales. En este sentido, manifiesta:

Las ideas, los proyectos es lo que triunfaron este 28 de Octubre. Yo no me engaño, nunca he creido en los triunfos personales e individuales, descreo profundamente de ellos, porque creo en las construcciones colectivas y la sociedad. ${ }^{176}$

Para cambiar un país hace falta un buen gobierno y una buena sociedad. ${ }^{177}$

...lo que caracterizó a aquella generación, a mi generación, fue que nunca hablábamos en la primera persona del singular, siempre hablábamos en la primera persona del plural, en nosotros, que es lo que distingue a los proyectos colectivos. ${ }^{178}$

Sin embargo, no puede dejar de reconocerse la referencia constante que hace hacia su persona -como política, luchadora, militante, abogada, legisladora-y, sobre todo, a su condición de primera Presidenta mujer elegida en las urnas, tal como evidenciamos en los ejes/capítulos anteriores.

Por otro lado, se desprende de sus palabras una permanente disponibilidad al diálogo y el llamado al respeto mutuo. En este sentido, resalta la unión con personas de otros espacios políticos para lograr la transformación nacional a la que se refiere. Un claro

\footnotetext{
${ }^{175}$ Entrevista realizada en Santiago de Chile, el 20 de agosto del 2015.

${ }^{176}$ En: Asunción del mando en el Congreso; 10/12/2007.

177 Ibídem.

${ }^{178}$ En: visita a la Escuela Latinoamericana de Medicina; Cuba, 21/1/2009.
} 
ejemplo de ello es que su compañero de fórmula, el Vicepresidente Julio César Cleto Cobos, es representante del Partido Radical; histórico partido rival del peronismo:

Creemos profundamente en la transformación, en el hacer y en el trabajar y hemos fructificado uniéndonos a hombres y mujeres de distinta pertenencia partidaria con un solo objetivo: cumplir con el mandato popular. ${ }^{179}$

Para terminar, quiero convocar a todos los hombres y mujeres de mi país, a los jóvenes, a los ciudadanos, a las ciudadanas, a las que nos votaron y a los que no lo hicieron, porque en definitiva hoy estamos representando los intereses de todos (...) (Néstor Kirchner y yo) en aquellos años soñábamos con cambiar el mundo, ahora nos conformamos con cambiar este nuestro país, nuestra casa. ${ }^{180}$

A pesar de lo afirmado previamente, también es cierto que Fernández suele utilizar sutiles ironías, como cuando se expresa sobre profundizar el rol del Congreso y pide que todos tengan "memoria histórica" de sus orígenes políticos y de qué modelo de país representó en cada caso.

Creo sinceramente que hemos recorrido un largo camino en estos años de democracia y espero profundizar este rol del Congreso, donde podamos discutir y debatir sin adjetivaciones, sin agravios, con propuestas alternativas y viables, con memoria histórica de dónde viene cada uno, qué hizo cada uno y qué representó cada uno que es lo que nos da legitimidad para poder plantear una propuesta. ${ }^{181}$

Por su parte, Verónica Michelle Bachelet Jeria manifestó en el discurso anual del 2006 haberse propuesto "renovar el modo como se ejerce el poder desde el gobierno" y para ello indicó que implementó la constante consulta con especialistas de las distintas áreas y construir desde el "diálogo social". De este modo, plantea su gobierno como una etapa de cambio, en cuanto a la posibilidad de escuchar, intercambiar ideas y de sentirse cerca de la gente. A saber:

El compromiso de mi Gobierno es abrir un amplio camino de oportunidades. Un compromiso para todos, no para un solo bando. ${ }^{182}$

Para mí gobernar es también ver, escuchar y responder a las personas. ${ }^{183}$

\footnotetext{
${ }^{179}$ Op.cit.

${ }^{180}$ Op. cit.

${ }^{181}$ Op. cit.

182 En: Congreso de la Nación, Chile, 21/5/2006.

183 Ibidem.
} 
Me propongo también renovar el modo como se ejerce el poder desde el gobierno (...) Es un método, el del diálogo social, muy usado en democracias muy desarrolladas. ${ }^{184}$

Dije: diré lo que pienso y haré lo que digo. Es mi estilo en la politica. Se trata de cumplir la palabra y precisar las prioridades. ${ }^{185}$

También y como parte de ese cambio de paradigma al que alude Michelle, surge la idea de "negociación colectiva", en la que hace partícipe a distintos actores de la sociedad civil (por ejemplo, trabajadores y empresarios). Y respecto a la libre expresión de sectores de la oposición, se refiere a ellos como parte de la democracia, pero aclara que el límite es el respeto y la responsabilidad.

Hace unos días logramos un acuerdo inédito. Llegaron hasta el Palacio de la Moneda dirigentes sindicales y los representantes de los trabajadores y de las empresas de todos los tamaños. (...) Pudimos construir un acuerdo en materia de empleo que, estoy segura, será un referente en la manera como se enfrentan las crisis, no sólo en Chile, sino que en el mundo entero. ${ }^{186}$

Ya lo he dicho: Queremos más y mejor negociación colectiva, porque ésa es la mejor herramienta para asegurar el fluido diálogo entre trabajadores y empresarios. ${ }^{187}$

$\mathrm{Y}$ es justamente sobre ese ejercicio del poder que desempeñó Bachelet en su primer gobierno que Ximena Jara, Jefa de Contenidos de Presidencia, reflexionó:

Yo creo que el cambio cultural que se venía acumulando por décadas, que la gente tenía necesidad, ganas de un liderazgo distinto. Un tipo de liderazgo que rompiera con lo vertical, que fuera más horizontal...y que en ese sentido desafiara lo patriarcal, pero que asegurara al mismo tiempo, cierto nivel de orden. Necesitaban un liderazgo más cercano y menos autoritario. ${ }^{188}$

En otra instancia, en el corpus discursivo analizado de Rousseff, se nota un evidente posicionamiento como continuadora de la obra iniciada por su antecesor político, Lula da Silva; líder al que le reconoce que "transformó la manera de gobernar" en Brasil ${ }^{189}$ y al que ella afirma querer homenajear, ampliando y avanzando en las conquistas sociales que aquél inició en su gestión. Es decir, en el caso de la economista brasilera podemos referenciar a una construcción colectiva en el sentido de consolidar un cambio en el modo de gestionar los asuntos del Estado, que se inició con el líder del Partido de los Trabajadores. Esta

\footnotetext{
${ }^{184}$ Ibidem.

185 Ibídem.

${ }^{186}$ En: Congreso de la Nación de Chile, 21/5/2009.

${ }^{187}$ En: Congreso de la Nación de Chile, 21/5/2008.

${ }^{188}$ Entrevista realizada en Santiago de Chile, el 20 de agosto del 2015.

${ }^{189}$ En: Acto de asunción en el Congreso, Brasil, 1/1/2011
} 
postura puede ser comparable, como vimos anteriormente, con la de Fernández respecto al gobierno de su marido.

Vengo para consolidar la obra transformadora del Presidente Luiz Inácio Lula da Silva, con quien tuve la más vigorosa experiencia política de mi vida y el privilegio de servir al país, a su lado, en estos últimos años. De un presidente que transformó la manera de gobernar y llevó al pueblo brasileño a confiar aún más en sí mismo y en el futuro del País. El mayor homenaje que puedo prestarle es ampliar y avanzar las conquistas de su gobierno. ${ }^{190}$

En el aspecto social, la inclusión solamente será plenamente alcanzada con la universalización y la cualificación de los servicios esenciales. Este es un paso, decisivo e irrevocable para consolidar y ampliar las grandes conquistas obtenidas por nuestra población en el periodo del Gobierno del Presidente Lula. ${ }^{191}$

Además de hacia su propio país, la mandataria sostiene también esta perspectiva de

“continuidad" y diálogo en el ámbito internacional:

Nuestro desafío y compromiso político mayor hacia la región, como el Presidente Luiz Inácio Lula da Silva mencionó en el discurso de clausura de la reunión de la CEPAL en 2010, es el de implementar políticas de desarrollo para la gran mayoría de la población, a la inversa de lo que se hacía anteriormente. Mi Gobierno continúa persiguiendo esa meta. ${ }^{192}$

Nuestra relación bilateral se desarrolla con una agenda diversa y con un notable grado de madurez. He mantenido reuniones con el primer ministro Mariano Rajoy y el rey Juan Carlos, donde se puede observar la mutua disposición de profundizar en el diálogo y en conjunto construir una asociación eficaz y centrada en resultados concretos. ${ }^{193}$

Por último, es igualmente interesante destacar la postura de Rousseff sobre la relación que pretende tener con otros espacios políticos y opositores al oficialismo.

La economista pondera y respeta la diversidad ideológica y el debate de ideas:

Quien les habla y mi vicepresidente Michel Temer fuimos elegidos por una amplia coalición partidaria. Estamos construyendo con ellos un gobierno donde capacidad profesional, liderazgo y la disposición de servir al país serán los criterios fundamentales. Una vez más extiendo mi mano a los partidos de oposición y a los sectores de la sociedad que no estuvieron con nosotros en la reciente jornada electoral. No habrá de mi parte ni de mi gobierno, discriminación, privilegios o compadraje. A partir de este momento soy la presidenta de todos los brasileños. ${ }^{194}$

\footnotetext{
${ }^{190}$ Ibídem.

${ }^{191}$ Ibídem.

${ }^{192}$ En: $34^{\circ}$ Periodo de Sesiones de la CEPAL; 31/8/2012.

${ }^{193}$ En: Apertura del seminario "Brasil en la Senda del Crecimiento"; Madrid, 19/11/2012.

${ }^{194}$ Op. cit.
} 
No creo que haya que juntarse con personas que piensan como nosotros solamente. Es esta profunda característica de Brasil que nos hace un país respetado en todas las áreas, porque somos un país capaz de dialogar. ${ }^{195}$

\subsubsection{El Estado cerca de los pueblos}

Fernández afirma que la motivación de convertirse en Presidenta no fue el de cuidar los intereses de los empresarios o formar parte de alguna interna sindical o partidaria. Por el contrario, tiene un discurso a favor de la clase trabajadora y de la búsqueda de soluciones a través de la construcción o el refuerzo de lazos con actores de la región:

Representar los intereses del pueblo significa, esencialmente, mejorar su calidad de vida y utilizar todos los instrumentos de articulación e integración regionales precisamente en un espacio como Latinoamérica. ${ }^{196}$

Yo no he venido a ser Presidenta de la República para convertirme en gendarme de la rentabilidad de los empresarios; que se olviden. Tampoco he venido a ser Presidenta para convertirme en parte de alguna interna sindical o política. Tampoco, tampoco. ${ }^{197}$

Es imprescindible para todo gobierno que todas sus políticas y todas sus acciones estén orientadas a sostener la permanencia de los trabajadores en sus empresas. ${ }^{198}$

...creo que el Estado se tiene que dar un rol de intervención como el que nosotros, por ejemplo, lo estamos dando en la República Argentina. ${ }^{199}$

El trabajo, la vivienda, la educación, el aporte que el Estado, la presencia del Estado en un país y en un mundo que durante mucho tiempo nos dijeron que estábamos equivocados porque el Estado complicaba la vida de los ciudadanos. El Estado nunca ha complicado la vida de los ciudadanos, al contrario. ${ }^{200}$

Por su parte, en el caso de Bachelet, resultan interesantes los conceptos de servicio a la gente y de un Estado que debe atender y ocuparse de sus gobernados. El ejercicio de toma de decisiones de Bachelet es planteado como un servicio al pueblo chileno, sin distinción. La responsabilidad, como señala en varias oportunidades, es hacia todos y no sólo con algunos sectores:

${ }^{195}$ En: Instituto Rio Branco, 20/4/2012.

${ }^{196}$ Firma de acuerdos con Venezuela, 6/03/2008.

${ }^{197}$ En: Asunción del mando en el Congreso, 10/12/2007.

${ }^{198}$ En: Asamblea OIT; 15/6/2009.

${ }^{199}$ En: Encuentro Mundial de Sindicalistas en Ginebra; 15/6/2009.

${ }^{200}$ En: Malvinas Argentinas; 5/10/2009. 
...el norte de nuestra acción es el ciudadano. Él o ella estarán al centro de la política pública. ${ }^{201}$

Solo hay una manera de hacer buena politica, y es logrando que la actividad pública gire en torno a las necesidades y los anhelos de las personas. ${ }^{202}$

De hecho, la funcionaria llega a presentarse como una persona autoexigente en todas las áreas que participa y refuerza su sentido de compromiso con el que asumió el programa de acciones y metas de su presidencia:

Ustedes saben que si hay algo que a mí no me caracteriza es que no me exija más, me exijo cada vez más en todos los temas. ${ }^{203}$

¡Ese es el camino de progreso y justicia social por el que debemos perseverar! ¡Este es el camino con el que este gobierno y esta Presidenta estamos profundamente comprometidos! ${ }^{204}$

Ligado a lo anterior, la funcionaria del Servicio Nacional de la Mujer de Chile, Claudia Godoy Caroca, le reconoce a Michelle la incorporación de una vasta gama de políticas de inclusión social; así como también destaca su rol de lideresa durante la Presidencia Pro Témpore de la Unión de Naciones Suramericanas (UNASUR), en el año 2008:

Se hizo el Tratado Constitutivo y efectivamente uno podía ver en la región el liderazgo distinto que tenía la Presidenta, de convocar (...) lideró, a través de la UNASUR, yo te diría un proceso de constitución de la organización y de importancia política, sobre todo en ese tipo de conflictos, muy fuerte. ${ }^{205}$

En otro orden, además de referirse a su constante trabajo, la pediatra socialista deja entrever que su esfuerzo es por el pueblo y que finalmente será éste quien evaluará y juzgará si ella cumplió con lo prometido; en este caso refiriéndose al programa que ella denominó de "cuatro transformaciones", que consistió en: 1) sistema de previsión

\footnotetext{
${ }^{201}$ En: Congreso de la Nación, Chile, 21/5/2006.

${ }^{202}$ En: Congreso de la Nación, Chile, 21/5/2009.

${ }^{203}$ En: Congreso de la Nación, Chile, 21/5/2008.

${ }^{204}$ En: Congreso de la Nación, Chile, 21/5/2007.

${ }^{205}$ Se refiere a la crisis política boliviana, protagonizada por la zona conocida como la Media Luna (Tarija, Pando, Santa Cruz y Beni), durante el año 2008. En Pando se produjo un enfrentamiento entre opositores y seguidores del Presidente Evo Morales Ayma, que tuvo como resultado varias muertes. Además, Claudia Godoy hacía mención a un contexto de cuestionamiento a la OEA, en función de garantizar transparencia en el proceso electoral que se debatía. Entrevista realizada en el SERNAM, Santiago de Chile; 20/8/15.
} 
(pensiones más dignas y seguras); 2) educación (más salas cunas y jardines para los más pequeños, y escuelas y liceos de mayor calidad para los niños y niñas más grandes); 3) innovación y emprendimiento (una nueva política de desarrollo para el crecimiento); y 4) barrios amables, con calidad de vida para las personas:

...estas cuatro transformaciones habrán sentado las bases de la sociedad moderna e inclusiva que queremos seguir construyendo. Ese año 2010, al final de mi gobierno, los ciudadanos evaluarán si hemos cumplido con estas cuatro grandes metas. ${ }^{206}$

Además, Bachelet se muestra con una imagen de lideresa cercana al pueblo, a sus necesidades y ambiciones. Por eso no es casual encontrar en sus palabras, expresiones como "comparto esta preocupación", seguida por la promesa de alguna medida o directamente, la descripción de la política pública pensada para paliar ciertas situaciones que vulneran los derechos de sus conciudadanos. En este sentido, ella explicita en varios pasajes de sus discursos que el norte de sus decisiones es lograr una mejor calidad de vida para su pueblo:

"Él o ella estarán al centro de la política pública". ${ }^{207}$

...qué tan cerca podemos estar de la gente a la que servimos. Porque, amigas y amigos, no es la gente la que debe estar al servicio del Estado. Es el Estado el que debe estar al servicio de la gente. ${ }^{208}$

Quiero que las familias sepan que el gobierno está con ellos en estos momentos dificiles. ${ }^{209}$

Por último, Rousseff se expresa con términos y frases que hacen alusión a su promesa de gobernar con el fin de lograr una mejor calidad de vida para los sectores más vulnerables:

Brasil ha descubierto que la mejor política de desarrollo es la lucha contra la pobreza. ${ }^{210}$

A la vez que luchar contra la pobreza, tenemos que ser capaces de afrontar los retos del siglo XXI: la ciencia, la tecnología y la innovación. ${ }^{211}$

\footnotetext{
${ }^{206}$ En: Congreso de la Nación de Chile, 21/5/2006.

${ }^{207}$ Ibídem.

${ }^{208}$ Ibidem.

${ }^{209}$ Op. cit.

${ }^{210}$ En: ONU, 21/9/2011.
} 
La lucha contra la pobreza, el hambre y la desigualdad es el mayor desafio de nuestro tiempo. Por lo tanto, hemos adoptado en Brasil un modelo económico con inclusión social, que se basa en la creación de empleo, el fortalecimiento de la agricultura familiar, la expansión del crédito, la mejora de los salarios y la construcción de una vasta red de protección social, en particular a través nuestro programa de subsidio familiar. Además de los logros anteriores, hemos eliminado la pobreza extrema. ${ }^{212}$

Ahora estamos luchando para hacer de este país un país más inclusivo, más igualitario, con mayor distribución del ingreso, una nación que los brasileños de todo el mundo puedan reconocer. ${ }^{213}$

Por lo anterior, se hacen coherentes expresiones tales como "la lucha más obstinada" cuando se refiere al trabajo que realizará junto con su equipo de funcionarios para aumentar el nivel socioeconómico de sus dirigidos/as: "La lucha más obstinada de mi gobierno será por la erradicación de la pobreza extrema y la creación de oportunidades para todos". ${ }^{214}$ En ese mismo sentido se enmarcan los siguientes fragmentos:

Para superar la exclusión -esa histórica deuda de América Latina- nuestro gobierno, al igual que otros varios en la región, está redefiniendo y fortaleciendo los instrumentos de planificación y de acción del Estado. ${ }^{215}$

El Programa Brasil sin Miseria eliminará la pobreza absoluta hasta el 2014. Nuestra política industrial, los avances macroeconómicos y las políticas sociales no deben contraponerse entre sí. Sí deben convergir hacia un fin común que es el crecimiento con cambio estructural e igualdad. ${ }^{216}$

Asimismo, afirma que quiere estar junto "a los que trabajan por el bien de Brasil" desde cualquier región del país. En este sentido, hace un llamado a los otros poderes Legislativo y Judicial- y al resto de los funcionarios para continuar trabajando por el desarrollo. Por último, y en el marco de la $68^{\mathrm{a}}$ Asamblea General de las Naciones Unidas, se refiere a los cinco pactos sociales que comenzaron en su gobierno, pensando en las necesidades de la ciudadanía:

\footnotetext{
211 Op. cit.

${ }^{212}$ En: $68^{\mathrm{a}}$ Asamblea General de las Naciones Unidas; 24/9/2013.

${ }^{213}$ En: Instituto Rio Branco; 30/4/2014.

${ }^{214}$ En: Acto de asunción en el Congreso Nacional, Brasil, 1/1/2011.

${ }^{215}$ En: $34^{\circ}$ Periodo de Sesiones de la CEPAL; 31/8/2012.

216 Ibídem.
} 
Quiero estar al lado de los que trabajan por el bien de Brasil en la soledad amazónica, en la sequía nordestina, en la inmensidad de la sabana, en la vastedad de las pampas (...) Quiero convocar a todos para participar del esfuerzo de transformación de nuestro país. Respetada la autonomía de los poderes y el principio federativo, quiero contar con el Poder Legislativo y con el Judicial, y con la alianza de gobernadores y alcaldes para continuar desarrollando nuestro País, perfeccionando nuestras instituciones y fortaleciendo nuestra democracia. ${ }^{217}$

Transformar esta energía extraordinaria de las manifestaciones en el rendimiento para todos. Por lo tanto, puse en marcha cinco pactos principales: el pacto para combatir la corrupción y la reforma política; el pacto para la movilidad urbana, la mejora del transporte público y la reforma urbana; el pacto por la educación, nuestro gran pasaporte para el futuro, con la ayuda de las regalías y fondo petrolero social; el Pacto por la Sanidad, que prevé el envío de médicos para atender y salvar la vida de los brasileños que viven en los rincones más remotos del país y pobres; y el pacto de responsabilidad fiscal, para asegurar la viabilidad de esta nueva etapa. ${ }^{218}$

\subsubsection{Democracia y derechos humanos}

Del corpus discursivo de Cristina Fernández cabe destacar la idea de grandes responsabilidades y de "trabajo" que cruzan todos sus discursos: de "hacerse cargo" de la hermandad latinoamericana; de sacar adelante la región (junto a Brasil, principalmente); de abogar por los derechos humanos y de profundizar la integración y cooperación en América Latina:

Tenemos la suerte presidente Lula, querido amigo Lula, de estar en una época diferente. Somos la generación que va a tener el altísimo desafio, la inmensa responsabilidad de abordar el siglo XXI, de recolocar y reposicionar a nuestra región, que por primera vez ante una crisis mundial no entra en crisis como siempre pasaba. ${ }^{219}$

...vengo a hacerme cargo de aquella promesa de unidad latinoamericana y de profundización de los lazos que nos hermanan". 220

...también mi país ha recibido una ola inmigratoria de los países limítrofes de la región. Y podemos hablar con el ejemplo, porque hace pocos días sancionamos y reglamentamos la nueva Ley de Migraciones que permite la regularización de más de

\footnotetext{
${ }^{217}$ En: Congreso de la Nación, Brasil, 1 de enero del 2011.

${ }^{218}$ En: $68^{\mathrm{a}}$ Asamblea General de las Naciones Unidas; 24/9/2013.

${ }^{219}$ En: Almuerzo en honor al presidente de Brasil, 22/2/2008.

${ }^{220}$ En: visita a una Iglesia Jesuita en Quito, 21/4/2008.
} 
700.000 extranjeros con absolutamente todos los mismos derechos y las mismas responsabilidades que los ciudadanos argentinos. ${ }^{221}$

En esta misma línea, ella expresa que la idea de cambiar el país hacia un escenario de mayor desarrollo y justicia social es un sueño que compartió siempre con su esposo Néstor Kirchner, ex Presidente de la Nación, fallecido en octubre del 2010:

...creo que no hay argentino ni persona en el mundo que pueda dudar acerca de la convicción del gobierno del presidente Kirchner y de esta Presidenta en la necesidad de que sean juzgados y castigados todos aquellos que han violado los derechos humanos en la República Argentina. ${ }^{222}$

La Argentina en estos casi seis años ha completado el crecimiento económico más importante de sus 200 años de historia contra todos los pronósticos. ${ }^{223}$

... siento que vengo a cumplir una promesa que él hizo ${ }^{224}$ y siento que, en definitiva, somos los argentinos los que estamos cumpliendo con nosotros mismos de haber terminado el trabajo que otros iniciaron. ${ }^{225}$

...dudo que haya habido alguna otra etapa en la vida institucional de este nuestro querido país donde se haya podido hablar con mayor libertad que en la etapa que me ha tocado gobernar a mi la República Argentina. ${ }^{226}$

Los Derechos Humanos "no son planteos ideológicos, son simplemente eso, respeto a la condición humana". 227

Por otro lado, en el caso de Bachelet, el concepto de "cumplir con la palabra" y las promesas, aparece como una constante en sus discursos. Asimismo, enfatiza en la decisión de hacerse cargo de tareas inconclusas que dejaron gestiones anteriores. Por ejemplo, cuando se refiere al trabajo iniciado por Lagos, con el Programa "Chile Califica" y que ella está dispuesta a concluir para que miles de chilenos puedan completar sus estudios:

Tenemos otra asignatura pendiente. En 1990 la mitad de los chilenos mayores de edad no había completado su educación media. El Presidente Lagos inició el programa Chile Califica. En mi gobierno, más de 400 mil chilenos podrán completar sus estudios básicos y medios. 228

\footnotetext{
${ }^{221}$ En: VI Cumbre Unión Europea-América Latina y el Caribe; 18/5/2010.

${ }^{222}$ En: Reunión de Tribuna Iberoamericana; 10/2/2009.

${ }^{223}$ En: Almuerzo en honor al Presidente brasileño, Inacio Lula da Silva; 23/4/2009.

${ }^{224}$ Se refiere al ex Presidente Néstor Kirchner.

${ }^{225}$ En: Acto de elevación a la cota definitiva de la represa binacional Yacyretá; 25/2/2011

${ }^{226}$ En: 30 años de la visita de la Comisión Interamericana de Derechos Humanos a la Argentina; 11/9/2009.

${ }^{227}$ En: París por la inauguración del Jardín de Abuelas y Madres de Plaza de mayo; 7/4/2008.

${ }^{228}$ En: Congreso de la Nación, Chile, 21/5/2006.
} 
En un sentido similar, podemos asegurar que de su discurso surge la afirmación de hacerse cargo de "una herencia dolorosa", como son los casos de personas desaparecidas durante la dictadura de Pinochet. La perspectiva de derechos humanos, presente también en los discursos de Fernández y Rousseff, se presenta asociada a un compromiso con la memoria, verdad, justicia y reparación histórica. "Las grandes transformaciones requieren grandes decisiones", afirmó en el Congreso chileno en el 2009; haciendo alusión a los cambios que introdujo en su gestión para hacer de su país un territorio más inclusivo y democrático:

Me hago cargo de una herencia dolorosa. Responder con verdad, justicia y reparación a las violaciones a los derechos humanos de nuestro pasado reciente (...) Escúchenme bien, conciudadanos: mientras haya detenidos desaparecidos nunca dejaremos de buscarlos. ${ }^{229}$

Recuperamos la democracia para que todos tuvieran la posibilidad de plantear sus puntos de vista a la autoridad, de ejercer oposición, incluso vehementemente, pero con un límite: el respeto y la responsabilidad. ${ }^{230}$

...como Presidenta estoy convencida que todos caben en este salón del Congreso Pleno. Debemos reformar nuestro sistema electoral porque así como está, no representa la diversidad politica tal cual es. ${ }^{231}$

Su carácter de mujer fuerte se evidencia, por ejemplo, cuando envía al Congreso un proyecto de reforma al sistema electoral, para que puedan acceder al poder otros y otras representantes de la sociedad y aclara que nadie que esté a favor de la democracia debería oponerse. Ligado a esto, la lideresa chilena critica la histórica exclusión de las mujeres en los puestos de poder y lo atribuye a barreras culturales que desde su gestión está dispuesta a romper:

Enviaré prontamente al Congreso un proyecto de reforma al actual sistema electoral (...) espero que todos estemos de acuerdo en que es esencial para la calidad de nuestra democracia, un sistema electoral más representativo. (2006)

Digámoslo con fuerza, ¡esto no sucede por falta de capacidad! ¡No se trata de que nos interese menos lo que le sucede a Chile! ¡No se trata tampoco de que no sepamos usar el poder! Esto pasa porque se han mantenido barreras de siglos de nuestras instituciones, costumbres y mentes. Y ha llegado el momento de levantar esas barreras. (2006).

\footnotetext{
229 Ibídem.

${ }^{230}$ En: Congreso de la Nación, Chile, 21/5/2007.

${ }^{231}$ Ibídem.
} 
En ese sentido, Lorena Henríquez afirmó que "es responsabilidad de las mujeres de ayudar a las otras a llegar a sus cargos. Porque no es posible...porque cuando tú llegas a un cargo, tienes que tratar de hacer una escalera y darles la mano para que puedan también ir subiendo." 232

Por su parte, Claudia Godoy Caroca afirma que en el ámbito de la política exterior, durante la presidencia de Bachelet, hubo una fuerte transversalización de la perspectiva de género en materia multilateral. Del siguiente modo lo expresó la funcionaria, en la entrevista que nos concedió el 20 de agosto del 2015 en las oficinas de la SERNAM:

...yo me concentro en lo que es Naciones Unidas en un primer término, que nosotros como Chile en su minuto, seguimos patrocinando dos Resoluciones sobre Empoderamiento de las Mujeres y de la situación jurídica de la mujer en el Consejo de Derechos Humanos. Y ahí efectivamente hubo una mayor potencia de la política exterior en materia de Derechos humanos en los Consejos. También la elección de candidatas; nosotras ahí teníamos un variopinto de espacios donde se podían instalar mayor participación de mujeres en los espacios de decisión en los organismos multilaterales. Y en ese aspecto ahí hubo campaña por parte de la Cancillería, impulsada por la Presidenta y por el Servicio Nacional de la Mujer en ese minuto, donde efectivamente se lograron tener cinco mujeres electas en organismos internacionales, tanto en el Sistema Interamericano como en Naciones Unidas.

En forma análoga se expresa la Jefa de Contenidos de Presidencia, Ximena Jara:

El enorme cambio, si tú me preguntas, es más bien simbólico, más que efectivo (...) El sello de ella y la razón por la que después llega a ser jefa de ONU Mujeres, es la historia que encarnaba, ¿no? Esa historia de una mujer empoderando a otras mujeres y que era capaz de llevar a cabo en el mundo, mucho más de lo que había logrado hacer con Chile haciendo política internacional de género. Creo que es más bien un reconocimiento de lo que ella hace internamente y lo que encarna como líder internacional. ${ }^{233}$

Asimismo, tanto Godoy Caroca como Lorena Henríquez, de la Dirección de Gestión del Ministerio de Relaciones Exteriores de Chile, enfatizan en el logro que representó la aplicación de la Resolución 1325 del Consejo de Seguridad ${ }^{234}$, conocido como "Mujeres,

\footnotetext{
${ }^{232}$ Entrevista realizada en el Ministerio de Relaciones Exteriores, Santiago de Chile, el 19 de agosto del 2015.

${ }^{233}$ Entrevista realizada en Santiago de Chile, el 20 de agosto del 2015.

${ }^{234}$ Aprobada por el Consejo de Seguridad en su sesión 4213a , celebrada el 31 de octubre de 2000. Hay varias resoluciones que la suceden. Una de las más destacables es la 1820, donde cataloga la violencia sexual como crimen de guerra.
} 
paz y seguridad”, en un Plan de Acción que se inicia en el primer gobierno de la Presidenta Bachelet y que fue pionero en la región de América Latina y el Caribe:

...hay un llamado del Secretario General -a través del Consejo de Seguridad- de que los países puedan establecer y realizar Planes de Acción Nacional, para poder implementar esta Resolución. Pero esta resolución está enfocada al tema de conflicto por conflictos sólo armados. No hace una distinción sobre los conflictos sociales, civiles. Esa es otra discusión que se está siguiendo ahora. Pero en ese minuto, no. Pero hubo una voluntad de la Presidenta de efectivamente elaborar el primer Plan de Acción de la región, donde se unieron las tareas de Cancillería, SERNAM y Defensa. Eso vino acompañado por un proceso donde las Fuerzas Armadas estaban, producto también de que la Presidenta había sido Ministra de Defensa; y ahí empezó yo creo un proceso fuerte de introducción de las Fuerzas Armadas y efectivamente la incorporación de mujeres mucho más amplia en los temas de operaciones de paz. ${ }^{235}$

...no es lo mismo para una mujer agredida, ultrajada, violada, acercarse a un hombre con un fusil que acercarse a una mujer. Aunque los dos tengan fusil, la cercanía con una mujer es distinta. Entonces, fortalecer estas unidades que van compuestas por mujeres para poder llevar una buena atención; de proteger o capacitar o influir en cosas que sean beneficiosas para esta población de mujeres que está siendo afectada por una situación difícil (...) (La Presidenta) asume los compromisos de estos temas a través de la 1325 y luego ella los asume como parte (durante) la Primera Secretaria de ONU Mujeres. Ella puso su mirada en las mujeres que estaban en esas condiciones. Internacionalmente su apoyo, ella siempre ha tenido un discurso apoyando al género. $^{236}$

Finalmente, consultada Claudia Godoy sobre la ruptura de la ideología patriarcal -a nivel discursivo- por parte de la Presidenta, en el ámbito internacional, ella responde que Bachelet ha logrado instalar desde el punto de la política exterior y a "regañadientes", la perspectiva de género; avance que se visualiza más notablemente en este segundo período presidencial. En esta línea de pensamiento, afirma:

...yo creo que han sido procesos que no han sido de quebrar discursos, en el momento...yo creo que han sido procesos que -nos queda mucho- pero ha sido un poco tomar estos discursos patriarcales y tratar de alguna manera de instalar en el inconsciente, la cultura, que somos distintas pero somos -por lo menos en Chile-, el $50 \%$ de la población. ${ }^{237}$

En otro orden, es notorio cómo Rousseff destaca la necesidad de fortalecer la democracia y, para ello, se ubica muchas veces desde su propia historia personal -como

\footnotetext{
${ }^{235}$ Entrevista realizada a Claudia Godoy Caroca en el SERNAM; Santiago de Chile, 20 de agosto del 2015.

${ }^{236}$ Entrevista realizada a Lorena Henríquez en el Ministerio de Relaciones Exteriores; Santiago de Chile, 19 de agosto del 2015.

${ }^{237}$ Op. cit.
} 
militante detenida y torturada durante la dictadura brasilera que finalizó en 1985-, para reforzar sus afirmaciones y sostener la defensa irrenunciable de los derechos humanos:

Reafirmo lo que dije durante la campaña, que prefiero el barullo de la prensa libre al silencio de las dictaduras. Quienes, como yo y tantos otros de mi generación, luchamos contra el arbitrio y la censura y la dictadura, somos naturalmente amantes de la más plena democracia y de la defensa intransigente de los derechos humanos. ${ }^{238}$

...mi generación sintió en carne el abuso del poder, la crueldad del Estado; y sabe perfectamente que lo importante es el respeto fundamental de los derechos humanos. $^{239}$

Por su parte, Wicth y Cazarin (2015:106) afirman que en muchos pasajes de las declaraciones de Rousseff:

...es posible percibir la preocupación que la Presidenta tiene en demostrar que a través del nivel de participación de la mujer en la sociedad, se puede señalar el nivel de desarrollo de un país. Preocupación reafirmada cuando Dilma escoge a Argentina - gobernada también por una mujer, Cristina Kirchnerpara ser el primer país extranjero en recibir su visita. (Traducción nuestra)

Ejemplos del enunciado anterior son las siguientes expresiones de la funcionaria brasilera:

Brasil ha descubierto que la mejor política de desarrollo es la lucha contra la pobreza, $y$ que una verdadera política de derechos humanos se basa en la reducción de la desigualdad y la discriminación entre las personas, entre las regiones y entre los géneros. Brasil avanzó política, económica y socialmente sin comprometer incluso las libertades democráticas. ${ }^{240}$

Lo que distingue al Brasil de hoy es su determinación para convertirse en un pais de oportunidades, en el que todos sus hijos e hijas, independientemente de su origen social, la raza y el género, pueden imaginar un futuro mejor. ${ }^{241}$

Rousseff resalta la necesidad de terminar con los prejuicios por género, $\mathrm{y}$ -asimismo- con los raciales. Esta última característica -posiblemente por la diversa composición poblacional del Brasil, en términos étnicos-nacionales- la podemos encontrar enfatizada en ella y no así en el caso de Fernández o Bachelet.

\footnotetext{
${ }^{238}$ En: Acto de asunción en el Congreso de la Nación, Brasil, 1 de enero del 2011.

${ }^{239}$ En: Palacio de Itamaraty, 17/12/2012.

${ }^{240}$ En: ONU, 21/9/2011

${ }^{241}$ En: Apertura del seminario "Brasil en la Senda del Crecimiento"; Madrid, 19/11/2012.
} 
Así también nosotros, desde hace mucho tiempo, hemos sido un país de oportunidades para unos pocos, jugando a este sistema de exclusión que caracterizó durante mucho tiempo a nuestro país. $Y$ nos esforzamos por hacer de este país un país democrático. Ahora estamos luchando para hacer de este país un país más inclusivo, más igualitario, con mayor distribución del ingreso, una nación que los brasileños de todo el mundo puedan reconocer. ${ }^{242}$

En otro orden, es interesante notar cómo en algunos discursos emitidos en el ámbito multilateral, como el que realizó en Naciones Unidas el 21/9/2011, en lugar de expresarse en primera persona o en plural ("nosotros" como gobierno), se refiere a "Brasil" como el actor que interactúa en la escena internacional:

Brasil está haciendo su parte. Con sacrificio, pero con discernimiento mantenemos el gasto del gobierno bajo un estricto control, a fin de generar excedente considerable en las cuentas públicas, sin poner en peligro el éxito de las políticas sociales, ni nuestro ritmo de la inversión y el crecimiento. ${ }^{243}$

Brasil está dispuesto a asumir sus responsabilidades como miembro permanente del Consejo. Vivimos en paz con nuestros vecinos durante más de 140 años. Nosotros promovimos los procesos exitosos de integración y cooperación. ${ }^{244}$

En un sentido similar, se manifiesta en la XLVII Cumbre del Mercosur y Estados Asociados, asegurando que Brasil se esforzará en todos los sentidos para que el Mercosur siga avanzando. Sin embargo, este último caso, ella personaliza el honor sentido por asumir nuevamente la Presidencia Pro Témpore del organismo:

Es un placer para mí, un honor, y asumiendo de nuevo la Presidencia Pro Témpore del Mercosur (...) Brasil se esforzará en todos los sentidos para que el Mercosur siga avanzando. ${ }^{245}$

Así que quería decir a usted que, por otra parte, también me siento muy contenta de estar aquí porque la lucha por los derechos humanos es un tema muy importante para mí y para mi generación. Fue importante en mi vida política y marcó mi vida personal. Este tema, además de ser de importancia nacional, que me mueve, porque $m i$ generación sintió en carne el abuso del poder, la crueldad del Estado; y sabe perfectamente que lo importante es el respeto fundamental de los derechos humanos. $^{246}$

\footnotetext{
${ }^{242}$ En: Instituto Rio Branco; 30/4/2014.

${ }^{243}$ En: ONU, op.cit.

${ }^{244}$ Ibídem.

${ }^{245}$ En: XLVII Cumbre del Mercosur y Estados Asociados; 17/12/2014.

${ }^{246}$ En: Ceremonia del Premio de Derechos Humanos 2012; Palacio de Itamaraty, 17/12/2012.
} 
Por último, Rousseff expresa en el ámbito multilateral los valores de solidaridad y cooperación que definirían a ella y al proyecto político que representa. Así, se muestra como una lideresa atenta y dispuesta a colaborar con los países más vulnerables:

Queremos -y podemos- ayudar, mientras haya tiempo, en los países donde la crisis es ya aguda. ${ }^{247}$

Un nuevo tipo de cooperación entre los países emergentes y los países desarrollados, es la oportunidad histórica para redefinir, en solidaridad con responsabilidad y los compromisos que rigen las relaciones internacionales. ${ }^{248}$

${ }^{247}$ En: ONU, 21/9/2011.

${ }^{248}$ Ibídem. 


\section{Conclusión}

El Estado desde su estructura y concepción es altamente patriarcal; asimismo, esto no invalida que los tres países hayan sido construidos por y sobre mujeres en su ámbito íntimo, privado. A pesar de ello, la figura femenina sigue sin ser reconocida como protagonista o co-autora del relato oficial, del hacer político nacional e internacional. Tal como Bueno Sánchez y Valle Rodríguez (2006) rescatan, ya en su época (s.XVI), Hobbes acuñaba la frase "ella para él y él para el Estado". Lo curioso es que en la actualidad aquella afirmación aún sigue siendo relativizada por ciertos actores sociales; de ahí que la igualdad formal no se refleja en la igualdad real entre varones y mujeres.

Tal como quedó expuesto en la presente tesis, el discurso es un modo de acceso privilegiado a la concepción ideológica de las mandatarias. Por eso la importancia de partir de las palabras de las protagonistas, tomándolas como herramientas metodológicas, para desentrañar el posicionamiento de Fernández, Bachelet y Rousseff respecto a la ideología patriarcal y a la necesidad de partir desde una mirada de género.

En el contexto analizado en esta tesis, las reflexiones arrojadas por la implementación del modelo ideado y presentado a lo largo de la investigación, apuntan a reconocer que las afirmaciones que las mandatarias realizan en los ámbitos bi y multilaterales -también en contextos domésticos, como los trabajados en este estudio-, están atravesadas por una perspectiva de género, que refieren a su condición de mujeres muchas veces por sobre la autoridad de la investidura política. Esto quiere decir que el género es un tema recurrente en los discursos de las tres Presidentas, tanto para visibilizar las desigualdades de acceso al poder entre varones y mujeres, como para capitalizar los rasgos que - de forma estereotipada ${ }^{249}$ - se atribuyen a las mujeres (fortaleza, ternura, diálogo, cooperación, etc.).

Asimismo, las representaciones sociales que asocian ser mujer con "ser madre", y esto con la capacidad de proteger, amparar, y de generar lazos basados en la afectividad, también parecería ser un factor que está presente en los discursos. De esta forma, las funcionarias se presentan como incapaces de abandonar a sus pueblos y con una gran preocupación por cubrir sus necesidades y abogar por su desarrollo. Y aquí, hacemos una

\footnotetext{
${ }^{249}$ Nos referimos a los estereotipos de género, en los que hemos ahondado teóricamente en los capítulos 1 y 2.
} 
aclaración: esos discursos, a veces, no sólo responden a la autopercepción de las lideresas, sino también al imaginario social de sus connacionales. El caso más concreto es el de la Presidenta Bachelet, a la que el pueblo chileno apodó "la madre de la Patria".

En otro orden, el tema de la fuerza y el coraje son rasgos muy exaltados discursivamente en las tres Presidentas, y muchas veces como ejemplo de esa fortaleza que las caracteriza, se hace mención a la superación de situaciones límite. Esto puede verse sobre todo en los casos de Michelle Bachelet y Dilma Rousseff, que comparten un pasado de prisión y torturas durante las épocas dictatoriales en sus respectivos países. Ambas se muestran como personas resilientes ${ }^{250}$, que pelearon desde jóvenes por sus ideales y sus naciones. "Quería decirles que dediqué toda mi vida a la causa de Brasil”, afirmó Dilma en el Congreso Nacional el 1 de enero del 2011.

Por otro lado, tanto en los casos de Fernández como de Rousseff, se plantea una continuidad en el modo de ejercer el poder respecto a la gestión precedente; una búsqueda de extender las reivindicaciones y los derechos para los ciudadanos; y un posicionamiento de servicio y entrega al pueblo. El caso de Bachelet difiere, como han señalado las funcionarias entrevistadas, en la forma de ostentar el poder. Mientras su antecesor -Ricardo Lagos-, lo hacía con modismos bruscos, gestos de imposición y expresiones atribuibles desde el sentido común a la masculinidad (entendiendo a ésta de forma insuficiente y prejuiciosa, como asociada a la fuerza física y al carácter rudo); Michelle era percibida como dulce, empática, de movimientos suaves, dispuesta siempre a dialogar e, incluso, a perdonar a quienes tanto daño habían hecho a ella y a su familia de origen. Tal como lo expresara su Jefa de Contenidos, Ximena Jara ${ }^{251}$ :

(Bachelet) encarnaba la idea de la reconciliación en sí misma y Chile tenía mucha necesidad de reconciliación. Era una mujer que encarnaba la reconciliación, que era responsable, que respondía a las necesidades de orden que pretendía Chile; pero que, además, rompía esquemas...que tenía hijos de dos hombres distintos, a cargo sola de su vida... iguau! Fue pasando y Chile se fue enamorando de Michelle Bachelet.

\footnotetext{
250 Según la página oficial de la American Psychological Association, la resiliencia es "el proceso de adaptarse bien a la adversidad, a un trauma, tragedia, amenaza, o fuentes de tensión significativas, como problemas familiares o de relaciones personales, problemas serios de salud o situaciones estresantes del trabajo o financieras. Significa "rebotar" de una experiencia difícil, como si uno fuera una bola o un resorte".

${ }^{251}$ Entrevista realizada en Santiago de Chile, el 20 de agosto del 2015.
} 
En el marco descripto, y ante la pregunta de si efectivamente las Presidentas analizadas pusieron en crisis la ideología patriarcal desde lo discursivo, nos urge tomar las palabras de Carosio (2012:13), cuando sostiene que un "aporte feminista ha sido llevar al espacio público temas que se han considerado exclusivos del espacio privado (planificación familiar, aborto, violencia doméstica, etc.), ensanchando de este modo el ámbito de la política, llevándola de lo cotidiano y personal e impulsando su transformación”. Y es en este sentido en que no surgen dudas sobre el quiebre que la presencia y las palabras de estas mujeres generaron en el ámbito local e internacional.

Sin embargo, es igualmente real advertir que las tres Presidentas expresaron diversas formas de denunciar la opresión masculina ${ }^{252}$ sobre las mujeres: Fernández enfatizó sobre todo en su propia persona (y género) como objeto de crítica de opositores y medios de comunicación (desde su forma de vestirse y maquillarse hasta en cómo se relacionaba con los demás, donde se incluía su relación conyugal). Por su parte, Bachelet se mostró más interesada por demostrar que, tanto ella como otras mujeres, quieren y tienen la capacidad para trabajar en política; pero que hay partidos políticos que -bajo cierta fachada de pregonar la "igualdad"- no lo permiten. Esta afirmación de Michelle sobre el liderazgo femenino, quedó expresada en términos de reivindicación al conformar el primer gobierno paritario de la historia chilena.

Finalmente, en el caso de Rousseff, la denuncia se asemeja a la de Bachelet en cuanto a que resalta la importancia de una incorporación más significativa de la mujer en la esfera pública; pero, a diferencia de su par chilena, la lideresa brasilera realiza una demanda de cómo - además del género- la clase social y la raza son variables decisivas para el logro de la tan ansiada representación. Este posicionamiento, de acuerdo a Wicth y Cazarin (2015: 106), “demuestra y reafirma que la Presidenta sabe que esa participación aún es pequeña, elitista y necesita avanzar" (Traducción nuestra).

Para concluir, quisimos rescatar y hacer nuestras las palabras de Facio (2001:16), cuando sostiene que:

\footnotetext{
${ }^{252}$ Opresión ejercida tanto desde prácticas concretas como desde lo simbólico.
} 
Si Olimpia no hubiese sido desaparecida, nuestra historia sería muy distinta. ${ }^{253}$ Tendríamos dos siglos de estar desarrollando teorías y prácticas sobre los derechos humanos de las mujeres en vez de sólo unos quince años a lo sumo. Tendríamos mucho más experiencia para saber cuáles estrategias realmente nos avanzan y cuáles más bien nos atrasan. Tendríamos más mujeres en la ONU y en todos los espacios de toma de decisión.

${ }^{253}$ Ya Olimpia de Gouges, en 1791, se soñó humana y escribió la Declaración de los Derechos de la Mujer y de la Ciudadana, tal vez la primera vez que se enmarcaban los derechos de las mujeres en una declaración de derechos humanos. 


\section{BIBLIOGRAFÍA}

-Alberdi, I. (2011). Temas y desafíos de la igualdad entre los géneros. El liderazgo de las Naciones Unidas. Pensamiento iberoamericano, (9), 263-280.

-Anzorena, C. (2006). Movimientos feministas y Naciones Unidas: del optimismo de los '60 a la paradoja de Beijing. Ponencia presentada en las VIII Jornadas Nacionales de Historia de las Mujeres, III Congreso Iberoamericano de Estudios de Género, Universidad Nacional de Córdoba, Villa Giardino (Córdoba, Argentina), 25 al 28 de octubre de 2006.

-Anzorena, C. (2013). Mujeres en la trama del Estado: una lectura feminista de las politicas públicas. Mendoza, Argentina: EDIUNC.

-Baptista, M y Coelho, L.M. (2009). A História da Inserção Política da Mulher no Brasil: uma Trajetória do Espaço Privado ao Público. Psicología política, 9 (17), 85-99.

-Barrancos, D. (2008). Introducción. En: Primer Congreso Femenino Internacional de la República Argentinal con prólogo de Dora Barrancos (pp.7-19). Córdoba, Argentina: Universidad Nacional de Córdoba.

-Brandau, M. (1898). Derechos civiles de la mujer. Santiago de Chile, Chile: Imprenta Cervantes.

-Brownmiller, S. (1975). Contra nuestra voluntad. Hombres, mujeres y violación. (Título original: Against our Will. Men, Women and Rape). Barcelona, España: Editorial Planeta. -Bueno Sánchez, E., y Valle Rodríguez, G. M. (2006). Las políticas Públicas desde una perspectiva de género. Revista Novedades en Población, (4), 1817-4078.

-Camacho y Bueno, M. (1910). Una sola moral para ambos sexos. En: Primer Congreso Femenino Internacional de la República Argentina/ con prólogo de Dora Barrancos (2008). (pp. 259-262). Córdoba, Argentina: Universidad Nacional de Córdoba.

-Carosio, A. (2012). Feminismo y cambio social en América Latina y el Caribe. Ciudad Autónoma de Buenos Aires, Argentina: CLACSO.

-Carvallo Ponce, P. M. (2006). Género, Posmodernismo y Relaciones Internacionales. La identidad femenina en el discurso de las organizaciones internacionales. Confines, 2 (3), 89-100.

-Castillo, N. y Montes, R. (2013). Hijas del General. La historia que cruza a Bachelet y Matthei. Santiago de Chile, Chile: Catalonia. 
-Cervantes Carson, A. (1994). Identidad de género de la mujer: tres tesis sobre su dimensión social. Frontera Norte 12, (6), 9-23.

-Chaves, D. D. (octubre 2015). Primer gobierno de Cristina Ferrnández de Kirchner: análisis discursivo desde algunos aportes de van Dijk. En: Documento de trabajo N¹0, Selección de trabajos de estudiantes de la Maestría en Relaciones Internacionales del IRI (año 2012/2014), pp. 190- 207.

-Chaves, D. D., y Pávez, L. (2016). La Política Exterior de Chile: entre el Comercio Global y la Integración Regional. En D. D. Chaves. (Coord.), Una década de política exterior (2000-2010): Colombia, Chile, Bolivia, Venezuela, Surinam y Ecuador (pp.8-26). Recuperado de

http://www.iri.edu.ar/wpcontent/uploads/2016/08/documentos_trabajos_11.pdf

-Chiriguini, M. C. (2004). Identidades socialmente construidas. En M. C. Chiriguini (comp.): Apertura a la Antropología. Alteridad-Cultura-Naturaleza humana (61-78). Buenos Aires, Argentina: Proyecto Editorial.

-Cohen, R. (1979). El sistema político. En: J. Llobera. (Comp), Antropología política (pp.27-53). Barcelona, España: Editorial Anagrama.

-Colacrai, M., y Lorenzini, M. E. (2010). Identidad y Fuerza profundas en la política exterior de Chile. En: A. Busso. (Ed.), Fuerzas profundas e identidad. Reflexiones sobre su impacto en la politica exterior: un recorrido de casos (6-41). Rosario, Argentina: UNR Editora.

-Conway, J. K., Bourque, S. C., y Joan W. Scott, J.W. (1987). The Concept of Gender. En J.K. Conway y otros (Eds.), Learning about Women: Gender, Politics and Power. Ann Arbor: University of Michigan Press.

-Coria, C. (2006). El sexo oculto del dinero. Buenos Aires, Argentina: Paidós.

-Creus, N. (mayo-agosto 2015). El peso de las imágenes waltzianas en la relación de Argentina con el sistema financiero internacional. Análisis político, (84), 155-166.

-Cuder Domínguez, P., Lemus López, E., Villegas López, S. (2013-2014). En Programa oficial 2013-2014 de la materia "Introducción al pensamiento feminista y a la historia de las mujeres". Universidad de Huelva, España.

-De Beauvoir, S. (1989). The Second Sex. Nueva York, USA: Vintage. 
-De Miguel, A. (1995). Feminismos. En C. Amorós. (dir.), 10 palabras claves en mujer (217-255). Navarra, España: Verbo Divino.

-Evans, M. (1997). Introducción al pensamiento feminista contemporáneo. Madrid, España: Minerva Ediciones, S.L.

-Facio, A. (Coord.) (2001). Declaración Universal de Derechos Humanos: texto y comentarios inusuales. En Programa Mujer, Justicia y Género. San José de Costa Rica, Costa Rica: ILANUD.

-Facio, A. y Fries, L. (2005). Feminismo, género y patriarcado. Buenos Aires, Argentina: LOM.

-Facio, A. (2011). Viena 1993, cuando las mujeres nos hicimos humanas. Pensamiento iberoamericano, (9), 3-20.

-Federici, S. (2010). Calibán y la bruja. Mujeres, cuerpo y acumulación originaria. Madrid, España: Traficantes de Sueños.

-Fermandois, J., \& Henríquez, M.J. (2005). ¿Contradicción o díada? Política exterior de Chile ante el Mercosur. Revista de Estudios Internacionales, 38 (148), 55-77.

-Fernández Ramil, M. D. A. (2008). Equidad Política de Género en el Chile Actual: entre promesas y resistencias. Anuario Derechos Humanos Santiago, Centro de Derechos Humanos Universidad de Chile, 221-228.

-Fernández Ramil, M. d. Á., Oliva Espinosa, D. (2012). Presidentas latinoamericanas e igualdad de género: un camino sinuoso. Nueva Sociedad, (240), 119- 133.

-Franceschet, S. (2006). El triunfo de Bachelet y el ascenso político de las mujeres. Nueva sociedad, (202), 13-22.

-Fraser, N. (1997). Justicia interrupta. Reflexiones críticas desde la posición postsocialista. Bogotá, Colombia: Universidad de los Andes.

-Friedan, B. (1963). The Feminine Mystique. New York, USA: W.W. Norton Y Company, Inc.

-Funk, R. L. (2009). Chile: segundo tiempo. Revista de Ciencia Política, 29, (2), 301 -326.

Gregorio Gil, C. (2012). "Marcamos el camino andando: construyendo identidades políticas con mujeres inmigrantes". En: XVII Congreso de Estudios Vascos, pp. 1207-1221.

-Guzmán, V. (2011). Procesos político-institucionales e igualdad de género. Chile: 19802010 (Tesis Doctoral). Universidad Autónoma de Barcelona, España. 
-Guzmán, V. y Bonan Jannotti, C. (2008). La institucionalización del tema de la equidad género y la modernización del Estado en América Latina. En M. J. Astelarra Bonomi (Ed.), Pacto entre géneros y políticas públicas: género y cohesión social (pp. 64-72). España: Ministerio de Trabajo e Inmigración, Instituto de la Mujer.

-Halperin, J. (2009). Las muchachas peronistas: Eva, Isabel y Cristina. ¿Por qué desatan odios las mujeres en el poder? Buenos Aires, Argentina: Aguilar.

-Harding, S. (1987). Is There a Feminist Method? En S. Harding. (Ed.), Feminism and Methodology. Indianapolis, Estados Unidos: Indiana University Press.

-Hill, C. (2003). The Changing Politics of Foreign Policy. New York, USA: Palgrave and MacMillan.

-Jelin, E. (1997). Igualdad y diferencia: dilemas de la ciudadanía de las mujeres en América Latina. Ágora. Cuadernos de estudios políticos, 3 (7), 189-214.

-Kirkwood, J. (1985). Feministas y políticas. Nueva Sociedad, (78), 62-70.

-Kollontay, A. (2014). Catorce conferencias en la Universidad de Sverdlov de Leningrado 1921: mujer, economía y sociedad. Ituzaingó, Argentina: Cienflores.

-Lamas, M. (1999). "Usos, dificultades y posibilidades de la categoría "género" ". Papeles de Población, v. 5, nº 21, pp. 147-178. Toluca: Universidad Autónoma del Estado de México.

-Lasagna, M. (1996). Cambio institucional y política exterior: un modelo explicativo. CIDOB d'Afers Internacionals, (32), 45-62.

-Ledesma, L. S. (2007). La posición histórica de Argentina frente al Tratado de No Proliferación de Armas Nucleares y su cambio en los 90. (Tesis de Maestría en Relaciones y negociaciones internacionales). Recuperado de: http://flacso.org.ar/wpcontent/uploads/2014/06/Tesis_Luciana_Soledad_Ledesma.pdf

-Locher, B. (1998). Las relaciones internacionales desde la perspectiva de los sexos. Nueva Sociedad, (158), 40-65.

-López, I. (2005). Género en la agenda internacional del desarrollo. Un enfoque de derechos humanos. Revista Académica de Relaciones Internacionales, (2), 35-62.

-Macías Lovera, K.M. (2011). Las cuotas de género en Latinoamérica. Una apuesta común. Recuperado de http://www.te.gob.mx/ccje/Archivos/ponencias/Karla_Macias.pdf -Maristany, J. (2000). Hablemos de la mujer. Buenos Aires, Argentina: El Ateneo. 
-Martín Casares, A. ([2006], 2008). Antropología del Género. Culturas, mitos y estereotipos sexuales. Madrid, España: Ediciones Cátedra, Universitat de València, Instituto de la Mujer

-Miranda, R. y otros. (2011). Política exterior: conceptos y enfoques en torno a Argentina. Rosario, Argentina: Pia.

-Moreno, I. (1991). Identidades y rituales. En I. Moreno, J. Prat y otros. (Eds.), Antropología de los pueblos de España (pp.601-604). Madrid, España: Taurus.

-Ortiz Hedesa, O. (2013). El amor patriarcal en la Copla Española. Asamblea de Mujeres Yerbabuena de Córdoba. Recuperado de: http://www.feministas.org/IMG/pdf/EL-AMORPATRIARCAL-EN-LA-COPLA_OLGA-HEDESA.pdf

-Ortner, S. (Enero-febrero 2006). Entonces, ¿es la mujer al hombre lo que la naturaleza a la cultura? Revista de Antropología Iberoamericana, Ed. Electrónica, 1 (1), 12-21. ISSN: 1578-9705

-Osborne, R. (2005). Debate en torno al feminismo cultural. En C. Amorós, A. De Miguel (Eds.), Teoría feminista: de la Ilustración a la globalización, (pp.211-252). Madrid, España: Minerva Ediciones.

-Palermo, A., (2006). El acceso de las mujeres a los estudios universitarios (siglo XIX).

Revista Argentina de Sociología, 4 (7), 11-46. Recuperado de http://www.redalyc.org/pdf/269/26940702.pdf

-Perea Ozerin, I. (2014). El papel del feminismo en el movimiento antiglobalización: contribuciones y desafíos. CIDOB d'Afers Internacionals, 67-88.

-Pichardo Galán, J. I. (2003). Antropología y matrimonio homosexual. Revista de Antropología Iberoamericana, (33). Recuperado de www.aibr.org/antropologia/34mar/index.html

-Portales, C. (2011). Desafíos para la política exterior en las próximas décadas: Chile y la región en un mundo global. Estudios Internacionales, (169), 171-193.

-Red Internacional de Información sobre Mujeres y Política. (19-30 mayo del 2010). Resumen del Debate Virtual sobre "Participación política de las mujeres en el siglo XXI: usando las tecnologías de la comunicación".

-Riera Madurell, T. (2006). El papel de las mujeres en la política exterior. Tiempo de paz, (81), 47-50. 
-Ríos Tobar, M. (Ed). (2008). Mujer y política. El impacto de las cuotas de género en América Latina. Santiago de Chile, Chile: Catalonia.

-Ríos Tobar, M.; Villar, A. (2006). Cuotas de género: democracia y representación. Santiago de Chile, Chile: IDEA-FLACSO.

-Rodríguez Manzano, I. (2001). Mujer, género y Teoría Feminista en las Relaciones Internacionales. En Cursos de Derecho Internacional y Relaciones Internacionales de Vitoria-Gasteiz 2000 (pp. 239-292). Madrid, España: Servicio Editorial de la Universidad del País Vasco/Tecnos.

-Rubin, G. (1986). El tráfico de mujeres: notas sobre la "economía política” del sexo. Revista Nueva Antropología, VIII (030), 95- 145.

-Ruiz Giménez Arrieta, Itziar. (2000). El feminismo y los estudios internacionales. Revista de Estudios Políticos, (108), 325-360. ISSN 0048-7694

-Sagot Rodríguez, M. (2010). Demandas desde la exclusión: representatividad democrática y cuotas de participación política en Costa Rica. Revista Ciencias Sociales, (130), 29-43.

-Sarlo, B. (2011). La audacia y el cálculo. Buenos Aires, Argentina: Sudamericana.

-Scott, Joan W. (1986). El género: útil para el análisis histórico. American Historial Review. 91, 1053-1075.

-Segato, R. L. (2013). La escritura en el cuerpo de las mujeres asesinadas en Ciudad Juárez. Buenos Aires, Argentina: Tinta Limón.

-Sierra Ríos, J. (2017). Liderazgo político y patriarcado mediático: las imágenes políticas de Cristina Fernández y Dilma Rousseff. RIPS, 16 (1), 65-86.

-Simmel, G. (1938). Cultura femenina y otros ensayos. Buenos Aires, Argentina: EspasaCalpe Argentina, S.A.

-Simonoff, A. (junio/diciembre 2008). La Política Exterior de los Gobiernos Kirheneristas y la Tercera Posición. Intellector/ Centro de Estudos em Geopolitica e Relaçoes Internacionais, $V(9), 11-33$.

-Stolen, K. (2004). De estudios campesinos a estudios de género. En La decencia de la desigualdad. Género y poder en el campo argentino (pp.19-44). Buenos Aires, Argentina: Antropofagia.

-Stuart Mill, J. (1860). El sometimiento de la mujer. Traducción y compilación de Carlos Mellizo Cuadrado (2010). Madrid, España: Alianza Editorial 
-Stuart Mill, J. (1869). La esclavitud femenina. Traducción y prólogo de Emilia Pardo Bazán (2008). Madrid, España: Artemisa.

-Subercaseaux, E. y Sierra, M. (2005). Michelle. Santiago de Chile, Chile: Catalonia.

-Tejero Coni, G. (2014). Estudio Preliminar. En A. Kollontay, Catorce conferencias en la Universidad de Sverdlov de Leningrado 1921: mujer, economía y sociedad. (pp. 7-50). Ituzaingó, Argentina: Cienflores.

-Tickner, J. A. (1997). You Just Don't Understand: Troubled Engagements Between Feminist and IR Theorists. En International Studies Quarterly, (41), 611-632.

-Tickner, J. A. (1998). Hans Morgenthau's principies of political realism: a feminist reformulation. En Grant y Newland: Gender in International Relations: feminist perspectives on archieving global security, New York, USA: Columbia University Press.

-Trujillo López, M. (2014). Feminismo y género. En J.A. Schiavon Uriegas (Ed.), Teorías de las Relaciones Internacionales en el siglo XXI: Interpretaciones críticas desde México (pp. 455- 471). México: Benemérita Universidad Autónoma de Puebla; El Colegio de San Luis; Universidad Autónoma de Baja California; Universidad de Nuevo León; Universidad Popular Autónoma del Estado de Puebla.

-Valdivieso Ide, M. (2014). Otros tiempos y otros feminismos en América Latina y el Caribe. En A. Carosio (Coord.), Feminismos para un cambio civilizatorio (23-38). Caracas, Venezuela: CELARG-CLACSO.

-Van Klaveren, A. (Abril-Junio 1992). Entendiendo las políticas exteriores latinoamericanas: modelo para armar. Estudios Internacionales, 25, (98), 169-216.

-Vargas, V. (2002). Los feminismos latinoamericanos en su tránsito al nuevo milenio. (Una lectura político personal). En D. Mato. (comp.), Estudios y otras prácticas intelectuales latinoamericanas en cultura y poder. Caracas, Venezuela: CLACSO.

-Waltz, K. N. (1959). Man, the state, and war: A theoretical analysis. New York, USA: Columbia University Press.

-Waltz, K. (1979). Teoría de la política internacional. Buenos Aires, Argentina: Grupo Editor Latinoamericano.

-Wollstonecraft, M. (1792). Vindicación de los derechos de la mujer. (Título original: A Vindication of the Rights of Woman). Primera edición: septiembre 1998. Madrid, España: Editorial Debate, S.A. 
-Zalewski, M. (1997). Feminist scholarship in International Relations. European Journal of International Relations.

-Zerrilli, Linda M. G. (2008). El feminismo y el abismo de la libertad. Buenos Aires, Argentina: Fondo de Cultura Económica.

\section{$\underline{\text { Discursos presidenciales }}$}

Discursos de Michelle Bachelet:

-Mensaje presidencial. Congreso de la Nación, Santiago de Chile, 21 de mayo del 2006.

-Mensaje presidencial. Congreso de la Nación, Santiago de Chile, 21 de mayo del 2007.

-Mensaje presidencial "Contigo mejor país. Contigo vamos por más". Congreso de la Nación, Santiago de Chile, 21 de mayo del 2008.

-Mensaje Presidencial "Protección social, el sello del gobierno. Contigo mejor país". Congreso de la Nación, Santiago de Chile, 21 de mayo del 2009.

Discursos de Cristina Fernández en:

-Acto de Asunción del mando en el Congreso de la Nación ante la Asamblea Legislativa, 10 de diciembre del 2007.

-Acto de Asunción como Presidenta del Mercosur, 18 de diciembre del 2007

-Acto de Apertura de ofertas económicas para el gasoducto noroeste argentino, con la presencia del Presidente Evo Morales; 25 de enero del 2008.

-Almuerzo en honor al presidente de la República Federativa del Brasil, Lula Da Silva, 22 de febrero del 2008.

-XX Cumbre de Jefes Estado del Grupo de Río en Santo Domingo, 7 de marzo del 2008.

-Firma de convenios con Ecuador, 21 abril del 2008.

-Acto de apertura del Seminario "La mujer y la alianza de civilización, oportunidades y desafíos”. Palacio San Martín, 28 de abril del 2008.

-Almuerzo con el Presidente Lula, 8 de septiembre del 2008.

-Cena de empresarios egipcios y argentinos; El Cairo, 20 de noviembre del 2008.

-En el marco de firma de acuerdos con Argelia, 17 de noviembre del 2008.

-Consejo de las Americas, en Nueva York, 25 de septiembre del 2008. 
-Visita a una Iglesia Jesuita en Quito, 21 de abril del 2008

-Inauguración jardín abuelas y madres de Plaza de mayo; 7 de abril del 2008, París.

-Firma de convenios con el BID, 17 de abril del 2008.

-Cena con Bachelet en Punta Arenas; Chile, 5 de diciembre del 2008.

-Firma de acuerdos con la República de Chile, en Monte Aymond, 5 de diciembre del 2008.

-Firma de acuerdos con Venezuela, 6/03/2008.

-Clausura del Seminario Oportunidades de Comercio, Inversiones y Negocios entre la Argentina y Cuba, 20 de enero del 2009.

-Aula Magna de la Universidad de La Habana, 20 de enero del 2009.

-Casa de América en la Reunión Tribuna Iberoamericana, España, 10 de febrero del 2009.

-Cena de gala ofrecida en el Palacio Real de Madrid, 10 de febrero del 2009.

-Apertura del $127^{\circ}$ Período ordinario de sesiones realizado ante la Asamblea Legislativa en el Honorable Congreso de La Nación, 9 de marzo del 2009.

-Cumbre Extraordinaria de la UNASUR, 28 de agosto del 2009.

-30 años de la visita de la Comisión Interamericana de Derechos Humanos a la Argentina, 11 de septiembre del 2009.

-Foro Líderes Mundiales, Universidad de Columbia; 21 de septiembre del 2009.

-Cena agasajo de la Cámara de Comercio de Mumbai, India- 15 de octubre del 2009.

-IV Cumbre de UNASUR. 26 de noviembre de 2010.

-XL Cumbre del Mercosur. 17 de diciembre de 2010.

-la VI Cumbre Unión Europea-América Latina y el Caribe; 18 de mayo de 2010

-A la Asamblea Legislativa con motivo de la apertura del $128^{\circ}$ período de sesiones ordinarias del Congreso de la Nación, 1 de marzo del 2010.

-Asamblea General de la Organización de las Naciones Unidas, 24 de septiembre de 2010. Nueva York.

-Acto de designación a la República Argentina durante el año 2011 para presidir el grupo G-77. 28 de septiembre de 2010 .

$-66^{\circ}$ Asamblea General de las Naciones Unidas; Nueva York, 21 de septiembre del 2011. -Acto de elevación a la cota definitiva de la represa binacional Yacyretá. 25 de febrero de 2011.

-Día Universal de los Derechos Humanos. Argentina, 10 de diciembre de 2011. 
Mensajes de Dilma Rousseff en:

-Acto de asunción en el Congreso de la Nación. Brasil, 1 de enero del 2011.

-Reinauguración de la Embajada de la República Argentina en Brasil. Brasilia, 29 de julio del 2011.

-Apertura del Seminario "Brasil en la senda del crecimiento". Madrid, 11 de noviembre del 2011.

-66 Apertura de la Asamblea General de las Naciones Unidas, 21 de septiembre del 2011.

-XLII Cumbre de Jefes de Estado del Mercosur, 20 de diciembre del 2011.

-Acto de graduación de la clase 2010-2012 en el Instituto Río Branco. Brasilia, 20 de abril del 2012.

-Palacio de Itamaraty, 17 de diciembre del 2012.

-34 Período de Sesiones de la CEPAL, 31 de agosto del 2012.

-Ceremonia del Premio de Derechos Humanos 2012.

-Apertura de la 67ª Asamblea General de las Naciones Unidas.

-XLVII Cumbre del Mercosur y Estados Asociados, 17 de diciembre del 2014.

-Acto de graduación en el Instituto Río Branco, 30 de abril del 2014.

-Asunción del segundo mandato de Michelle Bachelet en Chile, 11 de marzo del 2014.

-IV Sesión de los BRICS. Nueva Delhi, India; 29 de marzo del 2012.

-Cierre de la VI Sesión plenaria de los BRICS. Fortaleza, 15 de julio del 2014.

\section{Entrevistas realizadas:}

-Claudia Godoy Caroca, responsable del ex Servicio Nacional de la Mujer, SERNAM (Actualmente, Ministerio de la Mujer y la Equidad de Género). Santiago de Chile, 20 de agosto del 2015.

-Lorena Henríquez, Área Dirección de Gestión del Ministerio de Relaciones Exteriores de Chile. Santiago de Chile, 19 de agosto del 2015.

Paulina Díaz Pérez, Área Dirección de Gestión del Ministerio de Relaciones Exteriores de Chile. Santiago de Chile, 19 de agosto del 2015. 
-Ximena Jara, Jefa de Contenidos de la primera y segunda presidencia de Michelle Bachelet. Santiago de Chile, 20 de agosto del 2015.

-Raphael Fernandes Vieira Moreira Gonzaga, Analista en Relaciones Internacionales. La Plata, abril del 2017.

\section{Otras fuentes:}

-Conferencia Internacional "El impulso del empoderamiento político de las mujeres en la toma de decisiones”. Evento organizado por el Partido de la Revolución Democrática a través de la Secretaría de Relaciones Internacionales del Comité Ejecutivo Nacional, el día 12 de noviembre del 2016 en la Ciudad de México.

-Programa 2015 de la materia "Metodología de investigación e intervención en estudios de género". A cargo de: Dra. Emilia Moreno Sánchez, Dña. Rosario Carrasco Tristancho y Dra. Beatriz Domínguez García. Doctorado en Estudios Interdisciplinares de Género, Universidad de Huelva. 